\title{
Compétitivité des villes portuaires: \\ Le cas de Marseille-Fos - France
}
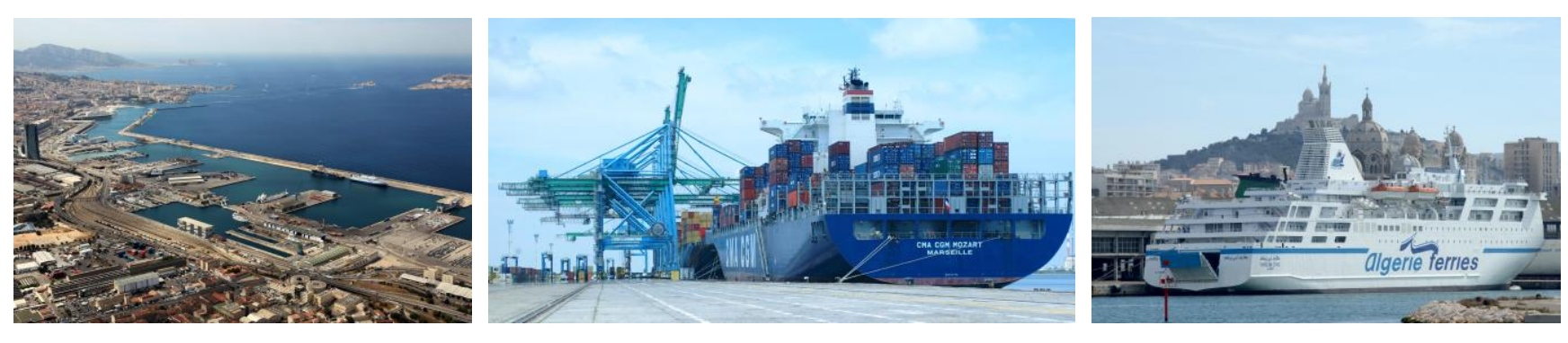

Veuillez citer ce document de la manière suivante :

Merk, O., Comtois, C. (2012), «Compétitivité des villes portuaires: Le cas de Marseille-Fos », OECD Regional Development Working Papers, 2012/11, OECD Publishing, Doi : $10.1787 / 5 \mathrm{k} 8 \times$ x 9 79bmlw-fr

\section{OECD Regional Development Working Papers, 2012/11}

Olaf Merk, Claude Comtois

Classification JEL:

R41, R11, R12, R15, L91, D57 


\section{DOCUMENTS DE TRAVAIL DE L'OCDE SUR LE DEVELOPPEMENT RÉGIONAL}

Cette série a pour but de mettre à la disposition d'un plus large public certaines études sur le développement régional initialement préparées pour l'usage interne de l'OCDE. Elles sont en général le fruit d'un travail collectif, mais les auteurs principaux sont cités. Les documents sont disponibles le plus souvent dans la langue d'origine uniquement, anglais ou français, avec un résumé dans l'autre langue s'il existe.

Les avis exprimés et les arguments utilisés dans ces documents sont de la seule responsabilité des auteurs, et ne reflètent par nécessairement ceux de l'OCDE ou des gouvernements de ses pays membres.

Tous commentaires sur cette série sont les bienvenus et doivent être envoyés à gov.contact@oecd.org ou à la Direction de la gouvernance publique et du développement territorial, 2, rue André Pascal, 75775

PARIS CEDEX 16, France.

Les documents de travail de l'OCDE sur le développement régional sont publiés sur www.oecd.org/gov/regional/workingpapers

Toute demande d'autorisation de reproduction ou de traduction totale ou partielle de ce document doit être adressée à: OECD Publishing, rights@oecd.org ou par télécopie +33145249930.

(C) OECD 2012

Crédits photos (page couverture: de gauche à droite): (C) GPMM 


\begin{abstract}
ABSTRAIT
Ce document de travail propose une évaluation de la performance du port de Marseille-Fos, une analyse de l'impact de ce port sur son territoire et une appréciation des politiques et de la gouvernance dans ce domaine. Il fait le constat du caractère déclinant de la performance portuaire au cours des dernières décennies et identifie les principaux déterminants de ce phénomène. Les différents impacts du port (en termes économiques et environnementaux) sont identifiés et quantifiés lorsque c'est possible. La valeur ajoutée du cluster portuaire du Marseille-Fos a été calculée et ses interconnexions avec d'autres secteurs économiques et d'autres régions de France ont été identifiées. Le rapport montre divers impacts du port, mais indique que beaucoup de ces impacts ont des retombées dans une autre région que celle dans laquelle le port de Marseille-Fos est situé. Les principales politiques à l'égard du port, des transports, du développement économique, ainsi que de l'environnement et de l'aménagement du territoire ont été évaluées. Cela inclut les politiques à l'échelle des autorités portuaires et aux échelles locales, régionales et nationales. Les mécanismes de gouvernance à ces différents niveaux sont décrits et analysés. A partir de l'analyse de ce rapport, des recommandations sont formulées afin d'améliorer la performance portuaire et d'augmenter l'impact positif du port de Marseille-Fos sur son territoire.
\end{abstract}

Classification JEL : R41, R11, R12, R15, L91, D57

Mots clés : ports, développement régional, croissance régionale, croissance urbaine, échanges interrégionaux, transports, input/output 


\begin{abstract}
AVANT-PROPOS
Cette étude est la quatrième d'une série d'études de cas du projet de l'OCDE sur les villes portuaires, qui tente d'identifier l'impact des ports sur leurs territoires et les politiques possibles pour augmenter les retombées positives des ports sur leurs régions. Elle a été réalisée sur la demande de différents acteurs, dont le Grand Port Maritime de Marseille-Fos (GPMM), la Région Provence-Alpes-Côte d'Azur, le Département des Bouches du Rhône, le syndicat mixte du Schéma de Cohérence Territoriale Ouest Étang de Berre, la Communauté d'agglomération Marseille Provence Métropole, la ville de Marseille, la Chambre de Commerce et d'Industrie Marseille Provence, l'agence d'urbanisme de Marseille et l'Union Maritime et Fluviale.

Ce document de travail s'inscrit dans une série de «OECD Regional Development Working Papers » de la Direction de la Gouvernance publique et du développement territorial de l'OCDE. Ce document a été écrit par Olaf Merk (OCDE) et Claude Comtois (Université de Montréal). Il a été dirigé par Olaf Merk et il s'appuie sur un certain nombre d'autres contributions, notamment de la part de César Ducruet (CNRS Université Paris 1 Panthéon-Sorbonne) Walter Manshanden et Evgueny Poliakov (TNO, Pays-Bas), Nicolas Winicki, Jing Li, Jasper Cooper, Lucie Billaud, Charlotte Lafitte, Caroline Guillet, Léonie Claeyman et Suzanne Chatelier. Dans le cadre de cette étude, des entretiens avec une série d'acteurs ont été réalisés (Annexe 1).

Le document peut être téléchargé sur le site Internet de l'OCDE : www.oecd.org/regional/portcities

Les demandes de renseignement plus approfondi concernant ce travail dans ce domaine doivent être adressées à :

Olaf Merk (olaf.merk@oecd.org) de la Direction de la Gouvernance publique et du développement territorial de l'OCDE.
\end{abstract}




\section{TABLE DES MATIÈRES}

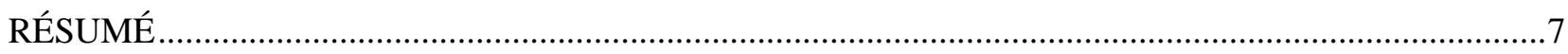

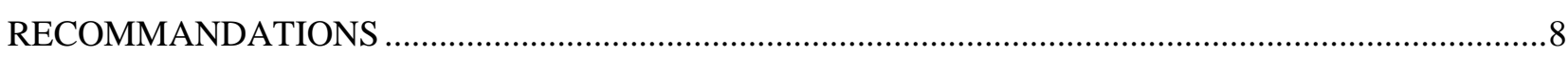

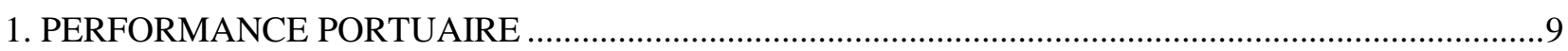

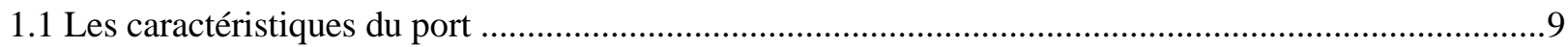

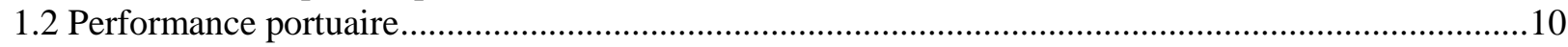

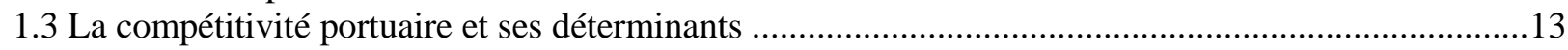

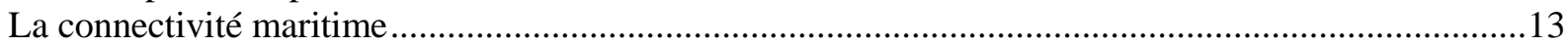

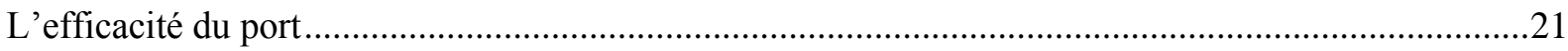

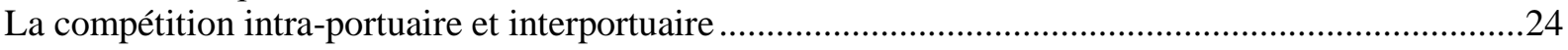

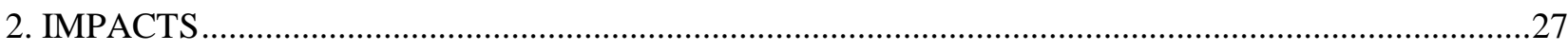

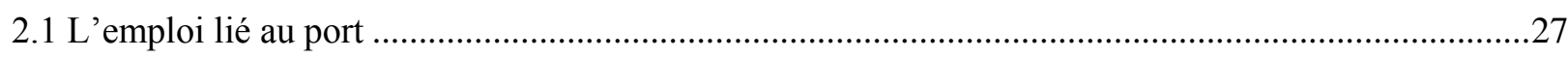

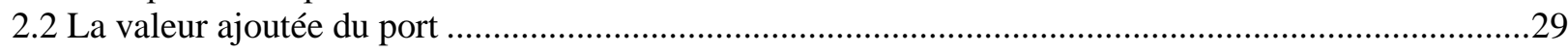

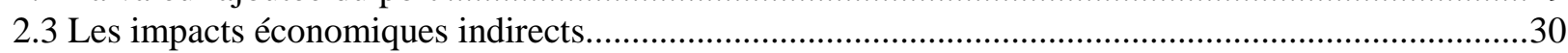

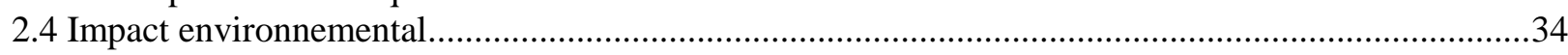

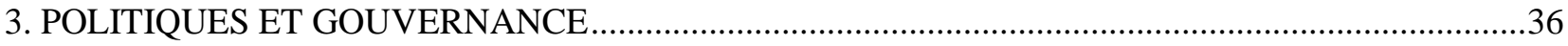

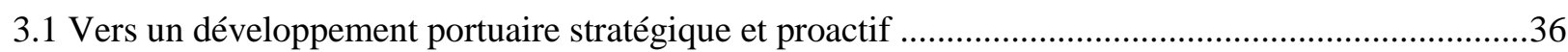

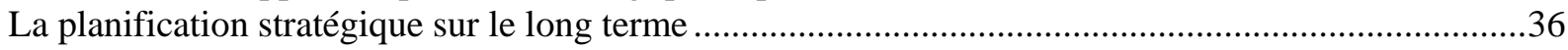

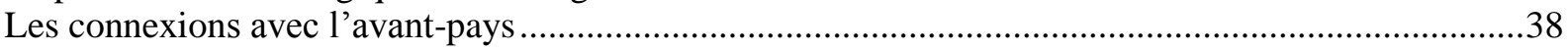

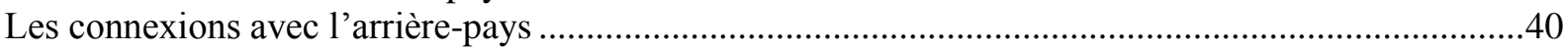

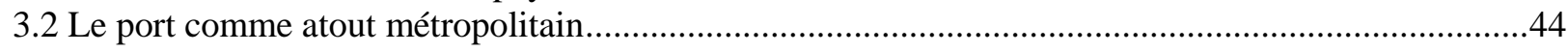

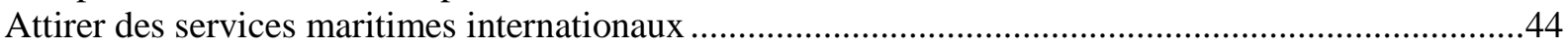

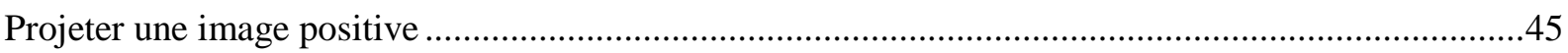

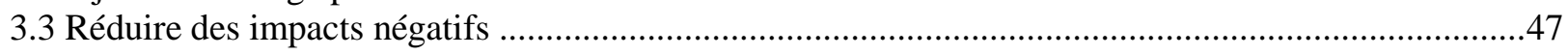

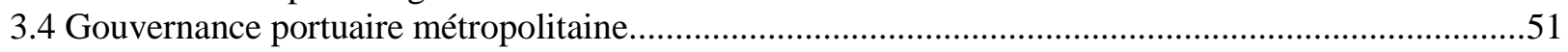

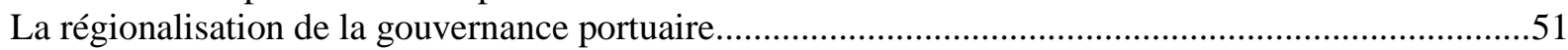

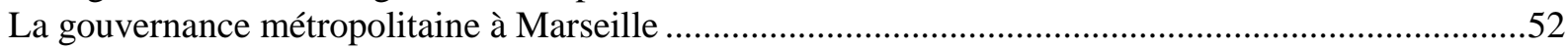

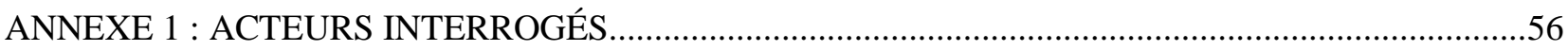

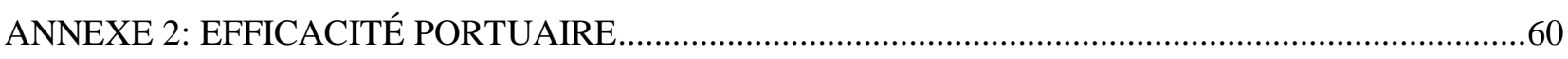

ANNEXE 3: EFFICACITE DES PORTS PETROLIERS ….....................................................................61

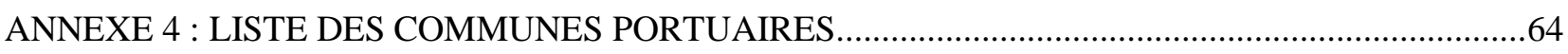

ANNEXE 5 : MÉTHODOLOGIE POUR L'ANALYSE INPUT/OUTPUT MULTIRÉGIONALE.............66

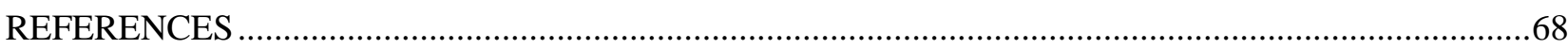

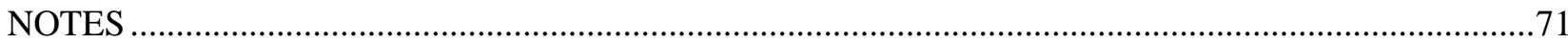




\section{Tableaux}

Tableau 1. Les indices de centralité des ports dans les réseaux mondiaux ......................................14

Tableau 2. Volumes des ports principaux de la zone Ouest de la Méditerranée européenne ..............25

Tableau 3. Indices de centralité des ports secondaires dans l'Ouest de la Méditerranée (2011) .........25

Tableau 4. Présence des quatre grands opérateurs de terminaux de conteneurs (2012)....................26

Tableau 5. Emplois liés aux ports français (2010) ..........................................................................28

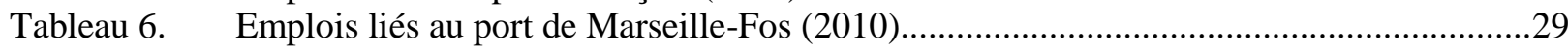

Tableau 7. Multiplicateur du cluster Marseille-Fos et d'autres ports européens .................................31

Tableau 8. Multiplicateur de Marseille-Fos par filière....................................................................

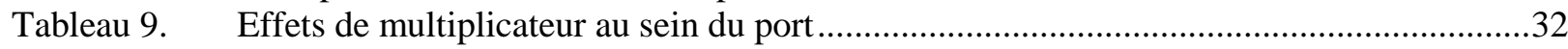

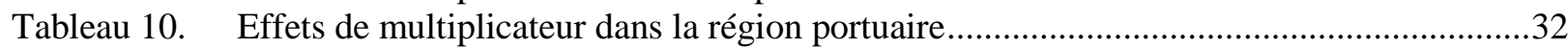

Tableau 11. Multiplicateurs de Marseille-Fos par filière et région en France.......................................33

\section{Figures}

Figure 1. Types de marchandises à Marseille-Fos et d'autres ports.............................................10

Figure 2. Développement des volumes portuaires (1971-2011) ...................................................11

Figure 3. Développement du trafic de conteneurs (1978-2011) ..................................................12

Figure 4. Développement du volume portuaire par type de marchandise à Marseille-Fos ..............13

Figure 5. Nombre d'escales directes sur les routes intercontinentales des grands armateurs ...........15

Figure 6. Diversité de connexions maritimes des ports méditerranéennes et européennes ...............16

Figure 7. L'Avant-pays maritime de Marseille-Fos en 2004..................................................17

Figure 8. L'Avant-pays maritime de Marseille-Fos en 2011.....................................................18

Figure 9. Connexions du transport maritime conteneurisé de courte distance (Méditerranée) ........20

Figure 10. Temps de manutention de conteneurs (jours/1000 EVP), trimestre 2, $2011 \ldots \ldots \ldots \ldots \ldots \ldots . . .21$

Figure 11. Scores d'efficacités des ports/terminaux pétroliers (2011) ............................................22

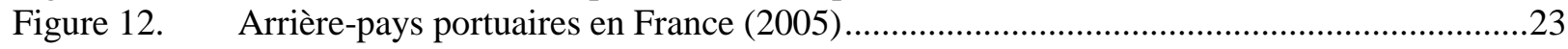

Figure 13. Relation entre valeur ajouté et volume portuaire ............................................................30

Figure 14. Répartition modale pour le trafic de conteneur en Europe (2010) ..................................35

\section{Encadrés}

Encadré 1. L'expansion des parts de marché maritime de Hong Kong................................................39

Encadré 2. L'expansion des parts de marché maritime de Shanghai...........................................................40

Encadré 3. Le système de fret ferroviaire à Göteborg ..............................................................................41

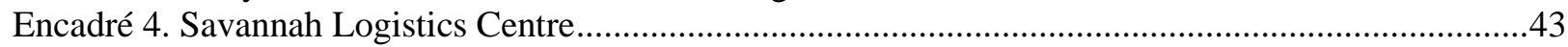

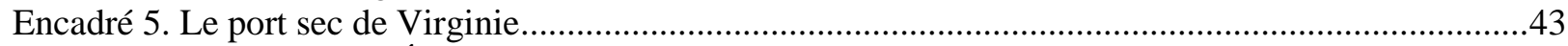

Encadré 6. Inventaire des Émissions Atmosphériques des Ports de Los Angeles et Long Beach.............46

Encadré 7. Plan d'Action pour la préservation de l'air des ports de la Baie de San Pedro .......................48

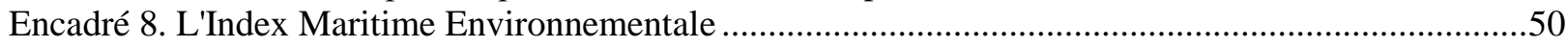

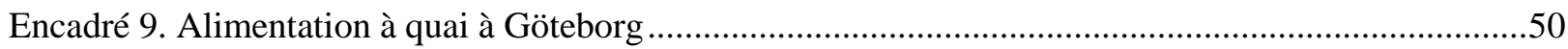

Encadré 10. Les mécanismes de concertation à Nantes Saint-Nazaire .................................................53

Encadré 11. Métropolitanisation et le rééquilibrage de multiples sites portuaires ; le cas de Auckland ...54 


\section{RÉSUMÉ}

La stagnation des volumes portuaires à Marseille-Fos a eu pour conséquence une diminution des parts de marché pour toutes les catégories de marchandises. De second port Européen dans les années 1970, Marseille-Fos est passé au rang de cinquième plus grand port. Particulièrement dans le trafic de conteneurs, Marseille-Fos a manqué des opportunités de s'étendre: les ports voisins de l'Ouest Méditerranéen ayant des trafics de conteneur comparables sont aujourd'hui de 2 à 4 fois plus importants que Marseille-Fos dans cette catégorie. Cependant, on observe quelques signes de relance du trafic de conteneurs depuis la mise en place de la réforme portuaire en mai 2011.

Les déterminants de la compétitivité portuaire ne sont pas favorables à la situation marseillaise. Ses rivaux sont plus efficaces, ont davantage de connexions à courte distance et en haute mer, allant jusqu'à être parfois considérés comme des plaques tournantes mondiales. Bien que Marseille-Fos ait longtemps été protégé par sa position de quasi-monopole, le port est aujourd'hui confronté à une compétition acharnée venant des ports d'Anvers et Le Havre envers son arrière-pays autrefois considéré comme acquis.

La performance du port a de lourdes conséquences économiques régionales, générant environ 40-45 000 emplois liés au port, et 4 milliards d'euros de valeur ajoutée. Dans la municipalité de Fos, la moitié des emplois sont liés à l'activité portuaire ; mais la zone souffre aussi de hauts niveaux de pollution de l'air. De plus, bien qu'il soit un port important, Marseille-Fos n'a pas une position de leader en tant que centre Européen de services maritimes.

Le port de Marseille-Fos est important pour l'ensemble de l'économie française. Il a un effet multiplicateur de $2:$ un euro de demande dans le cluster portuaire implique un euro additionnel dans l'offre française. Un tiers de cet effet multiplicateur touche essentiellement l'Ile de France, 10\% la région RhôneAlpes, et $6 \%$ la région PACA où le port de Marseille-Fos est situé.

Le port a formulé l'objectif ambitieux de 5 millions de conteneurs (EVP) en 2030 ; soit cinq fois plus que son trafic actuel. Afin d'atteindre cet objectif, plusieurs défis liés à l'arrière-pays, aux connections maritimes et à l'efficacité du port doivent être résolus. En parallèle, les impacts environnementaux doivent être réduits, et les autorités doivent projeter une image plus positive du port, afin d'obtenir le soutien de la communauté locale pour la croissance portuaire. L'héritage maritime de Marseille pourrait être mis à profit pour en faire un centre Européen de services maritimes de pointe, en parallèle avec les ambitions de la ville et de l'agglomération urbaine de Marseille.

La sous-performance relative de Marseille-Fos peut s'expliquer en partie par la gouvernance portuaire en France. Le débat politique actuel sur une forme de gouvernance métropolitaine pour Marseille peut être une opportunité pour réfléchir également à la régionalisation de la gouvernance portuaire. 


\section{RECOMMANDATIONS}

- Développer une perspective commune pour les Bassins Ouest sur le long terme, en consultant les partenaires et acteurs impliqués. Cette perspective pourrait notamment inclure une transition du secteur en déclin de l'industrie pétrochimique et des raffineries vers un cluster d'énergie durable. Un travail considérable a déjà été effectué sur la formulation d'une vision future pour le Bassin Est, mais il devrait être effectivement mis en œuvre.

- Initier des politiques commerciales proactives, par exemple en s'engageant dans des acquisitions ou des partenariats avec des ports étrangers ayant une position stratégique dans les marchés émergents

- Résoudre l'obstacle constitué par l'arrière-pays du port, et s'ouvrir vers de nouveaux arrièrepays, par exemple le contournement de Lyon par voie ferrée et le canal Saône-Rhin.

- Investir dans la communication externe du port, et assurer la transparence des informations afin d'obtenir une appropriation par la population locale.

- Développer un plan d'action concret pour attirer des services maritimes internationaux et des sièges sociaux à l'intérieur de la zone métropolitaine de Marseille.

- Continuer le «verdissement » du port de Marseille-Fos, en développant un plan d'action global sur la qualité de l'air, et introduire le système d'alimentation à quai pour les navires.

- Réfléchir à un modèle de gouvernance portuaire plus régionalisé, en parallèle à la création proposée d'une métropole 


\section{PERFORMANCE PORTUAIRE}

Quelle est la performance portuaire du port de Marseille-Fos? C'est la question centrale de ce premier chapitre du cas d'étude sur Marseille-Fos dans le cadre de l'étude de l'OCDE sur les villes portuaires. Ce cas d'étude évalue les principaux défis du développement portuaire de Marseille-Fos, et fournit des recommandations pour les surmonter. Dans plusieurs villes portuaires mondiales, les relations entre les ports et les villes auxquelles ils sont rattachés sont à la fois complexes et évolutives : les ports ont de moins en moins besoin de main d'œuvre, mais réclament de plus en plus de capital et d'espace, ce qui entre en conflit avec les contraintes spatiales des régions métropolitaines en expansion. Plusieurs phénomènes ont également renforcé une discordance entre les niveaux local-global, avec des retombées positives qui dépassent les frontières métropolitaines, mais des effets négatifs fortement localisés. Ce cas d'étude évalue cette dynamique dans le cas de Marseille-Fos, et suggère des voies d'amélioration. Cette étude comporte trois chapitres : les performances portuaires, les impacts portuaires et enfin les politiques et la gouvernance. Ce chapitre porte sur la performance portuaire en présentant les caractéristiques principales du port de Marseille-Fos et en évaluant ses performances avant de se concentrer sur quatre des déterminants de la compétitivité portuaire, à savoir la connectivité maritime, l'efficacité portuaire, la connectivité avec l'arrière-pays et la compétition.

\subsection{Les caractéristiques du port}

Le port de Marseille-Fos est un port étendu et multi-sites aux défis multiples. En 2011, il a traité 88 million de tonnes de marchandises, faisant de Marseille-Fos le plus grand port de France, le cinquième plus grand port d'Europe et parmi les 50 plus grands ports au niveau mondial. En termes de surface portuaire, le port de Marseille-Fos est très étendu, sur plus de 10000 hectares. Les activités du port ont lieu sur deux sites portuaires: un site situé dans la ville même de Marseille (appelé les Bassins Est), et un site situé dans les communes de Fos, Martigues, Port de Bouc, Port Saint Louis du Rhône (appelé les Bassins Ouest) situé à une cinquantaine de kilomètres de Marseille. La majorité des activités portuaires ont lieu dans les Bassins Ouest, représentant la moitié des escales, plus que deux tiers du volume total de cargo, et $95 \%$ de la surface portuaire. Le port de Fos fait partie d'un complexe industrialo-portuaire incluant des raffineries, des lieux de stockage et d'autres activités manufacturières. Les Bassins Est ont un aspect plus urbain, avec un trafic passager (ferry et croisière), des marchandises diverses et des escales plutôt de courte distance et orientées vers la Méditerranée.

Marseille-Fos est fortement spécialisé en vrac liquide, en particulier en pétrole brut et pétrole raffiné, qui représentent environ $70 \%$ du volume total des marchandises traitées. Pour le reste, le volume du port se divise entre le vrac sec, les conteneurs et les autres marchandises. Cette forte proportion de vrac liquide rend le profil de Marseille-Fos unique. Parmi les plus grands ports européens, le seul ayant une similaire spécialisation dans le vrac liquide est Le Havre, autre grand port français, pour lequel le vrac liquide représente 65\% du volume portuaire. Cependant, à la différence de Marseille-Fos, Le Havre est davantage spécialisé en chargements de conteneurs (en 2012, ils représentaient $28 \%$ du volume portuaire). Les ports européens ayant une similaire spécialisation à celle de Marseille-Fos sont cependant beaucoup moins diversifiés, comme le port de Sines (Portugal); ou encore les ports de Tees \& Hartlepool (Royaume-Unis) et Tallinn (Estonie), bien que ces deux derniers aient relativement plus de navire rouliers que de trafic de 
conteneurs. Sa forte spécialisation en vrac liquide distingue donc Marseille-Fos de ses compétiteurs directs (Anvers) et des ports voisins, en Espagne et en Italie (Figure 1).

Figure 1. Types de marchandises à Marseille-Fos et d'autres ports

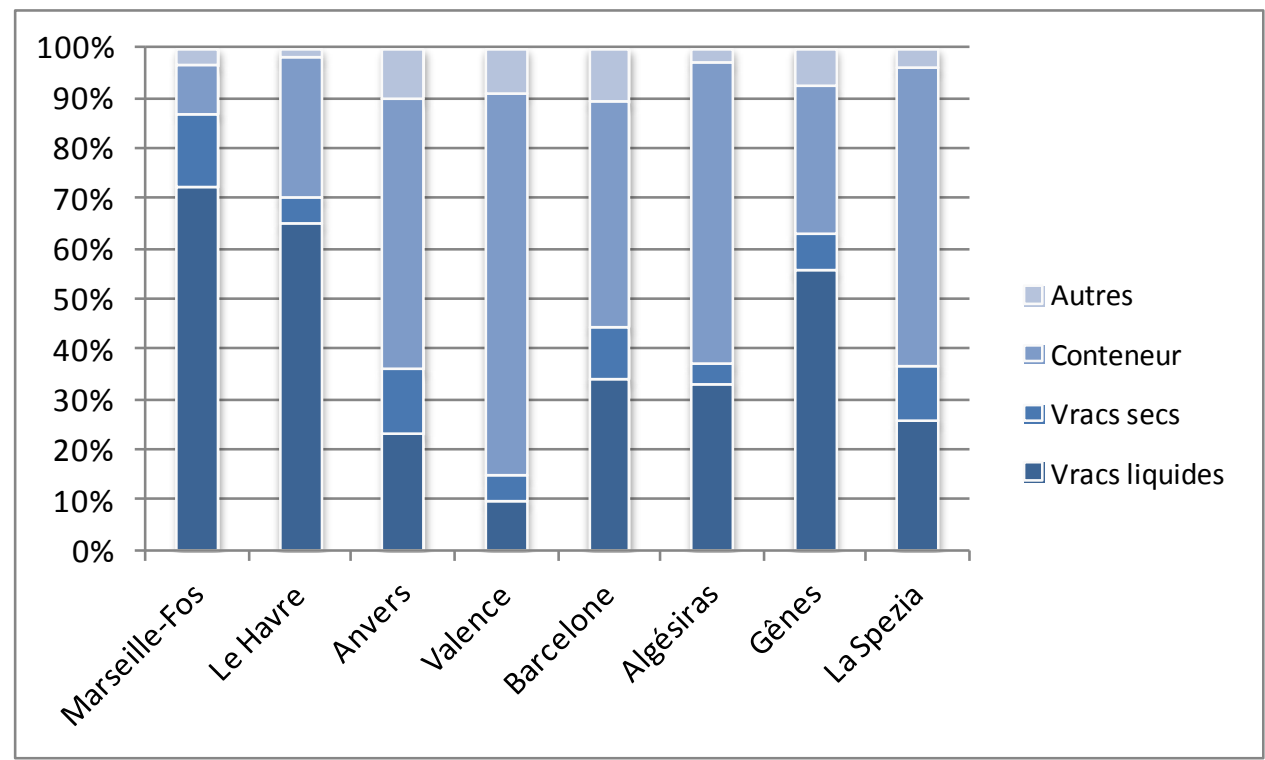

Source : calculs et élaboration par le secrétariat de l'OCDE à partir de données Eurostat

\subsection{Performance portuaire}

L'activité portuaire de ces dernières années à Marseille-Fos a été stagnante. Le volume moyen annuel dans les années 1970 était plus important que celui de ces dix dernières années; le plus grand volume, s'élevant à 109 million de tonnes, date de 1974 et n'a jamais été dépassé depuis. En 2011, le flux géré par le port de Marseille-Fos était de 88 millions. Cette croissance stagnante (-2\% entre 1990 et 2011) contraste avec les taux de croissance d'Anvers ( $83 \%$ pendant la même période) et avec ceux des ports espagnols de Valence et d'Algésiras, dont les taux de croissance sont encore plus spectaculaires, s'élevant respectivement à $427 \%$ et $238 \%$ sur la même période. Les taux de croissance restent plus modérés pour Le Havre (27\%) et Gênes (16\%), tout en restant cependant supérieurs à celui de Marseille-Fos (Figure 2). 
Figure 2. Développement des volumes portuaires (1971-2011)

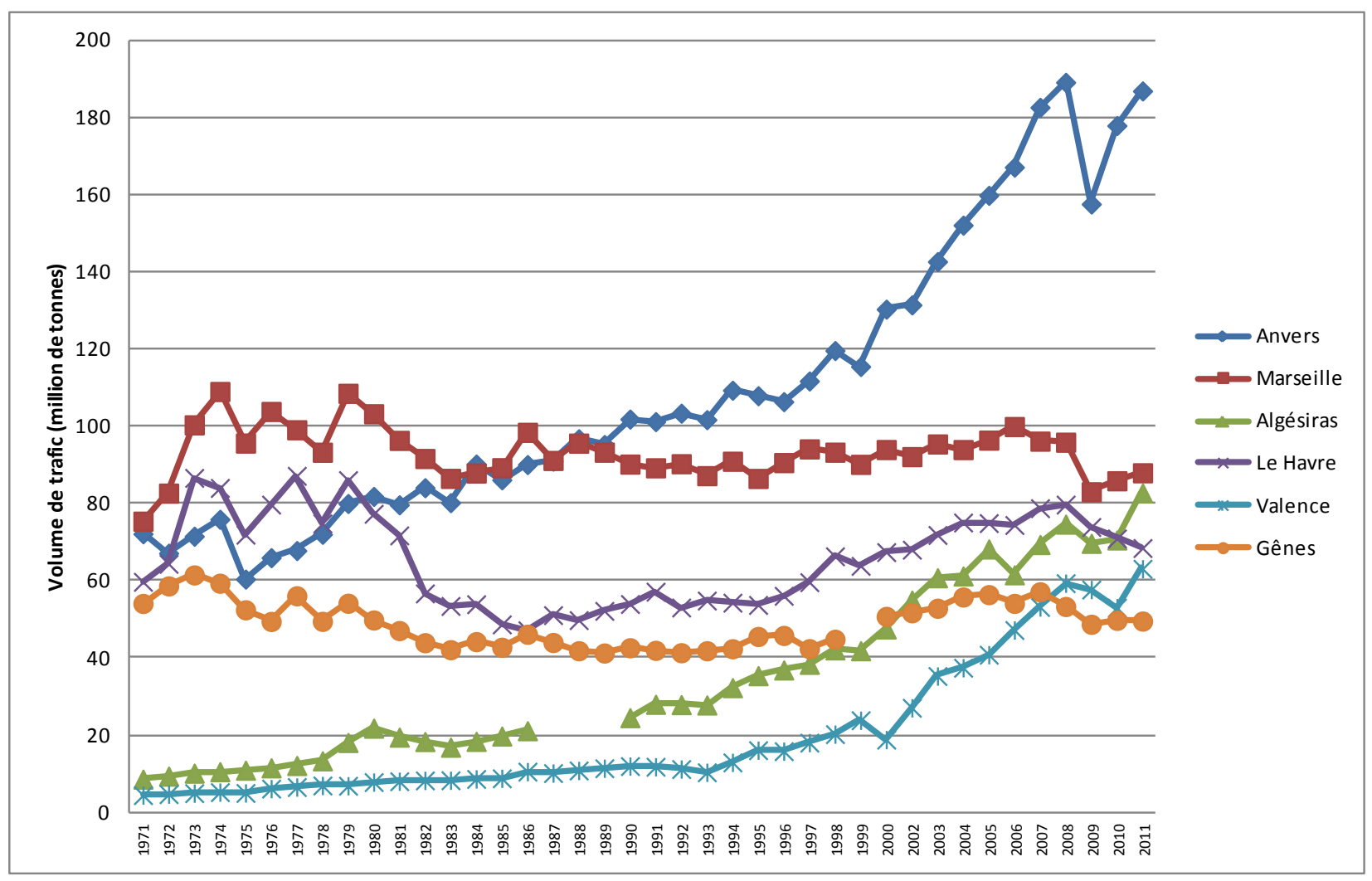

Source : calculs et élaboration par le secrétariat de l'OCDE à partir de données JMM

Ces taux de croissance décevants ont mené à un déclin des parts de marché détenues par le port de Marseille-Fos. La part du volume total de Marseille-Fos dans le volume total des ports européens a diminué, passant de $3,1 \%$ en 2001 à $2,4 \%$ en 2010 . On observe une baisse similaire concernant les volumes de conteneurs (de 1,5\% à 1,3\%) et les volumes de vrac liquide (de 5,0\% à 4,0\%).

On peut identifier plusieurs occasions manquées par le port de Marseille-Fos pour se trouver une place dans le trafic de conteneurs. Bien que Marseille-Fos ait connu une croissance relative du volume de conteneurs, ce volume reste bien inférieur à celui des ports rivaux et des ports voisins. Le port d'Anvers a aujourd'hui un volume de conteneurs neuf fois plus élevé que le port de Marseille, alors qu'en 1978 il était seulement trois fois plus élevé. Le volume de conteneurs traités à Marseille-Fos en 2011, s'élevant à 0,94 millions, a été dépassé par Anvers depuis 1983. De plus, d'autres ports de l'Ouest Méditerranéen dont le trafic de conteneurs était plus ou moins similaire en 1978 ont aujourd'hui doublé (cas de Gênes et Barcelone), voire quadruplé le volume du trafic de Marseille-Fos, comme c'est le cas à Valence et Algésiras (Figure 3). 
Figure 3. Développement du trafic de conteneurs (1978-2011)

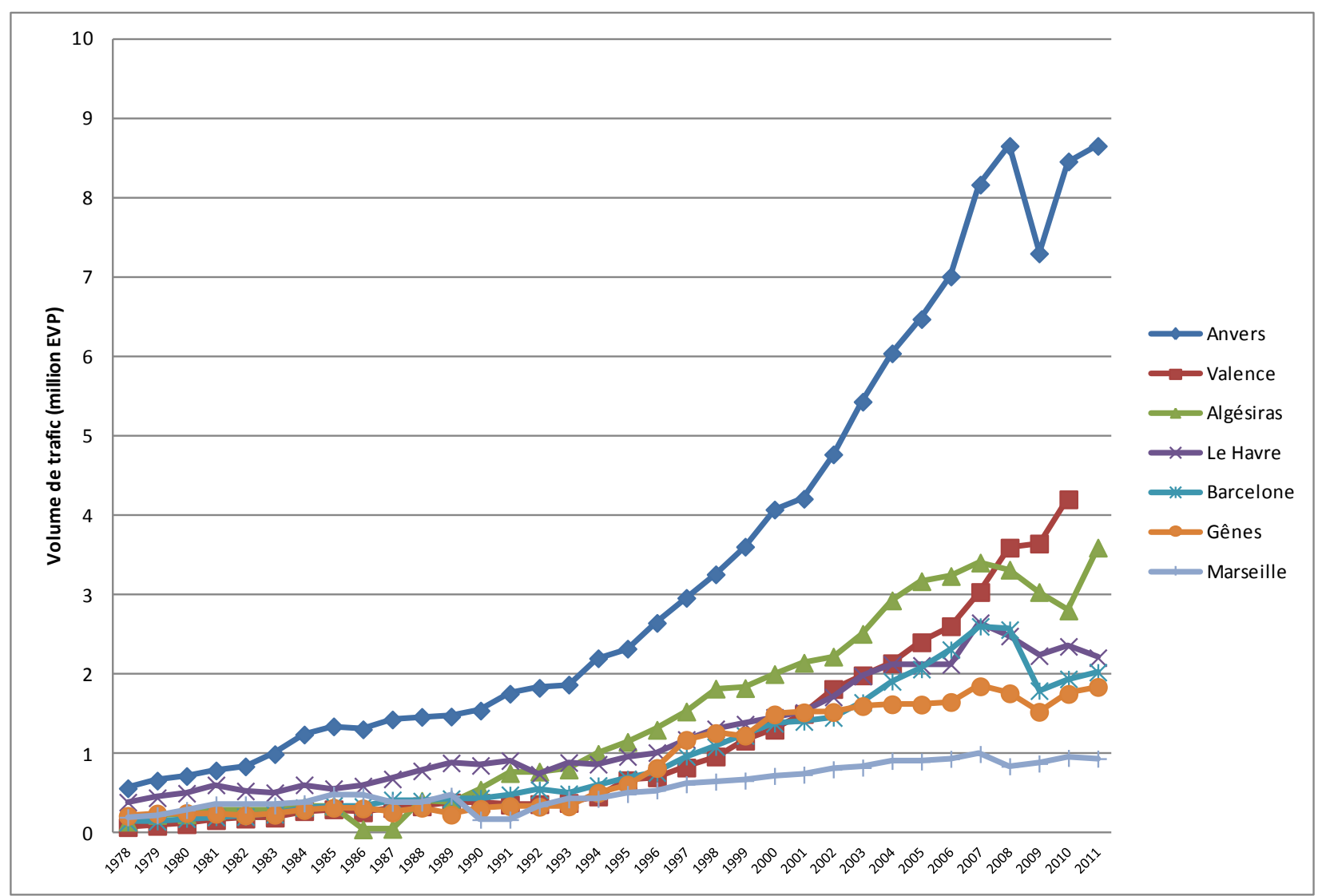

Source : calculs et élaboration par le secrétariat de l'OCDE à partir de données JMM

Il n'y a pas non plus eu de croissance des flux de vrac liquide. Suivant des fluctuations cycliques, la tendance générale relative aux flux de vrac liquide à Marseille-Fos est décroissante. Les volumes actuels sont à leur point le plus bas depuis 1973, et les volumes sur l'ensemble des années 2000 sont loin d'atteindre ceux observés dans les années 1970 et une partie des années 1980 (Figure 4). Le déclin du volume de vrac liquide a entraîné une dépendance moindre du port de Marseille-Fos vis-à-vis de ce produit. S'il représentait environ $90 \%$ du volume total des marchandises au début des années 1970, il est rapidement descendu à 75\% dans les années 1980, et en dessous de 70\% dans les années 2000, bien qu'au cours des années suivantes on observe une ré-augmentation soudaine de cette part. En parallèle de ce déclin sur le long terme du secteur du vrac liquide, l'évolution de la part des importations et des exportations dans le débit du port est plus équilibrée : $11 \%$ de l'ensemble des volumes portuaires en 1971 constituaient des exportations (le reste représentant les importations) ; cette part s'est accrue jusqu'à $24 \%$ en 2011. 
Figure 4. Développement du volume portuaire par type de marchandise à Marseille-Fos (1973-2010)

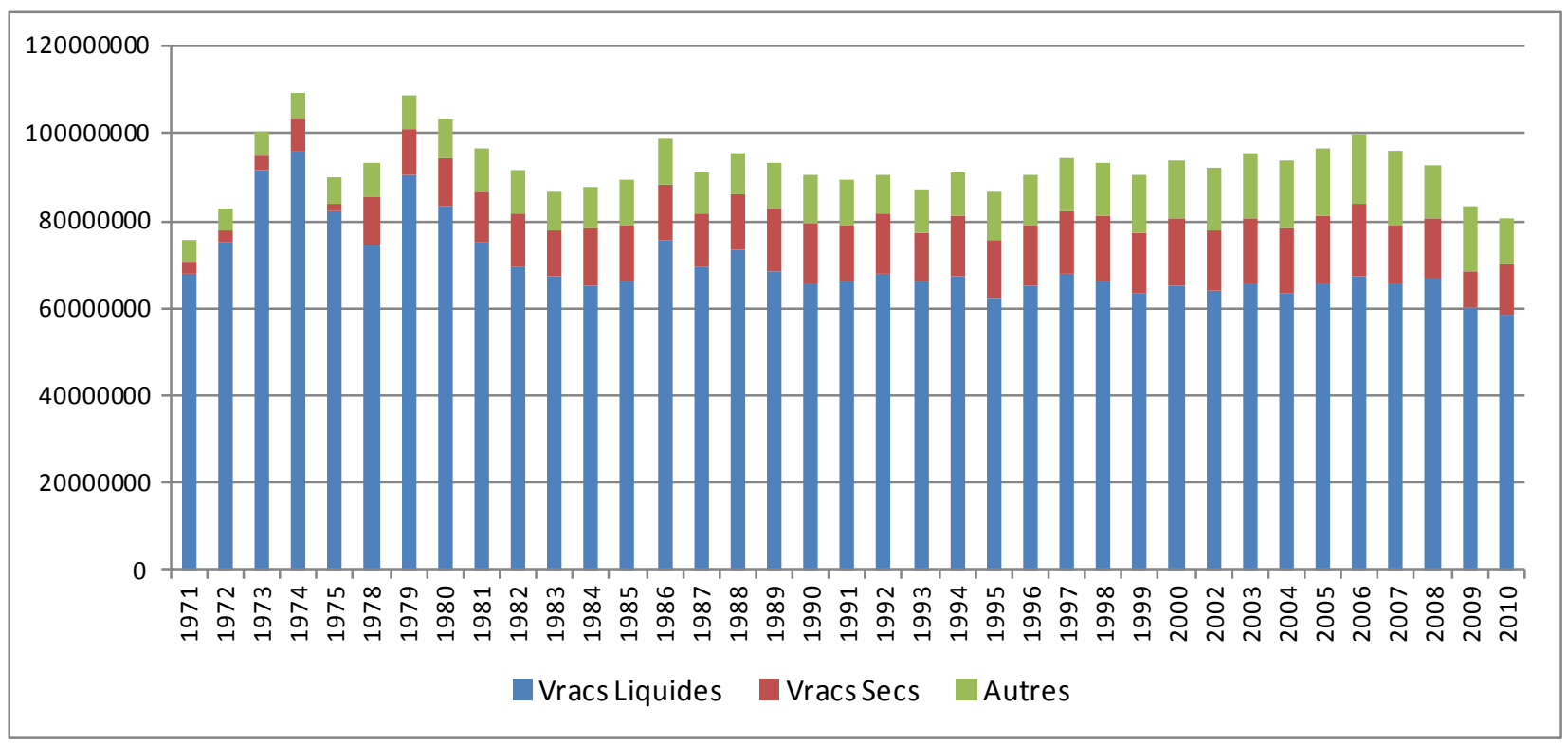

Source : calculs et élaboration par le secrétariat de l'OCDE à partir de données JMM

Cependant, on observe des signes récents de relance du trafic de conteneurs. Le volume de conteneurs à Marseille-Fos s'est accru de 14,2\% entre juillet 2011 et juillet 2012, tandis que les ports voisins et rivaux témoignent de moins bonnes performances, démontrant soit une croissance négative sur cette période, comme à Anvers $(-0,4 \%)$ et Barcelone $(-20,7 \%)$, soit de plus faibles taux de croissance, comme dans les cas de Gênes $(13,9 \%)$ et Le Havre $(11,1 \%)$. Bien qu'il soit évidemment trop tôt pour dire si cela marque réellement le début d'une relance de la croissance, il est intéressant de noter que MarseilleFos et Le Havre ont tous les deux démontré des taux de croissance du trafic de conteneurs relativement supérieurs à ceux de leurs compétiteurs, et cela après la très attendue mise en œuvre de la réforme des ports français en mai 2011, en dépit d'un contexte de crise économique mondiale, bien que l'évolution du total des marchandises soit moins prometteuse à Marseille-Fos.

\subsection{La compétitivité portuaire et ses déterminants}

\section{La connectivité maritime}

Une analyse des outils de mesure montre que Marseille-Fos est bel et bien une porte d'entrée régionale (gateway) mais cependant pas un hub mondial. Les ports peuvent être à la fois des hubs et des portes d'entrée (gateways), fonctions pouvant être qualifiées par trois outils de mesure différents: le degré de centralité, la centralité de sunexité (betweenness) et les coefficients d'agglomération (clustering). Afin d'obtenir des résultats quantitatifs, trois outils différents de mesure de la fonction de hub portuaire ont été calculés pour un échantillon de 2177 ports mondiaux et leur connexions en 2011, évaluant à la fois les valeurs absolues et le rang parmi les ports mondiaux. Les résultats pour le principal concurrent et les ports voisins de Marseille-Fos sont résumés dans le Tableau 1. La tendance générale émergeant de cette évaluation montre une grande similarité entre Marseille-Fos, Barcelone, Valence et Gênes en ce qui concerne les fonctions de connectivité portuaire. Leur valeurs absolues et relatives sont très proches les unes des autres, ce qui indique des profils similaires. Tous se caractérisent par une forte centralité, faisant 
partie du top 40 des ports en ce qui concerne le degré de centralité (DC) ainsi que la centralité de sunexité (BC). ${ }^{1}$ D'un autre côté, concernant le coefficient d'agglomération (CC), leurs rangs sont davantage modérés, ce qui indique des fonctions de hub limitées. Ils jouent ainsi le rôle de porte d'entrée régionale mais ne peuvent être considérés comme des hubs mondiaux.

Tableau 1. Les indices de centralité des ports dans les réseaux mondiaux

\begin{tabular}{|lcccccc|} 
& CC score & CC rang & BC score & BC rang & DC score & DC rang \\
\hline Anvers & 0.117 & 6 & 231455 & 3 & 475 & 3 \\
\hline Le Havre & 0.165 & 18 & 105358 & 12 & 332 & 8 \\
\hline Algésiras & 0.162 & 16 & 73992 & 15 & 297 & 15 \\
\hline Barcelone & 0.217 & 49 & 42777 & 33 & 240 & 22 \\
\hline Valence & 0.223 & 54 & 45146 & 30 & 237 & 23 \\
\hline Gênes & 0.226 & 58 & 36112 & 39 & 207 & 34 \\
\hline Marseille (Fos) & 0.220 & 53 & 46139 & 29 & 204 & 35 \\
\hline
\end{tabular}

Source : calculs et élaboration par le secrétariat de l'OCDE à partir de données Lloyd's Marine Intelligence Unit (LMIU)

Note : CC : coefficient d'agglomération ; BC : centralité de sunexité ; DC : degré de centralité

En revanche, les concurrents de Marseille-Fos dans le Nord Ouest de l'Europe, en particulier Anvers et dans une moindre mesure Le Havre, possèdent ces caractéristiques propres aux hubs. Anvers n'est pas seulement le troisième port le plus central au monde, il est également $6^{\text {ème }}$ en ce qui concerne le coefficient d'agglomération. Le Havre se place à la $18^{\text {ème }}$ position en termes de coefficient d'agglomération, ce qui est supérieur à ce que sa position de port mondial au travers des classements le suggère mais inférieur à son rang en termes de centralité portuaire. En Méditerranée de l'Ouest, seul le port d'Algésiras peut être considéré comme un véritable hub mondial, occupant un rang élevé au regard des trois outils de mesure de la fonction de hub portuaire. Son compétiteur Tanger-Med au Maroc n'a pas été capable d'atteindre des niveaux similaires de centralité et d'agglomération; et se place même loin derrière Marseille-Fos et d'autres ports de la Méditerranée Occidentale.

Marseille-Fos est plutôt bien intégré dans le réseau des routes intercontinentales empruntées par les armateurs les plus importantes mais cependant moins bien que d'autres ports de la Méditerranée Occidentale. On peut tirer cette conclusion d'une analyse des routes intercontinentales de neuf des onze armateurs mondiaux les plus importantes en Mars 2012 pour lesquelles ces routes sont disponibles publiquement. Dans cette analyse deux types de connexions intercontinentales ont été évaluées : la route Asie-Méditerranée et celle entre l'Amérique du Nord et la Méditerranée. Sur 14 des 60 routes AsieMéditerranée totales, Marseille-Fos était un port d'escale. Port Saïd était quant à lui le port le plus important pour ce trafic avec 26 routes sur un total de 60, mais les ports de Méditerranée de l'Ouest étaient bien représentés, incluant Gênes (21 fois), Barcelone (21) et Valence (19), tous faisant plus fréquemment office d'escales que Marseille-Fos sur ces routes. Les ports qui étaient moins cités en Méditerranée Occidentale que Marseille étaient Algésiras, Tanger, La Spezia et Livourne. Le rang occupé par MarseilleFos concernant son intégration dans le réseau des routes entre l'Amérique du Nord et la Méditerranée est moins conséquent : il est inclus sur ces routes seulement 5 fois sur un total de 23 boucles, derrière six autres ports de Méditerranée Occidentale, en particulier Gênes (11) et Valence (9) (Figure 5). 
Figure 5. Nombre d'escales directes au port sur les routes intercontinentales des plus grands armateurs en 2012

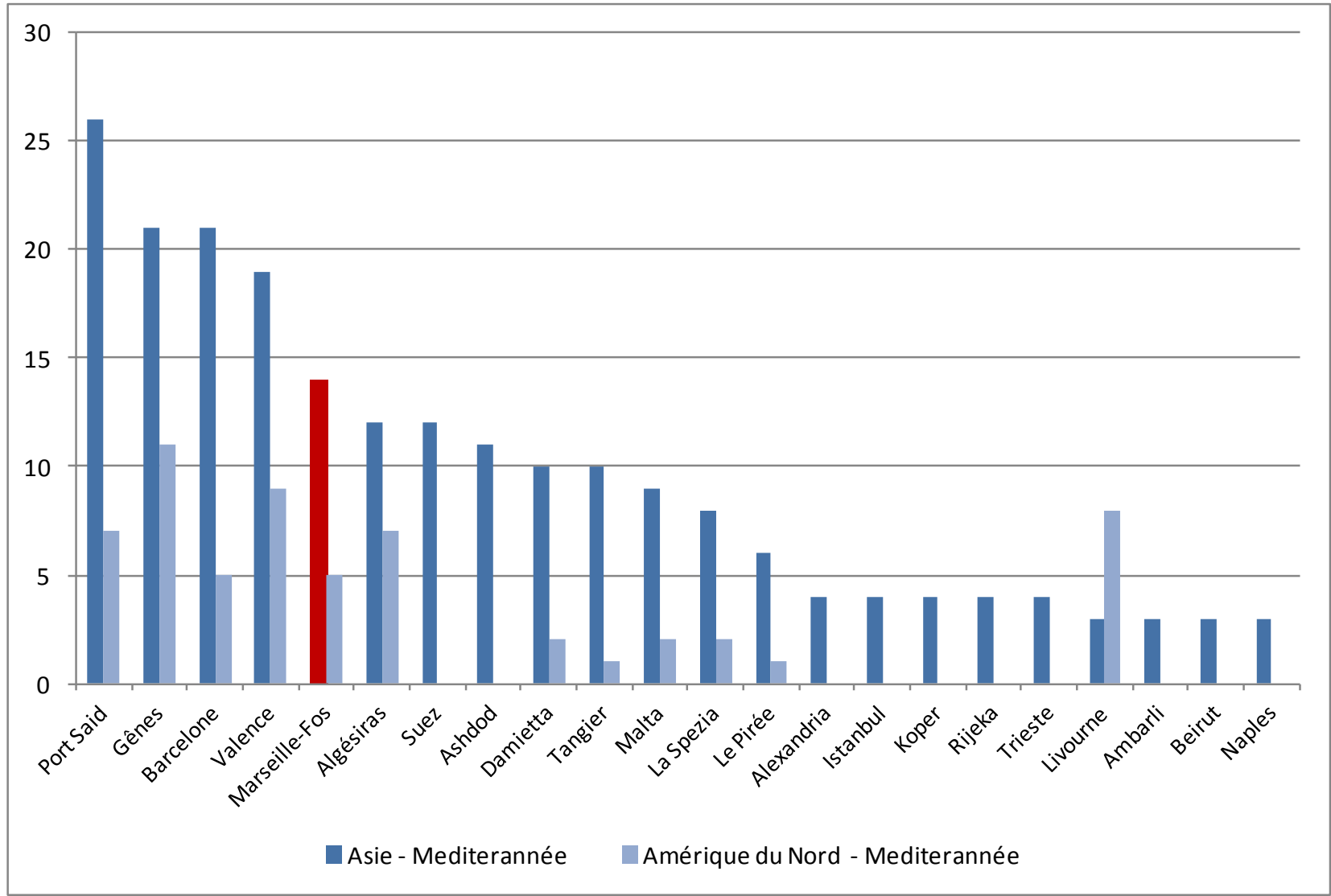

Source : calculs et élaboration par le secrétariat de l'OCDE à partir de données des grands armateurs

Concernant la connectivité maritime, Marseille-Fos ne peut pas être considéré comme étant en compétition avec d'autres ports de Méditerranée Occidentale comme Gênes, Valence ou Barcelone. Marseille-Fos et ces différents ports se chevauchent largement sur les routes de transport maritime intercontinentales : ils sont ainsi dans une très large mesure présents sur les mêmes boucles de service des grands armateurs. Par exemple, Gênes fait partie de l'ensemble des 14 boucles de service depuis l'Asie vers la Méditerranée dans lesquelles Marseille-Fos est inclus, Barcelone de 13 sur 14 et Valence 11 sur 14. Il existe des chevauchements similaires au niveau des routes entre l'Amérique du Nord et la Méditerranée, avec un chevauchement total de Marseille-Fos avec Gênes, Livourne et Valence; et dans une moindre mesure avec Algésiras et Barcelone. Ces configurations de chevauchement montrent que Marseille-Fos n'est pas qu'un simple remplaçant pour ces ports relativement proches, mais plutôt qu'il les complète. La compétition entre ces ports pour occuper une position stratégique de porte d'entrée régionale dominante est plutôt limitée. Cette situation est différente de la configuration en place en Europe du Nord Ouest. Le cas d'étude d'Hambourg montre ainsi peu de chevauchement entre les routes intercontinentales d'Hambourg et de Bremerhaven, Hambourg étant très intégré sur les routes entre l'Asie et l'Europe et Bremerhaven très présent au niveau des routes entre l'Amérique du Nord et l'Europe. Ces ports ne vont ainsi jamais de pair sur la même boucle de service intercontinentale mais font au contraire figure de parfaits remplaçants (Merk and Hesse, 2012). 


\section{Des connexions maritimes relativement modestes}

La diversité des connexions maritimes du port de Marseille-Fos est relativement limitée. C'est ce que l'on peut conclure des scores de l'index de connectivité de l'avant-pays maritime, établi pour cette étude, qui permet de comparer la diversité des connexions maritimes des grands ports mondiaux. Cet index s'applique au trafic de distribution mondiale des ports au niveau national, et est défini comme l'inverse de la somme des différences des parts de chaque port avec la moyenne mondiale, selon une méthode développée par Ducruet et al. (2011). Nos calculs de cet index sur l'année 2011 montrent que Singapour a le set de connexions maritimes le plus diversifié (score de 100). Le score de Marseille-Fos est lui de 61, ce qui le renvoie à la 122ème place dans le classement des ports en fonction de leur diversité. Les scores des ports rivaux et voisins, tels que Barcelone, Valence, Gênes, Le Havre et Anvers, sont tous supérieurs, indiquant une plus grande diversité dans leurs connexions maritimes (Figure 6). Les connexions majeures du port de Marseille-Fos se font avec la zone Méditerranéenne, l'Afrique de l'Ouest et l'Amérique du Nord. Ses connexions avec l'Asie sont relativement limitées.

Figure 6. Diversité de connexions maritimes des ports méditerranéennes et européennes

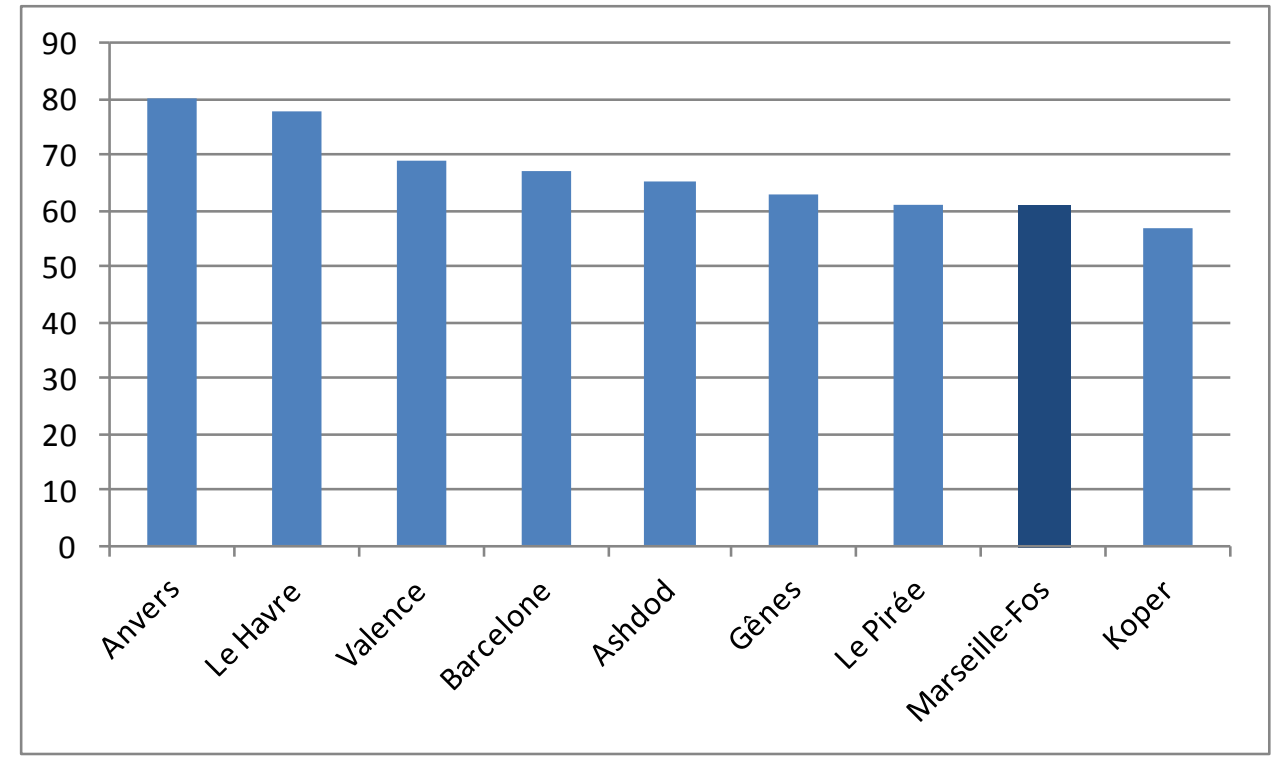

Source : calculs et élaboration par le secrétariat de l'OCDE à partir de données LMIU

Cette diversité de l'avant-pays maritime a décliné ces dix dernières années. C'est ce que l'on peut conclure des index standardisés de diversité de l'avant-pays maritime, qui ont décliné entre 2004 et 2011. Bien que cela soit une généralité plus ou moins observable dans tous les ports européens, ce qui s'expliquerait par des changements dans le commerce international et davantage de concentration portuaire vers les marchés émergents, on observe tout de même à Marseille-Fos un déclin plus prononcé que dans d'autres ports de l'Ouest Méditerranéen, dont Barcelone, Valence, Gênes, et La Spezia. Ce déclin de la connectivité maritime est aussi visible quand on observe les ports avec lesquels Marseille-Fos est connecté en termes de mouvements de navires. Sur les Figures 7 et 8, ces ports sont indiqués, suivis d'informations sur les valeurs absolue et relative de leurs connexions. En comparant les figures pour 2004 et pour 2011, on remarque non seulement que le nombre de connexions a baissé, mais que c'est aussi le cas du nombre de ports pour lesquels Marseille-Fos était un partenaire majeur (indiqué par la couleur rouge, exprimant une part relativement importante dans le trafic total du port). 


\section{MARSEILLES (2004)}

Traffic share at

world ports' total (\% GRT)

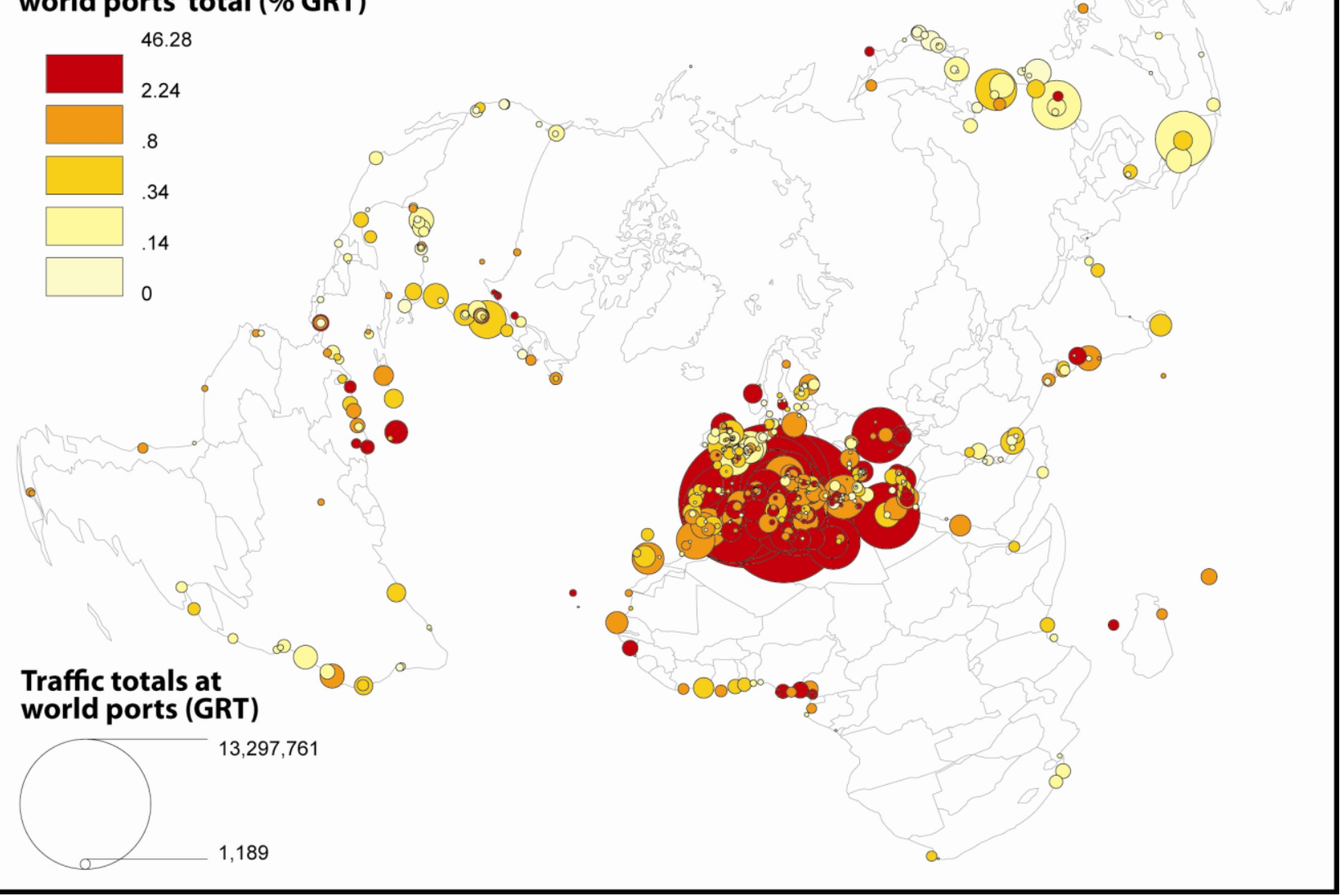

Source : calculs et élaboration par le secrétariat de I'OCDE à partir de données LMIU 
Figure 8. L'avant-pays maritime de Marseille-Fos en 2011

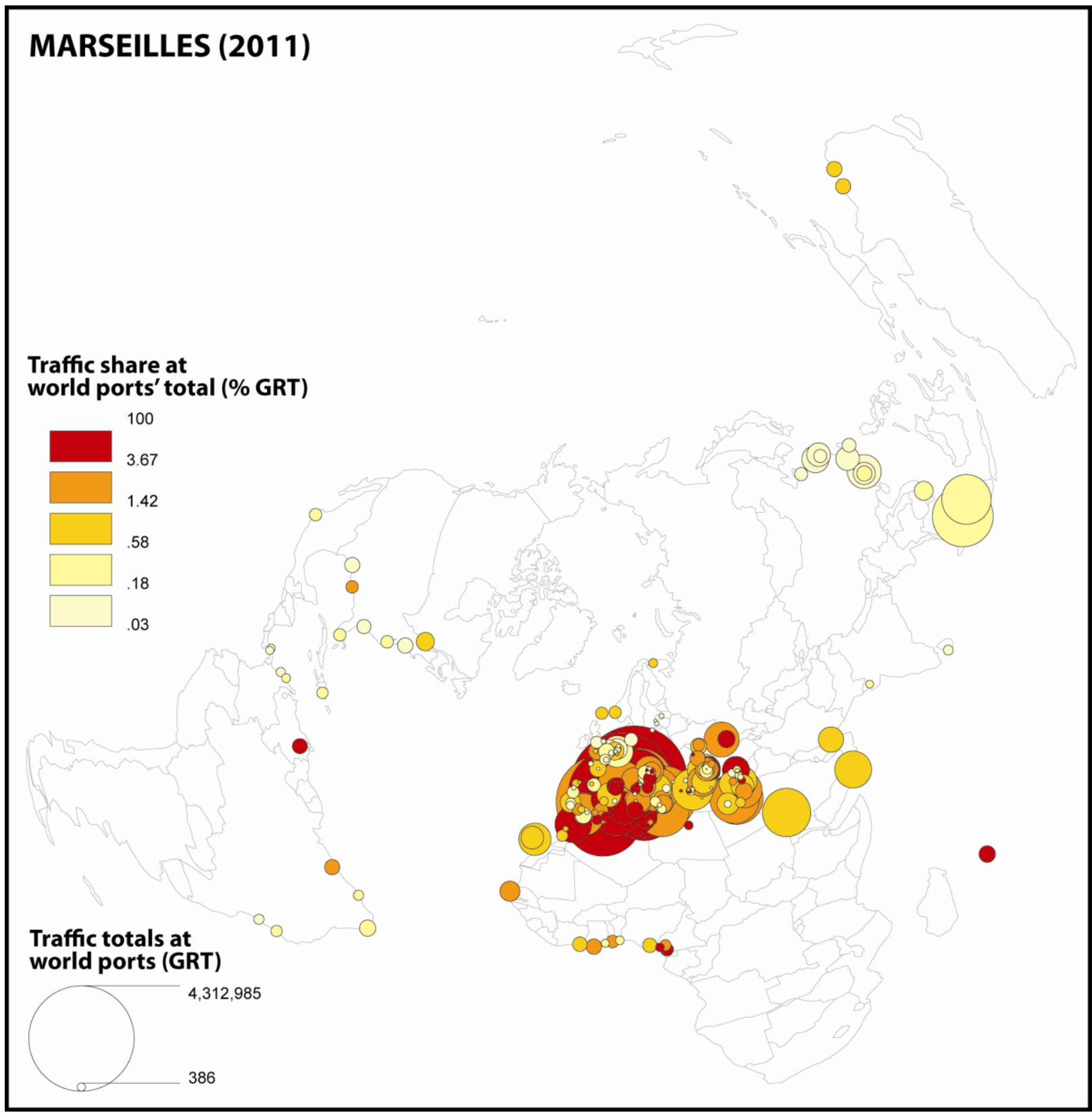

Source : calculs et élaboration par le secrétariat de l'OCDE à partir de données LMIU 


\section{Des connexions à courte distance limitées}

La position de Marseille-Fos dans le transport maritime à courte distance est relativement modeste. C'est ce qui ressort de l'analyse d'une base de données sur le transport maritime à courte distance établie pour ce rapport. Cette base de données est constituée des différentes grilles horaires (circuits de circulation) de 2011 pour les 34 principales compagnies de transport maritime à courte distance en Europe, étant les plus souvent mentionnées sur le site internet European Short Sea Network, ce qui permet de calculer des fréquences de 211 ports européens dans ces circuits, ainsi que du nombre de connections entre les ports. Le transport maritime à courte distance désigne ici les activités maritimes au sein de l'Europe entre des compagnies qui se désignent elle-même comme étant des compagnies de transport maritime de courte distance. Seules sont prises en compte les lignes régulières de transporteurs de conteneurs, ce qui fait preuve de parti pris dans notre étude comparative, sachant que Marseille (Bassin Est) compte un grand nombre de trafic roulier de courte distance qui n'apparaît donc pas dans cette analyse. A partir de cette base de données, on observe que le transport maritime à courte distance est peu développé à MarseilleFos : le port se positionne $17^{\text {ème }}$ en termes du nombre d'inclusions sur les routes maritimes à courte distance, et $17^{\text {ème }}$ concernant le nombre (29) de ports Méditerranéens avec lesquels il est connecté via le transport maritime à courte distance (Figure 9). Or, Barcelone dispose de deux fois plus de connexions portuaires via le transport maritime à courte distance. La majorité de ce type de transport a lieu dans les Bassins Est: Marseille y apparaît 51 fois contre seulement 11 fois pour Fos. De plus, Marseille est connecté à 27 autres ports, contre seulement 10 pour Fos ${ }^{2}$. Les connexions majeures de Marseille-Fos sont avec Barcelone, Valence, Gênes, Algésiras et Casablanca. 
Figure 9. Connexions du transport maritime conteneurisé de courte distance dans la Méditerranée (2011)

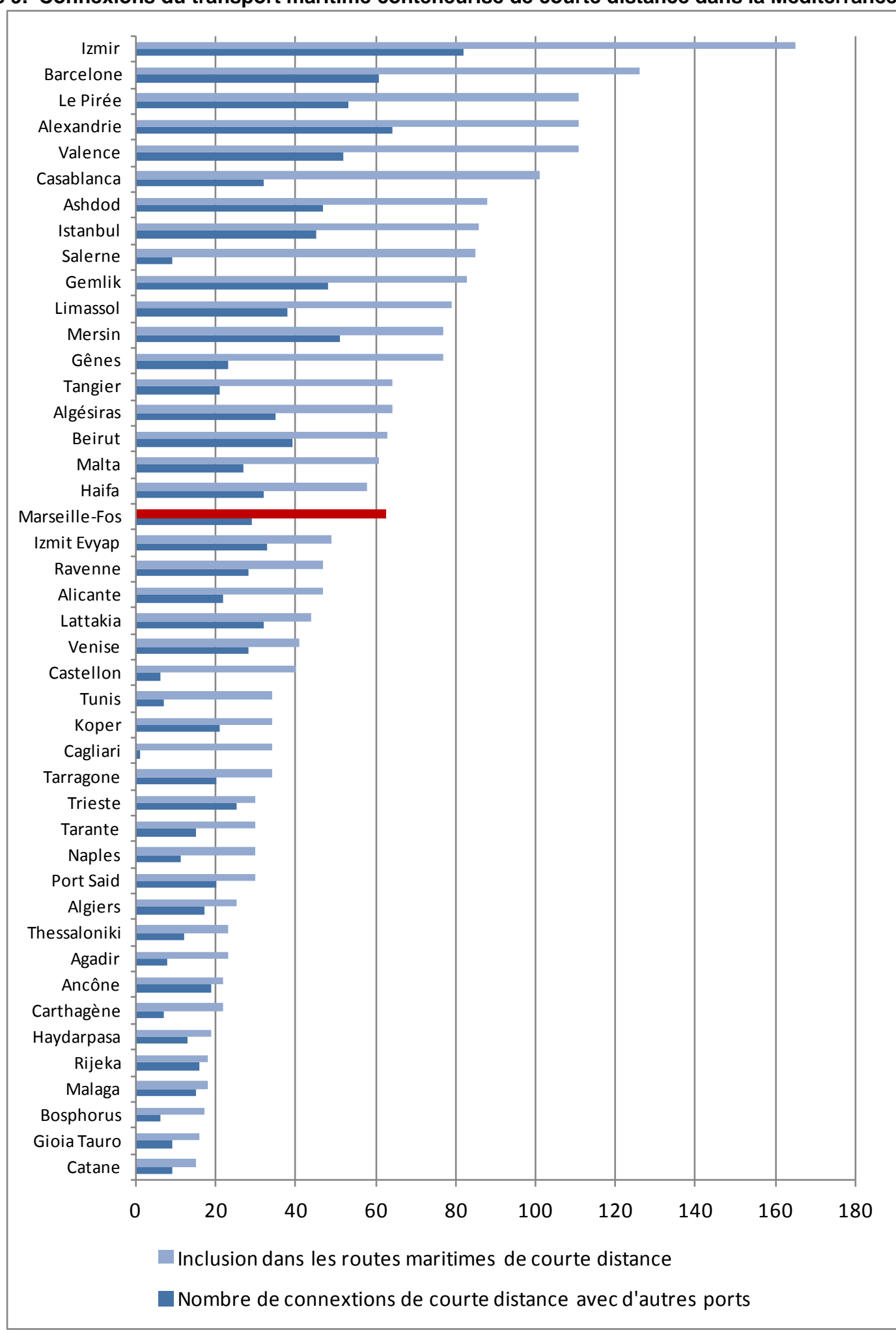

Source : calculs et élaboration par le secrétariat de l'OCDE à partir de données des 34 compagnies de transport maritime conteneurisé sur courte distance 


\section{L'efficacité du port}

Le délai d'opération des navires dans les ports (efficacité en termes de temps) est l'un des déterminants de la compétitivité d'un port. L'efficacité en terme de temps est ici considérée comme le temps moyen qu'un navire passe dans le port avant de repartir vers un autre port, et est calculée grâce aux données de mouvements des navires, collectées par la Lloyd's Marine Intelligence Unit (LMIU cf p.11). Ce délai d'opération est généralement considéré comme un déterminant important de la compétitivité d'un port, sachant qu'un délai rapide permet de réduire la congestion et les embouteillages, et de générer des flux plus importants. La productivité-temps des principaux ports européens a été mesurée à l'aide d'une méthode décrite en Annexe 2, de données de la LMIU datant de mai 2011, et de données d'Eurostat sur les volumes de conteneurs fin 2011. Les calculs finaux ont permis d'effectuer une mesure du temps d'opération moyen d'un port, en jours, par 1000 équivalents vingt pieds (EVP).

A cet égard, Marseille-Fos s'aligne avec la moyenne Méditerranéenne, bien qu'il soit moins économe en temps que ses compétiteurs directs. Le temps moyen de manutention d'un conteneur à Marseille-Fos, au second trimestre de 2011, était de 1,16 jours pour 1000 conteneurs (EVP), soit environ le double du temps nécessaire pour une telle opération à Valence et à Anvers. D'autres ports méditerranéens occidentaux, tels que Barcelone et La Spezia, ainsi que le principal rival français de Marseille-Fos, Le Havre, sont également plus efficace en termes de temps. Pourtant, Marseille-Fos s'avère plus efficace que Gênes, Tarragone et d'autres ports Méditerranéens (Figure 10). Ces scores divers en termes d'efficacité s'alignent avec les résultats trouvés dans un large ensemble d'études sur l'efficacité des ports.

Figure 10. Temps de manutention de conteneurs (jours/1000 EVP), trimestre 2, 2011

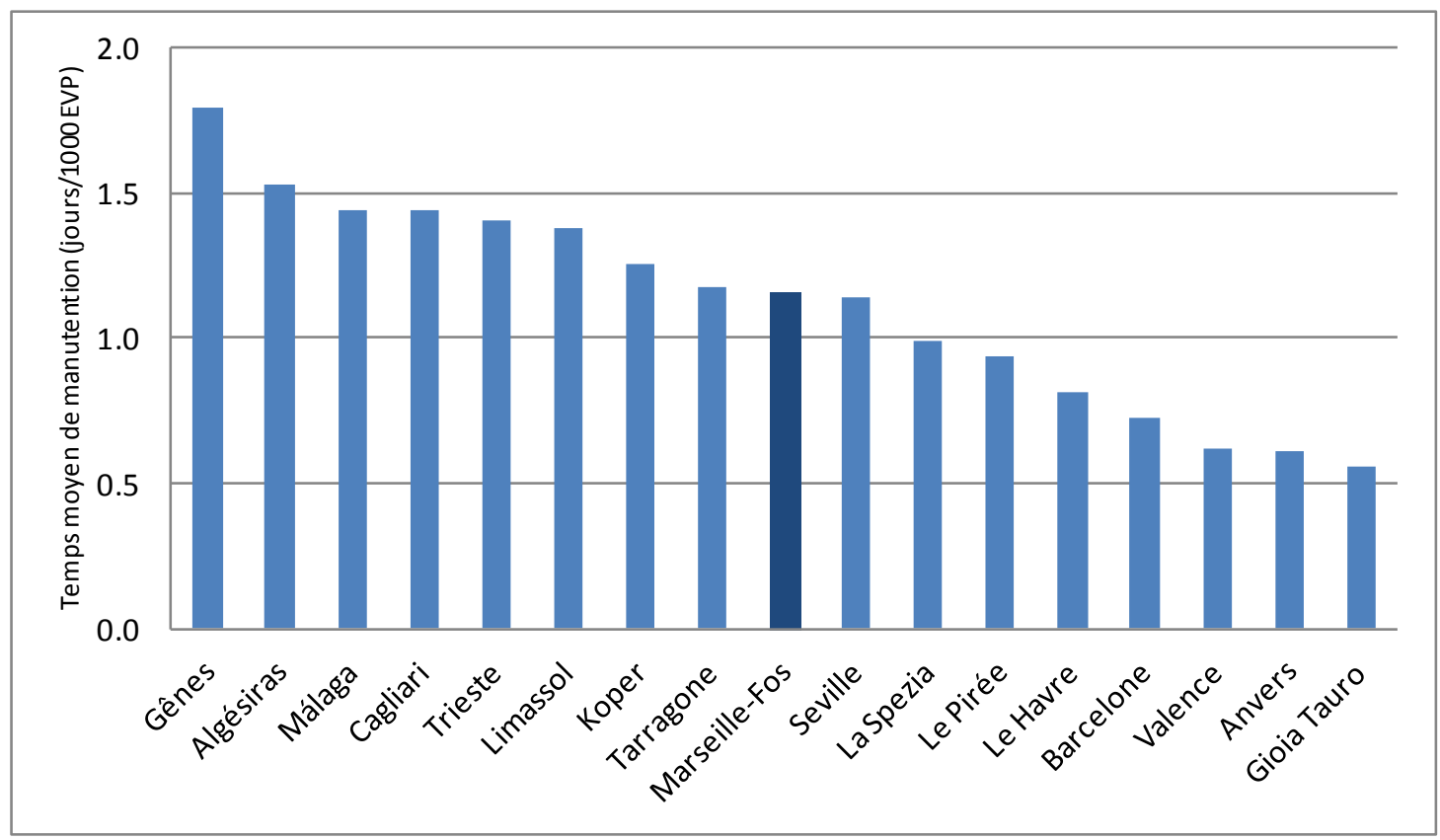

Source : calculs et élaboration par le secrétariat de l'OCDE à partir de données LMIU et Eurostat

Concernant les terminaux de vrac, Marseille-Fos ne figure pas parmi les ports les plus efficaces au niveau mondial, mais il se positionne relativement bien comparé à ses rivaux directs. Ceci est le résultat d'une de nos analyses sur l'efficacité portuaire relative aux biens en vrac, effectuée à l'aide d'une méthode DEA et d'une base de données créée spécialement pour cette étude (la base de donnée et la méthodologie sont décrites en Annexe 3). Nos résultats indiquent que les ports les plus efficaces en termes de trafic de pétrole brut sont les grands ports du Moyen Orient fortement spécialisés dans le pétrole, ainsi que quelques autres très grands ports, notamment le port de Rotterdam et des ports chinois. Fos ne figurait pas dans le 
haut du classement des ports pétroliers mondiaux, mais émerge comme le port pétrolier le plus efficace dans la Méditerranée, plus efficaces que les ports de Trieste et Algésiras. De plus, il avait une performance supérieure à celle des ports rivaux d'Anvers et Le Havre (Figure 11). On observe un phénomène similaire à l'égard de l'efficacité de Marseille-Fos en ce qui concerne le trafic de charbon et minerais: s'il ne fait pas partie des ports les plus performants au niveau mondial, il reste plus performant que d'autres ports Méditerranéens, tels que Tarragone, Savone, La Spezia, Algésiras et Gênes, ainsi que ses rivaux Le Havre et Anvers (Oliveira et Cariou, 2011).

Figure 11. Scores d'efficacités des ports/terminaux pétroliers (2011)

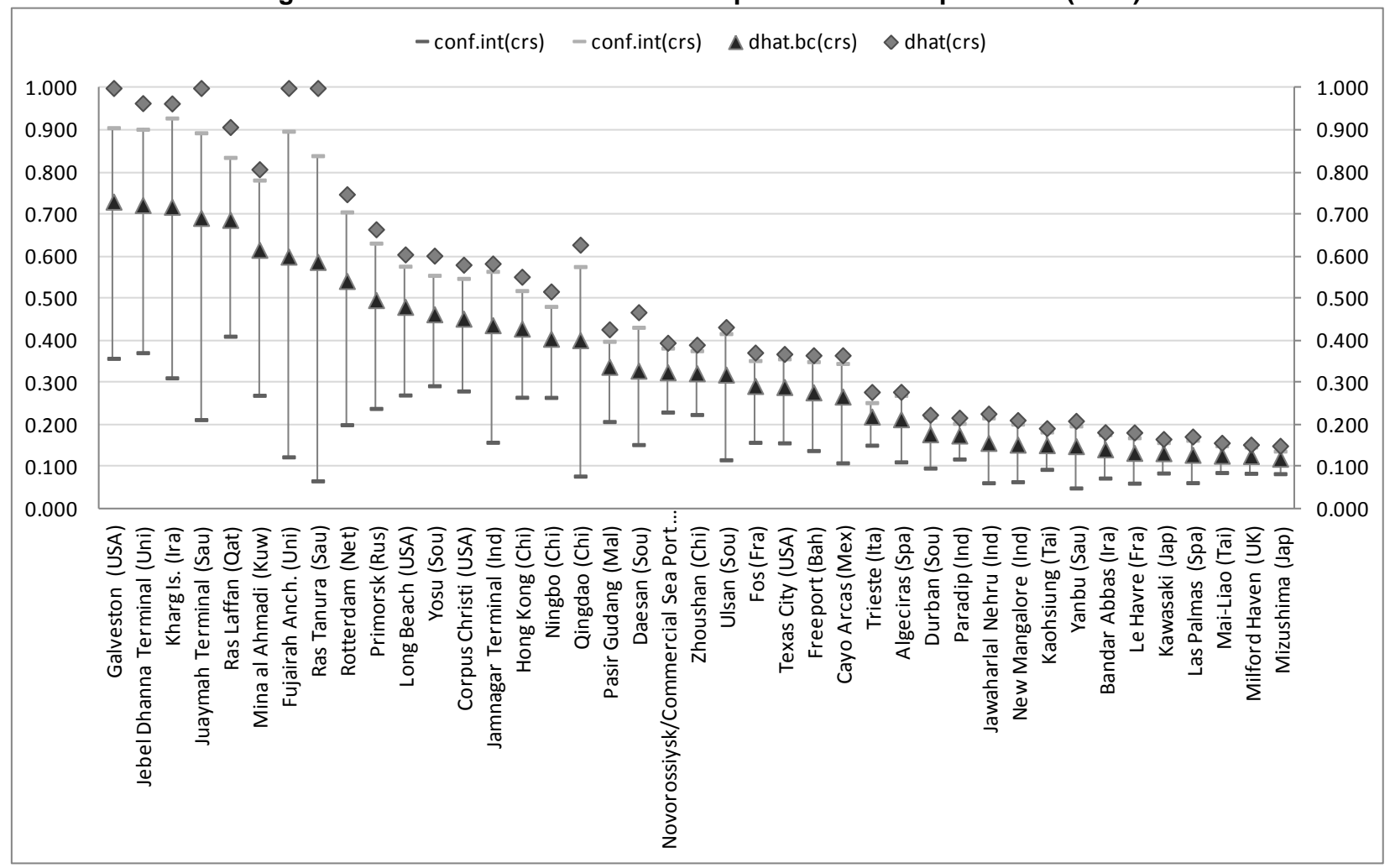

Source : calculs et élaboration par le secrétariat de l'OCDE à partir de données LMIU, Ports of the World 2011 et d'autres sources Note: (dhat) fait référence aux scores d'efficacité dérivés en utilisant la méthode DEA standard. (dhat/bc) indique les scores dérivés en utilisant la méthode du bootstrap, et (cong.int) indique les valeurs aux extrémités de l'intervalle de confiance ; (crs) est l'abréviation de « rendements d'échelle constants », un postulat utilisé dans les deux méthodes.

\section{La connectivité de l'arrière-pays}

Une analyse détaillée des arrière-pays portuaires en France, basée sur des données de 2005, montre que les principaux rivaux de Marseille-Fos pour l'arrière-pays sont Le Havre et Anvers. Cette analyse s'appuie sur des données de la douane française portant sur l'origine et les destinations des biens d'importation et d'exportation en France, en volume et en valeur (Guerrero, 2010). Les régions françaises pour lesquelles le port de Marseille-Fos est le plus important sont la région PACA, la région MidiPyrénées, la Région Rhône-Alpes, ainsi que les départements de la Lozère et du Gard (LanguedocRoussillon), de Haute-Loire (Auvergne), Saône-et-Loire (Bourgogne), et du Jura (Franche-Comté). Excepté les arrières pays locaux autour des ports secondaires, la majorité du reste de l'arrière-pays appartient au port du Havre. Bien que les ports du Benelux dominent le Nord et l'Est de la France, ils sont également sur représentés dans les départements des Hautes-Alpes dans la région PACA, où est situé le port de Marseille-Fos (Figure 12). 
Figure 12. Arrière-pays portuaires en France (2005)

a) Importations en tonnage

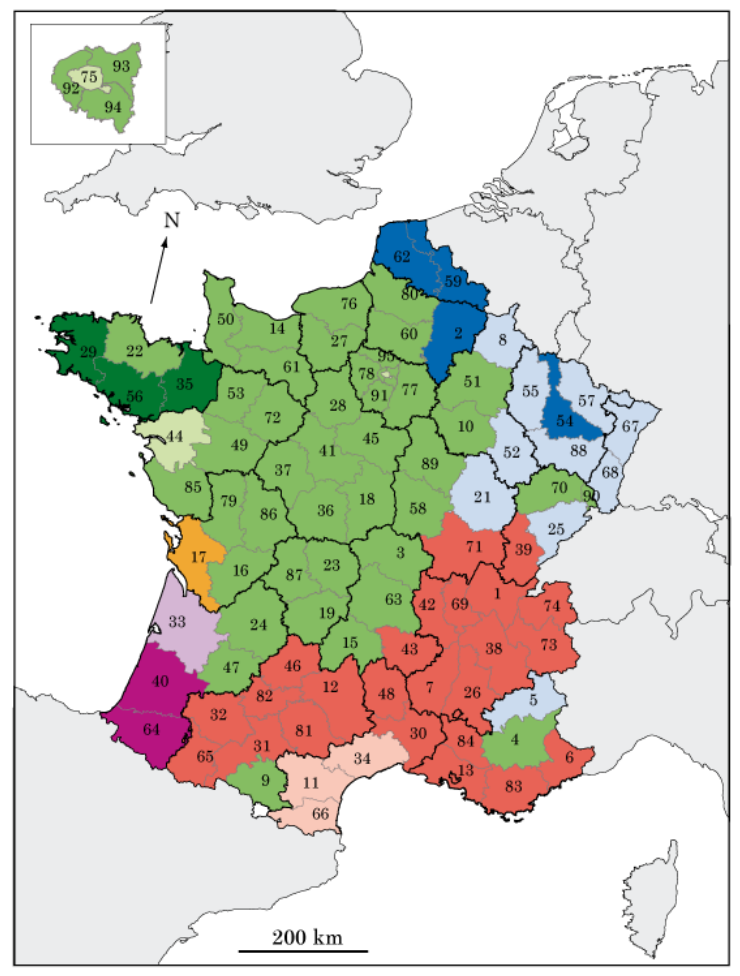

c) Exportations en tonnage

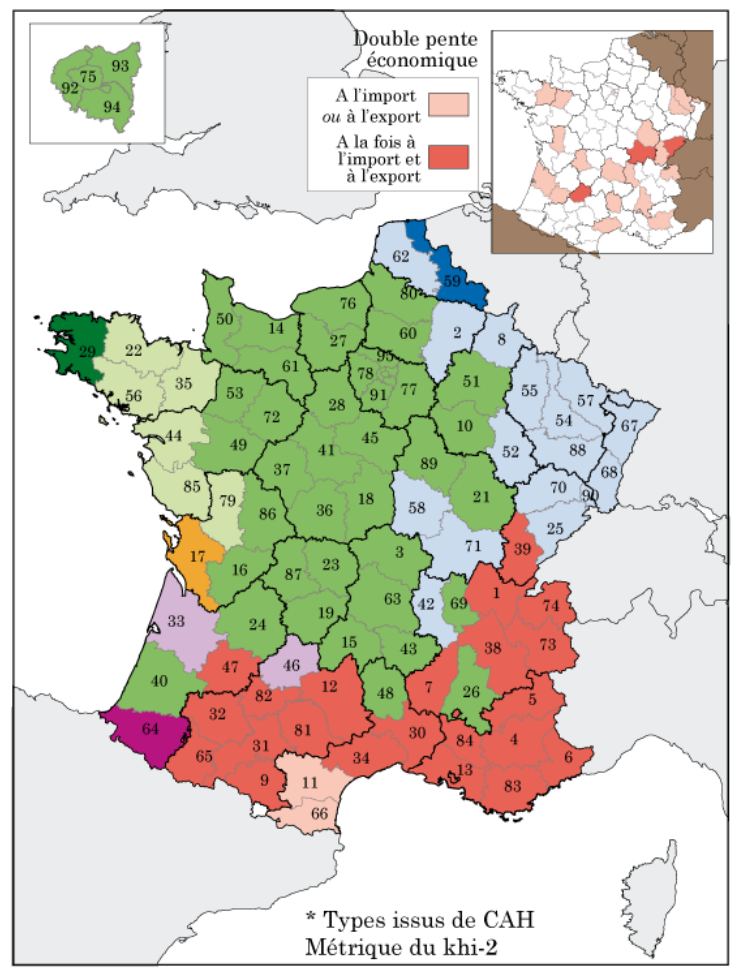

b) Importations en valeur

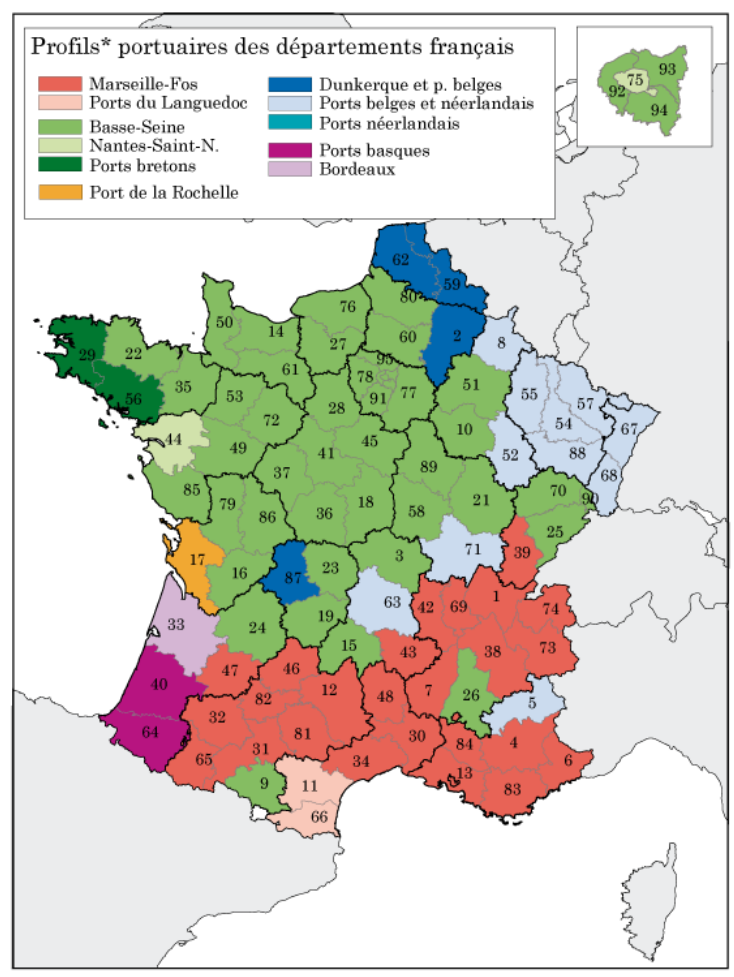

d) Exportations en valeur

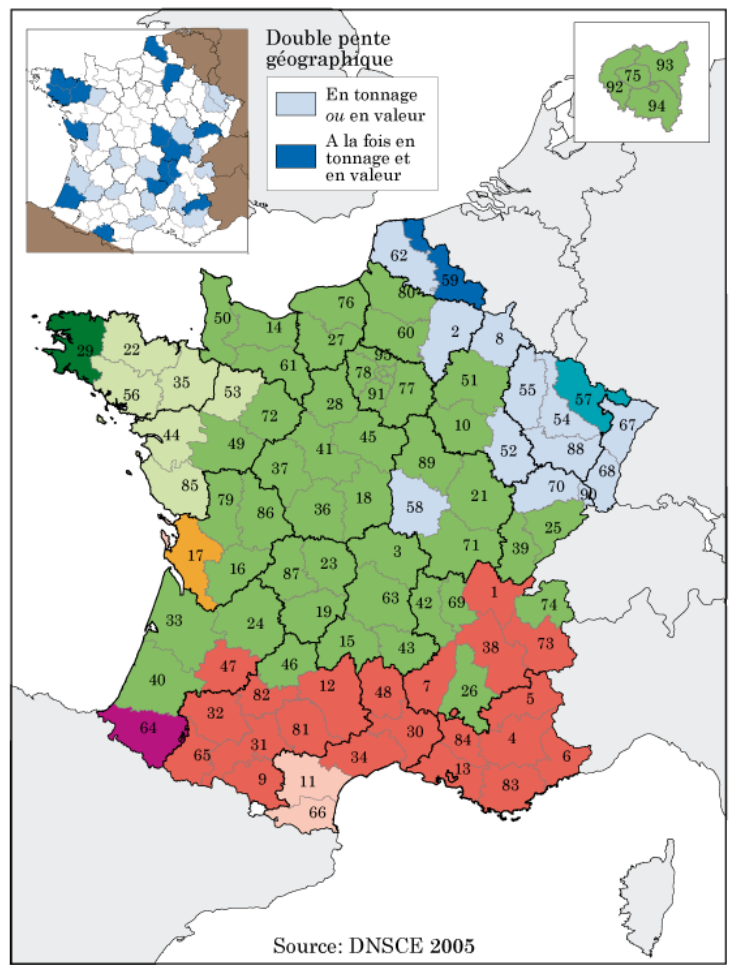

Source: Guerrero 2010 
Des données additionnelles plus récentes confirment la domination des arrière-pays du port de Marseille-Fos. La connaissance de l'arrière-pays des ports français est limitée depuis la disparition des données issues de déclarations douanières utilisées pour calculer les parts de marché par région, en 2007. En l'absence d'autre source fiable aujourd'hui, les ports français ont une connaissance ponctuelle de leur arrière-pays, basée sur des études spécifiquement réalisées. Peu de données précises sont disponibles : toutefois, des études réalisées en internes et recoupées par quelques études effectuées par le ministère des transports français permettent une vision plus précise sur quatre régions: Rhône-Alpes (part de marché du GPMM 60\%), Région Parisienne (part de marché 3\%), Région Bourgogne (20\%) et Région Midi-Pyrénées $(60 \%)$.

L'arrière-pays du port de Marseille-Fos n'inclut pour le moment pas les régions des pays voisins, tels que la Suisse, l'Allemagne ou le Nord de l'Italie. C'est particulièrement visible dans l'analyse des flux de biens transportés entre le département des Bouches-du-Rhône et les régions du Nord de l'Italie et la Suisse. Ces flux sont limités, en particulier en comparaison avec ceux en provenance d'Anvers et de Hollande méridionale (Rotterdam). Les grands couloirs ferroviaires, tels que ceux reliant Rotterdam-Gênes et Barcelone-Lyon-Turin-Trieste-Budapest, compliquent les tentatives de Marseille-Fos de conquérir ces zones d'arrière-pays.

\section{La compétition intra-portuaire et interportuaire}

Le port de Marseille-Fos n'est pas particulièrement sujet à une compétition vis à vis des autres ports, en comparaison avec Valence, Barcelone ou Gênes. Il reste de loin le plus grand port français méditerranéen, et représente environ $90 \%$ du volume portuaire français méditerranéen, et $100 \%$ du trafic de conteneurs. Les autres ports méditerranéens en France tels que Sète, Toulon, Nice et Port-La-Nouvelle sont beaucoup plus petits, plus spécialisés et n'ont pas une telle fonction de plateforme régionale. Cette situation contraste avec celle des principaux ports méditerranéens espagnols et des ports ligures, au nord de l'Italie. Le port de Valence, le plus important port méditerranéen espagnol, représente seulement $20 \%$ du volume portuaire méditerranéen du pays ${ }^{3}$. Cela s'explique par le fait que deux autres ports, Barcelone et Tarragone, atteignent environ deux tiers de son trafic et, comme Valence, ont un trafic diversifié avec un nombre important de conteneurs. De même, les ports de la Ligurie en Italie forment une constellation de ports, dominée par celui de Gênes, suivi de trois autres ports, Livourne, La Spezia et Savone, qui rassemblés ont un volume plus important que le port de Gênes (Tableau 2).

Les ports méditerranéens espagnols et italiens sont en compétition les uns avec les autres pour assurer des rôles de passerelles régionales, alors que le port de Marseille-Fos peut considérer cette fonction comme déjà acquise. Cela est visible en observant les routes intercontinentales des porte-conteneurs mondiaux, que nous avons discuté précédemment. Par exemple la majorité des trajets en provenance d'Asie ou d'Amérique du Nord passent par les ports de Gênes, mais ils passent aussi par ceux de La Spezia et Livourne. De même pour les ports de Valence, Barcelone et Tarragone, qui entrent souvent en compétition pour devenir des passerelles régionales. A l'inverse, Marseille-Fos est l'unique port méditerranéen français sur ces trajets intercontinentaux. Cela est confirmé si l'on compare la centralité de ces ports : les ports secondaires de ces systèmes régionaux sont proches du système du port principal en Espagne et en Italie, mais pas dans le cas français (Tableau 3). Une telle compétition incite les ports Italiens et Espagnols à atteindre de meilleurs performances, sachant que cela peut avoir un impact réel, comme on l'observe dans différents cas où des compagnies maritimes ont réorienté leur trafic d'un port à l'autre : la compagnie ZIM, en 2009, du port de Barcelone à celui de Tarragone ; Evergreen, en 2009, du port de Barcelone à celui de Tercat; Maersk en 2009 du port de Tercat à celui de Barcelone; China Shipping, en 2007, du port de Valence à celui de Barcelone. De telles incitations à la performance dérivant d'une compétition entre plusieurs ports n'existent pas dans le cas de Marseille-Fos. Son arrière-pays est longtemps resté une zone captive difficilement contestable par les ports ligures ou les ports d'Espagne ; 
cela peut également expliquer le fait que le déclin du port de Marseille-Fos n'ait pas été aussi dramatique qu'il aurait pu l'être.

Tableau 2. Volumes des ports principaux de la zone Ouest de la Méditerranée européenne $(2010,1000$ tonnes)

\begin{tabular}{|lcc|}
\hline France & Total & Conteneur \\
\hline Marseille-Fos & 82,423 & 7,647 \\
\hline Sète & 3,282 & 52 \\
\hline Port-La-Nouvelle & 2,074 & 0 \\
\hline Toulon & 73 & 0 \\
\hline Espagne & & \\
\hline Algésiras & 57,286 & 29,551 \\
\hline Valence & 53,075 & 40,441 \\
\hline Barcelone & 35,322 & 15,180 \\
\hline Tarragone & 32,072 & 2,336 \\
\hline Carthagène & 19,045 & 612 \\
\hline Castellon De La Plana & 12,236 & 1,151 \\
\hline Italie & & 10,746 \\
\hline Gênes & 41,427 & 4,660 \\
\hline Livourne & 22,662 & 9,573 \\
\hline La Spezia & 16,091 & 1,442 \\
\hline Savone & 12,874 & \\
\hline
\end{tabular}

Source : calculs et élaboration par le secrétariat de l'OCDE à partir de données Eurostat

Tableau 3. Indices de centralité des ports secondaires dans l'Ouest de la Méditerranée (2011)

\begin{tabular}{|lcccccc|} 
& CC score & CC rang & BC score & BC rang & DC score & DC rang \\
\hline Tarragone & 0.227 & 68 & 23056 & 75 & 187 & 42 \\
\hline Livourne & 0.251 & 116 & 21796 & 78 & 178 & 48 \\
\hline La Spezia & 0.376 & 491 & 9128 & 193 & 126 & 126 \\
\hline Savone & 0.338 & 374 & 12692 & 145 & 94 & 223 \\
\hline Sète & 0.362 & 444 & 1762 & 549 & 53 & 491 \\
\hline Port la Nouvelle & 0.515 & 996 & 335 & 913 & 19 & 1028 \\
\hline Nice & 0.429 & 676 & 2715 & 469 & 8 & 1470 \\
\hline Toulon & 0.679 & 1405 & 124 & 1115 & 8 & 1477 \\
\hline
\end{tabular}

Source : calculs et élaboration par le secrétariat de l'OCDE à partir de données LMIU

Note : CC : coefficient d'agglomération ; BC : centralité de sunexité ; DC : degré de centralité

De plus, le manque de compétition du port de Marseille-Fos avec d'autres ports n'est pas compensé par une compétition à l'intérieur même du port qui reste très limitée. Une telle compétition à l'intérieur du port n'existe que depuis 2010, avec la création du terminal de conteneurs Fos 2XL, provoquant une situation où l'un des terminaux est exploité par CMA-CGM et DP World, et l'autre par MSC. En pratique cependant, la majorité du trafic de conteneur reste sous la direction de CMA-CGM. La présence de quatre grands opérateurs mondiaux de terminaux dominant le marché est limitée, DP World étant le seul 
réellement actif à Marseille-Fos, et pas APMT, HPH ou PSA. Or, dans la plupart des plus grands ports mondiaux, plus d'un de ces exploitants est impliqué, parfois même les quatre à la fois (Tableau 4).

Tableau 4. Présence des quatre grands opérateurs de terminaux de conteneurs dans les ports du monde (2012)

\begin{tabular}{|ll|}
\hline Nombre de grands opérateurs & Nom du port \\
& $\begin{array}{l}\text { Anvers, Sydney, Brisbane, Chennai, Dammam, Guangzhou, Ho Chi Minh } \\
\text { City, Le Havre, Qingdao, Shanghai, Xiamen, Zeebruges }\end{array}$ \\
\hline Trois & Busan, Hong Kong, Rotterdam, Xingang \\
\hline Quatre & Buenos Aires, Laem Chabang \\
\hline
\end{tabular}

Source : calculs et élaboration par le secrétariat de l'OCDE à partir de données collectionnées auprès des grands opérateurs de terminaux

Ces dix dernières années, cependant, une compétition accrue a commencée à émerger au Nord Ouest de l'Europe, plus particulièrement d'Anvers et Le Havre. Les deux ports opèrent dans le très compétitif axe Hambourg-Le Havre, au sein duquel les ports principaux se disputent des parties d'arrière-pays. Ce qui était autrefois un arrière-pays captif pour Marseille-Fos, tel que la zone métropolitaine autour de Lyon, devient progressivement une zone disputée par Anvers, Le Havre et même Rotterdam qui s'emploient à élargir leurs parts de marché. Des zones de croissance potentielle pour Marseille-Fos, telles que l'Est de la France et la Suisse, doivent à présent être gagnées aux ports compétiteurs. De plus, en parallèle, la compétition portuaire en Espagne et la volonté de soutenir la croissance des ports a provoqué l'expansion de l'arrière-pays vers la région du Sud de la France, originellement une partie de l'arrière-pays naturel de Marseille-Fos (et de Bordeaux). Le port de Marseille-Fos, face à ces pressions de compétitivité croissantes, doit s'adapter, après s'être isolé de la compétition durant plusieurs décennies. 


\section{IMPACTS}

La performance portuaire est un sujet pertinent en général, mais d'autant plus pertinent quand elle est étudiée en relation avec ses implications : de quelle façon est-ce que la croissance portuaire se transforme en croissance métropolitaine ; est-ce qu'elle génère des emplois, attire des entreprises ; quels sont ses effets négatifs, par exemple ses effets environnementaux ? Telles sont les questions auxquelles ce chapitre va répondre, en étudiant à la suite l'emploi portuaire, la valeur ajoutée crée par le port, les effets économiques indirects et les impacts environnementaux.

\subsection{L'emploi lié au port}

Des études précédentes ont montré que le port de Marseille-Fos génère environ 40,000 à 45,000 emplois. En 2007, une étude recensait 41,300 emplois liés au port (Entreprises et territoires, 2009). D'après l'étude plus de la moitié de ces emplois $(22,700)$ étaient liés à la logistique, environ un tiers $(16,700)$ à la confection et à peu près $5 \%(1,900)$ correspondait au secteur des services essentiellement basé dans la ville de Marseille. La méthodologie utilisée pour cette étude s'appuyait sur une micro-analyse des réponses à des sondages par les entreprises, indiquant ou non un lien avec le port. Cette étude offre également une bonne vue d'ensemble sur quelles sortes d'emplois peuvent être trouvés dans quelles intercommunalités du département des Bouches-du-Rhône. Dans une étude comparative sur l'emploi généré par la présence d'un port en France réalisée par l'Observatoire Portuaire de la Fédération Nationale des Agences d'Urbanisme (FNAU), cette même étude précédemment évoquée fut utilisée, mais un nombre approximatif de 2,500 emplois dans le domaine de la plaisance fut ajouté à l'ensemble, donnant un résultat total de 43,800 emplois liés au port.

Bien que ces études présentent des avantages certains, leur méthodologie se base plus ou moins sur une définition discrétionnaire de ce qu'est l'emploi lié au port, rendant la comparaison avec d'autres villes portuaires difficile. En France plusieurs villes portuaires ont ainsi leur propre définition de l'emploi lié au port et celle-ci est indéniablement influencée par les contextes locaux, ce qui signifie que certains secteurs sont considérés comme faisant partie de l'emploi lié au port dans certaines villes mais pas dans d'autres. Les défauts dus à cette absence de définition précise sont bel et bien reconnus par la FNAU dans l'étude citée plus haut, dans laquelle un cadre conceptuel commun prenant en compte l'emploi lié aux ports, ainsi que les codes statistiques des emplois liés aux ports est proposé (FNAU, 2009). Cette base conceptuelle permet d'estimer l'emploi lié aux ports en France de manière comparative et correspond donc précisément à ce qui a été mis en œuvre dans le cadre de ce rapport.

Lorsqu'une définition commune de ce qu'est l'emploi lié au port est utilisée, on découvre que Marseille-Fos possède à la fois le nombre le plus important mais également la plus grande diversité d'emplois liés au port. Au total on dénombrait environ 32,400 emplois liés au port de Marseille-Fos (Tableau 5). Il s'agit très certainement d'une sous-estimation si l'on prend en compte le fait que plusieurs sous-secteurs n'ont pas pu être inclus car on ignorait quels aspects de ces sous-secteurs étaient en réalité liés au port: ce sont par exemple les sous-secteurs comme les services publics liés au port (douanes, pompiers, sauveteurs), les restaurants et hôtels, les travaux publics et les services liés au port, comme l'ingénierie, les inspections techniques, les assurances, la recherche, etc. Pour cette analyse les municipalités connectées à sept grands ports maritimes étaient considérées comme portuaires (voir 
l'Annexe 4 pour la liste des municipalités concernées) ; toutes les autres municipalités étaient considérées comme des localités non portuaires. L'emploi lié au port de Marseille-Fos est deux fois plus conséquentes que dans le second port français du Havre, et trois fois plus important que celui du troisième port, Dunkerque. Marseille-Fos offre une grande diversité d'emplois liés au port, à savoir dans tous les différents secteurs de l'emploi. Plus de la moitié d'entre eux concernent évidemment le secteur du transport maritime et terrestre ; moins du tiers des emplois sont dans le secteur de l'industrie liée au port, comme par exemple l'industrie pétrochimique, la métallurgie et l'industrie alimentaire, selon notre analyse. Cette diversité des emplois liés au port est encore plus visible lorsqu'une division plus détaillée de l'emploi lié au port est faite.

Tableau 5. Emplois liés aux ports français (2010)

\begin{tabular}{|lccccccc|} 
& $\begin{array}{c}\text { Marseille- } \\
\text { Fos }\end{array}$ & Le Havre & Dunkerque & $\begin{array}{c}\text { Nantes-St } \\
\text { Nazaire }\end{array}$ & Rouen & $\begin{array}{c}\text { Bordeaux } \\
\text { Rochelle }\end{array}$ \\
\hline 1. Transport maritime & 8533 & 5267 & 1193 & 2030 & 1106 & 947 & 360 \\
\hline 2. Transport terrestre & 9792 & 2648 & 1447 & 5571 & 3876 & 6486 & 881 \\
\hline 3. Logistique et négoce & 3619 & 5595 & 889 & 1146 & 2687 & 1203 & 131 \\
\hline 4. Exploitation ressources marines & 97 & 5 & 77 & 25 & 10 & 0 & 97 \\
\hline $\begin{array}{l}\text { 5. Construction et réparation } \\
\text { navale }\end{array}$ & 24 & 0 & 0 & 306 & 0 & 0 & 24 \\
\hline 6. Industries portuaires & 9632 & 3230 & 6853 & 3054 & 3894 & 1604 & 982 \\
\hline 7. Plaisance & 23 & 0 & 4 & 32 & 3 & 358 & 213 \\
\hline 8. Tourisme et loisirs & 672 & 86 & 28 & 507 & 153 & 274 & 48 \\
\hline & $\mathbf{3 2 3 9 2}$ & $\mathbf{1 6 8 3 1}$ & $\mathbf{1 0 4 9 1}$ & $\mathbf{1 2 6 7 1}$ & $\mathbf{1 1 7 2 9}$ & $\mathbf{1 0 8 7 2}$ & $\mathbf{2 7 3 6}$ \\
\hline
\end{tabular}

Source : calculs et élaboration par le secrétariat de l'OCDE à partir de données de l'INSEE

Note : Transport maritime est considéré comme : Services auxiliaires des transports par eaux (NAF 2008 Code : $5222 Z$ ), Transports maritimes et côtiers de passagers (5010Z), Transports maritimes et côtiers de fret (5020Z), Manutention portuaire (5224A), Service aux navires (9420Z). Transport terrestre est considéré comme : Transport routier (4941ABC, 5229A), Autres transport terrestres (5030Z, 4950 Z, 7712Z). Logistique et négoce est considéré comme : Négoce et transitaires (5229B), Entreposage et manutention non-portuaire (5224B). Exploitation des ressources marines est considérée comme : Pêche et produits de la mer (0311Z), Industries halieutiques (1020Z). Construction et réparation navale est considéré comme : Construction de navires et de structures flottantes (3011Z). Industries portuaires est considéré comme : Chimie, pétrochimie et raffinage (C20), Métallurgie et sidérurgie (C24), Agroalimentaire (C10). Plaisance est considéré comme : Construction de bateaux de plaisance (3012Z). Tourisme et loisirs est considérés comme : Autocaristes, agences de voyage (7911Z).

La plupart de ces emplois liés au port sont situés dans la ville de Marseille, mais ils représentent tout de même près de la moitié de l'emploi total dans certaines municipalités comme celle de Fos-sur-Mer. Environ 22,700 emplois liés au port se trouvent dans la ville de Marseille, la majorité d'entre eux dans le domaine du transport maritime et terrestre, de la logistique et de l'industrie liée au port. Ces emplois représentent environ 7\% de l'emploi urbain total. Les parts de l'emploi lié au port sont bien plus élevées dans les municipalités situées aux alentours des Bassins Ouest du port de Marseille-Fos, allant de $10 \%$ à Martigues à 50\% à Fos-sur-Mer (Tableau 6). La seule exception est Marignane, où l'emploi lié au port ne représente que $5 \%$ de l'emploi local total. Le profil de l'emploi lié au port varie d'une municipalité à l'autre. Fos se caractérise ainsi par une spécialisation relative dans la métallurgie, Martigues dans l'industrie pétrochimique, Port-de-Bouc le transport maritime et finalement Châteauneuf et Port St Louis du Rhône dans le transport terrestre. 
Tableau 6. Emplois liés au port de Marseille-Fos (2010)

\begin{tabular}{|c|c|c|c|c|c|c|c|c|c|c|}
\hline & $\begin{array}{l}\text { Mar- } \\
\text { seille }\end{array}$ & $\begin{array}{l}\text { Marig- } \\
\text { nane }\end{array}$ & $\begin{array}{l}\text { Mar- } \\
\text { tigues }\end{array}$ & $\begin{array}{l}\text { Fos- } \\
\text { sur- } \\
\text { Mer }\end{array}$ & $\begin{array}{l}\text { Port } \\
\text { de } \\
\text { Bouc }\end{array}$ & $\begin{array}{l}\text { Château } \\
\text {-neuf }\end{array}$ & $\begin{array}{l}\text { Port St } \\
\text { Louis }\end{array}$ & Aix & Berre & $\begin{array}{c}\text { Vi- } \\
\text { trolle }\end{array}$ \\
\hline 1. Transport maritime & 7578 & 36 & 126 & 314 & 467 & 2 & 10 & 32 & 10 & 0 \\
\hline 2. Transport terrestre & 7364 & 135 & 371 & 462 & 196 & 289 & 225 & 681 & 120 & 1913 \\
\hline $\begin{array}{l}\text { 3. Logistique et } \\
\text { négoce }\end{array}$ & 2574 & 587 & 110 & 465 & 148 & 157 & 98 & 75 & 1 & 504 \\
\hline $\begin{array}{l}\text { 4. Exploitation } \\
\text { ressources marines }\end{array}$ & 38 & 0 & 0 & 0 & 12 & 0 & 0 & 0 & 0 & 43 \\
\hline $\begin{array}{l}\text { 5. Construction } \\
\text { réparation navale }\end{array}$ & 13 & 0 & 7 & 0 & 4 & 0 & 0 & 0 & 0 & 0 \\
\hline $\begin{array}{l}\text { 6. Industries } \\
\text { portuaires }\end{array}$ & 4501 & 112 & 1018 & 3884 & 43 & 58 & 63 & 1003 & 1139 & 388 \\
\hline 7. Plaisance & 17 & 0 & 6 & 0 & 0 & 0 & 0 & 0 & 0 & 0 \\
\hline 8. Tourisme et loisirs & 643 & 8 & 12 & 3 & 1 & 5 & 0 & 307 & 5 & 12 \\
\hline $\begin{array}{l}\text { Total emplois } \\
\text { portuaires }\end{array}$ & 22728 & 878 & 1650 & 5128 & 871 & 511 & 396 & 2098 & 1275 & 2860 \\
\hline Total emplois & 321917 & 18230 & 17005 & 10847 & 4382 & 4178 & 1984 & 88540 & 4577 & 25943 \\
\hline $\begin{array}{l}\text { Partie emplois } \\
\text { portuaires }\end{array}$ & $7.1 \%$ & $4.8 \%$ & $9.7 \%$ & $47.3 \%$ & $19.9 \%$ & $12.2 \%$ & $20.0 \%$ & $2.4 \%$ & $27.9 \%$ & $11.0 \%$ \\
\hline
\end{tabular}

Source : calculs et élaboration par le secrétariat de l'OCDE à partir de données de l'INSEE

Les études portant sur les emplois liés à l'activité portuaire laissent suggérer que le profil du port de Marseille-Fos puisse avoir un effet relativement négatif sur la création d'emplois, en dépit du grand nombre d'emplois liés au port. Le port de Marseille-Fos est fortement spécialisé dans le vrac liquide, et cette catégorie nécessite une intensité de travail relativement limitée. C'est ce qui ressort d'une étude récente portant sur la relation entre les rendements du port et les emplois dans les régions portuaires. Alors que l'étude montre qu'un accroissement des rendements portuaires d'un million de tonnes en excluant le vrac liquide est associé à 600 emplois additionnels dans la région, le même accroissement en incluant le vrac liquide ne génère que 300 emplois additionnels (Ferrari et al,2012). Ces résultats s'alignent avec une autre étude récente sur le nombre d'emplois en fonction des différentes catégories de marchandises dans le Nord-Ouest de l'Europe, dont la conclusion générale montre que le ratio d'emplois en fonction de l'exploitation de pétrole brut et de conteneurs figurait parmi les plus bas, alors que le ratio d'emplois en fonction de l'exploitation de marchandises plus générales est le plus élevé (Haezendonck et al, 2000). Ainsi, le nombre total d'emplois liés au port est important, mais il pourrait l'être encore davantage si le port était spécialisé dans une autre catégorie.

\subsection{La valeur ajoutée du port}

La valeur ajoutée du cluster portuaire de Marseille-Fos s'élève à environ 4 milliards d'euros, soit environ 3\% du PIB de la région PACA. Ce calcul est basé sur une évaluation des emplois liés au port, discutés précédemment, et de la productivité du travail par secteur relié au domaine portuaire en France. ${ }^{4}$ Plus d'un tiers de la valeur ajoutée du port de Marseille-Fos provient de l'industrie minière, de l'extraction et de l'approvisionnement en énergie (lié aux industries métallurgique et pétrochimique). Plus d'un quart de sa valeur ajoutée provient des secteurs du transport, stockage et services de communications. Les autres secteurs ayant un rôle significatif sont la vente et la location de terrains immobiliers, les activités commerciales et autres activités manufacturières. Cette valeur ajoutée est légèrement inférieure à la valeur ajoutée produite par d'autres ports de tailles similaires. La valeur ajoutée du port de Marseille-Fos, en incluant les industries portuaires, est très proche de celle du port d'Hambourg ${ }^{5}$, et les deux ports ont un volume comparable. Cependant, la valeur ajoutée des deux ports de Gênes et Le Havre est plus importante, alors que leurs volumes sont inférieurs à ceux de Marseille-Fos (Figure 13). 
Figure 13. Relation entre valeur ajouté et volume portuaire

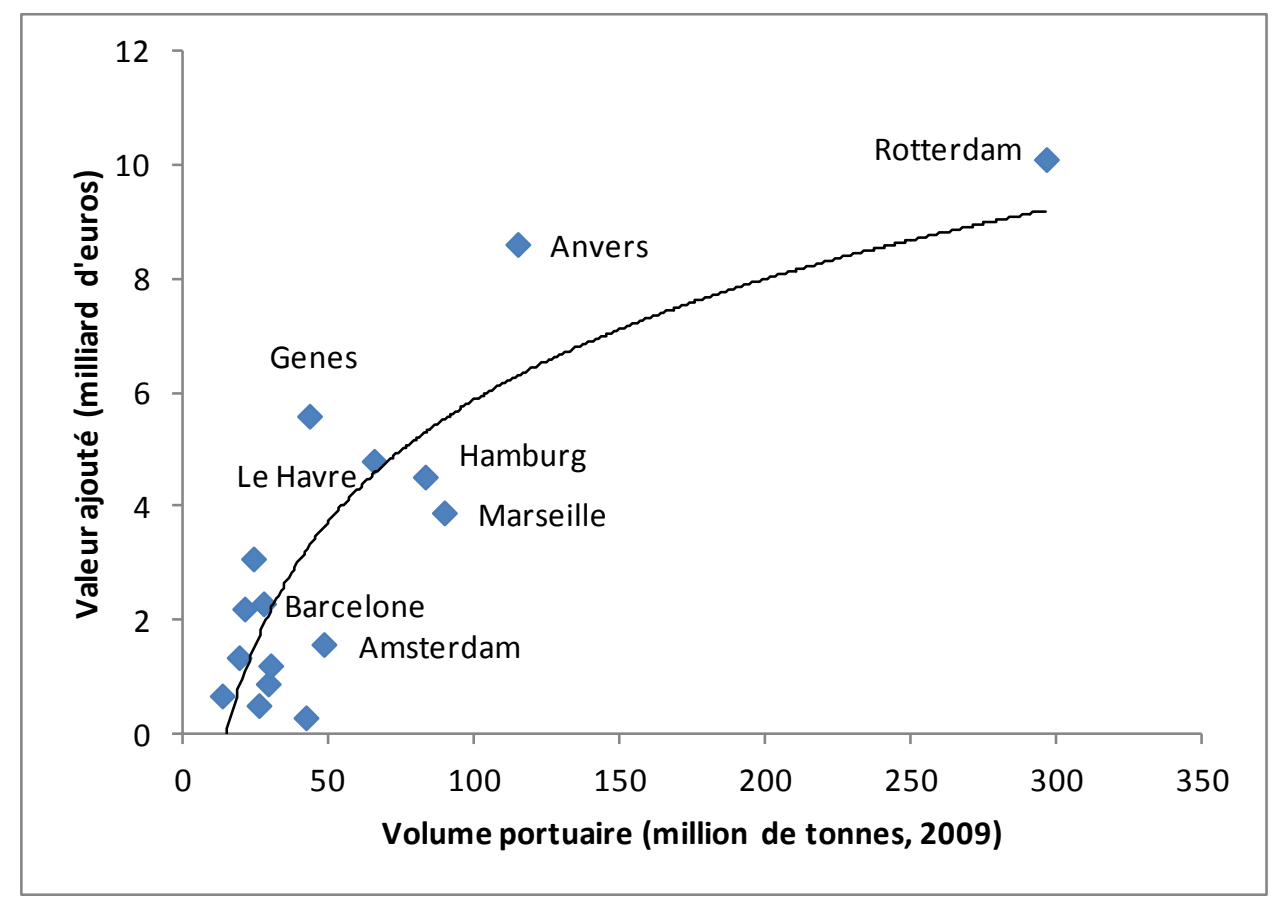

Source : calculs et élaboration par le secrétariat de l'OCDE à partir de ces données

\subsection{Les impacts économiques indirects}

Cette étude tente de remédier au manque d'informations relatives aux impacts économiques indirects du port de Marseille-Fos. Jusqu'à présent, il n'existait pas de calcul ni d'estimation des liens économiques indirects du pôle portuaire Marseille-Fos. Les liens économiques indirects indiquent dans quelle mesure le complexe portuaire est lié à ses fournisseurs en biens intermédiaires. Une telle analyse, basée sur les tableaux entrées/sorties français, révèle la nature et l'étendue des liens économiques indirects entre le port et les autres secteurs. Ces tableaux indiquent les entrées pour chaque secteur économique, tels que les ressources premières et les biens intermédiaires, dans tous les secteurs économiques en France. Notre estimation de la valeur ajoutée du cluster portuaire Marseille-Fos, telle que développée dans le paragraphe précédent, a été utilisée pour faire du port de Marseille-Fos une entité économique distincte dans ces tableaux d'entrées/sorties, afin d'identifier les liens avec les secteurs économiques en France. L'étendue de ces liens est exprimée par un coefficient multiplicateur, et la nature des liens est déterminée par les secteurs avec lesquels le complexe portuaire est lié. De plus, le tableau national d'entrées/sorties a été décomposé afin de mieux voir l'impact économique indirect du cluster portuaire dans différentes régions de France. Les régions qui se sont révélées intéressantes pour cette analyse sont, tout d'abord, la région dans laquelle le port de Marseille-Fos est situé, Provence-Alpes-Côte d'Azur (PACA), puis les régions voisines (RhôneAlpes, Languedoc-Roussillon, Bourgogne), ainsi que la région métropolitaine dominante en France, l'Île de France (voir Annexe 5 pour la méthodologie). Les résultats de cette analyse sont indiqués ci-dessous. Sachant que des analyses similaires ont été faites dans de précédents cas d'études de villes portuaires par l'OCDE, leurs résultats peuvent être comparés avec ceux de Marseille-Fos.

Le coefficient multiplicateur du complexe portuaire de Marseille-Fos est de 2,01; cela signifie qu'une nouvelle demande d'un euro à l'intérieur du complexe portuaire génère un euro supplémentaire d'offre dans l'économie française. Ce coefficient total est la somme des coefficients multiplicateurs de chaque secteur, divisé par la part de ces secteurs dans la demande finale pour le port de Marseille-Fos. Le 
coefficient multiplicateur de Marseille-Fos est légèrement inférieur à celui trouvé pour le pôle Le HavreRouen $(2,47)$, mais légèrement supérieur à celui d'Hambourg $(1,71)$, et bien supérieur aux multiplicateurs de Rotterdam $(1,13)$ et Anvers $(1,18)$ (Tableau 7). De telles différences peuvent être expliquées par la taille des pays et de leurs ports, avec d'une part les cas de Rotterdam et d'Anvers caractérisés par des ports très importants au sein de pays relativement petits, et d'autre part Le Havre, Hambourg et Marseille caractérisés par de petits ports situés dans des pays plus importants. Ainsi le fort coefficient multiplicateur du port de Marseille-Fos indique des impacts économiques indirects substantiels sur les différents secteurs de l'économie française.

Tableau 7. Multiplicateur du cluster Marseille-Fos et d'autres ports européens

\begin{tabular}{|lc|}
\hline \multicolumn{1}{|l|}{$\begin{array}{l}\text { Tableau 7. } \\
\text { Marseille-Fos }\end{array}$} & $\mathbf{2 . 0 1}$ \\
\hline Le Havre-Rouen & 2.47 \\
\hline Hambourg & 1.71 \\
\hline Anvers & 1.18 \\
\hline Rotterdam & 1.13 \\
\hline
\end{tabular}

Source : calculs et élaboration par le secrétariat de l'OCDE à partir de données Eurostat et INSEE

Les liens économiques les plus importants sont ceux avec le secteur des équipements de transport, l'industrie agro-alimentaire et le secteur pétrochimique. Dans ces trois secteurs l'effet multiplicateur atteint presque trois, ce qui signifie qu'un euro de demande supplémentaire à l'intérieur du complexe portuaire génère environ 2 euros de plus d'offre pour ces secteurs. Les autres secteurs économiques fortement liés au complexe portuaire de Marseille-Fos sont «les autres industries manufacturières », de l'équipement électrique et optique, aux industries minières, opérations d'extraction et approvisionnement en énergie. Les coefficients multiplicateurs pour les secteurs traditionnellement liés au port, tels que les transports, le stockage, les services de communication, ainsi que le commerce de gros et de détail, sont relativement hauts, bien que non parmi les plus élevés. Les secteurs avec lesquels les impacts économiques indirects du cluster portuaire de Marseille-Fos sont les plus faibles sont les services non-marchands et le secteur immobilier (Tableau 8).

Tableau 8. Multiplicateur de Marseille-Fos par filière

\begin{tabular}{|c|c|}
\hline & Multiplicateur \\
\hline Equipement de transport & 2.83 \\
\hline Agroalimentaire & 2.69 \\
\hline Coke, pétrole raffiné, combustible nucléaire et produits chimiques & 2.67 \\
\hline Autre industrie & 2.57 \\
\hline Équipement électrique et optique & 2.51 \\
\hline Mines, extraction et approvisionnement en énergie & 2.45 \\
\hline Agriculture & 2.27 \\
\hline Hôtels et restaurants & 2.18 \\
\hline Construction & 2.17 \\
\hline Intermédiation financière & 1.96 \\
\hline Transport, stockage et communication & 1.92 \\
\hline Commerces de gros et de détail & 1.90 \\
\hline Foncière, rentes et activités commerciales & 1.48 \\
\hline Services non-marchands & 1.39 \\
\hline Multiplicateur total & 2.01 \\
\hline
\end{tabular}


Les effets de synergie au sein du cluster portuaire Marseille-Fos sont limités. Comme dans le cas Le Havre-Rouen, les liens économiques des entreprises au sein du cluster sont proches de zéro. Cela contraste fortement avec les clusters portuaires d'Anvers et de Rotterdam. Par exemple le multiplicateur intraportuaire d'Anvers est de 1,05, ce qui signifie qu'une augmentation de la demande d'un euro dans le port génère une offre additionnelle de 5 cents. Ces effets sont encore supérieurs dans les secteurs des transports, stockage et communications, ainsi que dans l'industrie chimique, témoignant de la forte présence de ces secteurs dans la zone portuaire d'Anvers. Une distribution semblable des effets intraportuaires a lieu à Rotterdam, bien que l'étendue du multiplicateur soit moindre. Les seuls secteurs pour lesquels on observe un multiplicateur intra-portuaire important à Marseille-Fos, quoique faible $(1,01)$ sont l'industrie minière, l'extraction, l'approvisionnement en énergie, et l'industrie pétrochimique. La faiblesse des liaisons intra-portuaires à Marseille-Fos peut nous faire penser que les liens intersectoriels sont relativement lâches. Par contraste avec les ports d'Anvers et de Rotterdam, le regroupement spatial des développements industriels dans l'enceinte de la zone portuaire n'a généré que des effets de synergie limités (Tableau 9).

Tableau 9. Effets de multiplicateur au sein du port

\begin{tabular}{|c|c|c|c|c|c|}
\hline & Marseille-Fos & Le Havre & Hambourg & $\begin{array}{l}\text { Anver } \\
s\end{array}$ & Rotterdam \\
\hline $\begin{array}{l}\text { Coke, pétrole raffiné, combustible } \\
\text { nucléaire et produits chimiques }\end{array}$ & 1.01 & 1.00 & 1.00 & 1.05 & 1.05 \\
\hline Équipement de transport & 1.00 & 1.00 & 1.00 & 1.05 & 1.01 \\
\hline Agro-alimentaire & 1.00 & & 1.00 & 1.02 & 1.04 \\
\hline $\begin{array}{l}\text { Transport, stockage et } \\
\text { communication }\end{array}$ & 1.00 & 1.00 & 1.00 & 1.13 & 1.07 \\
\hline Commerces de gros et de détail & 1.00 & 1.00 & 1.01 & 1.03 & 1.01 \\
\hline Multiplicateur total & 1.00 & 1.00 & 1.01 & 1.05 & 1.03 \\
\hline
\end{tabular}

Source : calculs et élaboration par le secrétariat de l'OCDE à partir de données Eurostat et INSEE

Tableau 10. Effets de multiplicateur dans la région portuaire

\begin{tabular}{|lccccc|} 
& Marseille & Le Havre & Hambourg & Anvers & Rotterdam \\
\hline $\begin{array}{l}\text { Coke, pétrole raffiné, } \\
\text { combustible nucléaire et } \\
\text { produits chimiques }\end{array}$ & 0.11 & 0.06 & 0.03 & 0.05 & 0.05 \\
\hline Équipement de transport & & & & & \\
\hline Agro-alimentaire & 0.09 & 0.08 & 0.03 & 0.05 & 0.01 \\
\hline $\begin{array}{l}\text { Transport, stockage et } \\
\text { communication }\end{array}$ & 0.10 & & 0.03 & 0.02 & 0.04 \\
\hline $\begin{array}{l}\text { Commerces de gros et de } \\
\text { détail }\end{array}$ & 0.06 & 0.03 & 0.02 & 0.13 & 0.07 \\
\hline Multiplicateur total & 0.06 & 0.03 & 0.01 & 0.03 & 0.01 \\
\hline Sole & $\mathbf{0 . 0 6}$ & $\mathbf{0 . 0 5}$ & $\mathbf{0 . 0 2}$ & $\mathbf{0 . 0 3}$ & $\mathbf{0 . 0 1}$ \\
\hline
\end{tabular}

Source : calculs et élaboration par le secrétariat de l'OCDE à partir de données Eurostat et INSEE

Malgré une synergie intra-portuaire limitée, l' « intégration » du cluster Marseille-Fos dans la région PACA est relativement importante. Le cluster portuaire génère des externalités économiques indirectes : une nouvelle demande portuaire d'un euro provoque une offre additionnelle de 6 cents dans la région PACA. Bien qu'un tel impact puisse semble insignifiant, il est pourtant significatif en comparaison avec des externalités régionales d'autres grands ports, en particuliers ceux de Rotterdam et d'Hambourg. Les externalités économiques avec la région sont particulièrement importants dans le secteur pétrochimique, alimentaire, d'équipements de transport, et dans l'industrie minière, d'extraction et d'approvisionnement en énergie. Dans d'autres localités également (Rotterdam, Anvers, Le Havre), l'industrie pétrochimique est 
liée de près avec le port. Au niveau régional en PACA les secteurs du transport, du stockage et les services de communication sont moins liés avec le port que dans les cas de Rotterdam et d'Anvers (Tableau 10).

Tableau 11. Multiplicateurs de Marseille-Fos par filière et région en France

\begin{tabular}{|c|c|c|c|c|c|c|c|c|}
\hline & $\begin{array}{l}\text { Marseille- } \\
\text { Fos }\end{array}$ & PACA & $\begin{array}{l}\text { Rhône- } \\
\text { Alpes }\end{array}$ & $\begin{array}{l}\text { Île de } \\
\text { France }\end{array}$ & $\begin{array}{l}\text { Bourgogn } \\
e\end{array}$ & $\begin{array}{l}\text { Languedoc- } \\
\text { Roussillon }\end{array}$ & $\begin{array}{l}\text { Reste de } \\
\text { la France }\end{array}$ & Total \\
\hline Equipement de transport & 1.00 & 0.09 & 0.19 & 0.52 & 0.04 & 0.03 & 0.96 & 2.83 \\
\hline Agro-alimentaire & 1.00 & 0.10 & 0.15 & 0.42 & 0.05 & 0.05 & 0.92 & 2.69 \\
\hline $\begin{array}{l}\text { Coke, pétrole raffiné, } \\
\text { combustible nucléaire et } \\
\text { produits chimiques }\end{array}$ & 1.01 & 0.11 & 0.18 & 0.49 & 0.04 & 0.04 & 0.80 & 2.67 \\
\hline Autre industrie & 1.00 & 0.09 & 0.17 & 0.46 & 0.04 & 0.04 & 0.77 & 2.57 \\
\hline $\begin{array}{l}\text { Équipement électrique et } \\
\text { optique }\end{array}$ & 1.00 & 0.08 & 0.18 & 0.45 & 0.04 & 0.03 & 0.73 & 2.51 \\
\hline $\begin{array}{l}\text { Mines, extraction et } \\
\text { approvisionnement en } \\
\text { énergie }\end{array}$ & 1.01 & 0.10 & 0.15 & 0.42 & 0.03 & 0.04 & 0.70 & 2.45 \\
\hline Agriculture & 1.00 & 0.07 & 0.12 & 0.32 & 0.04 & 0.04 & 0.69 & 2.27 \\
\hline Hôtels et restaurants & 1.00 & 0.07 & 0.11 & 0.34 & 0.03 & 0.03 & 0.60 & 2.18 \\
\hline Construction & 1.00 & 0.07 & 0.13 & 0.35 & 0.03 & 0.03 & 0.56 & 2.17 \\
\hline Intermédiation financière & 1.00 & 0.06 & 0.08 & 0.41 & 0.02 & 0.02 & 0.37 & 1.96 \\
\hline $\begin{array}{l}\text { Transport, stockage et } \\
\text { communication }\end{array}$ & 1.00 & 0.06 & 0.09 & 0.32 & 0.02 & 0.02 & 0.41 & 1.92 \\
\hline $\begin{array}{l}\text { Commerces de gros et de } \\
\text { détail }\end{array}$ & 1.00 & 0.06 & 0.09 & 0.33 & 0.02 & 0.02 & 0.39 & 1.90 \\
\hline $\begin{array}{l}\text { Foncière, rentes et activités } \\
\text { commerciales }\end{array}$ & 1.00 & 0.03 & 0.05 & 0.18 & 0.01 & 0.01 & 0.20 & 1.48 \\
\hline Services non-marchands & 1.00 & 0.03 & 0.04 & 0.13 & 0.01 & 0.01 & 0.18 & 1.39 \\
\hline Multiplicateur total & 1.00 & 0.06 & 0.10 & 0.32 & 0.02 & 0.02 & 0.48 & 2.01 \\
\hline
\end{tabular}

Source : calculs et élaboration par le secrétariat de l'OCDE à partir de données Eurostat et INSEE

De plus, le cluster portuaire de Marseille-Fos a des liens économiques indirects avec d'importantes régions voisines, telles que la région Rhône-Alpes, bien que les effets sur l'Île-de-France et le reste de la France restent les plus importants. Le port de Marseille-Fos a en effet des liens économiques indirects plus forts avec la région Rhône-Alpes qu'avec la région PACA, comme le montre un coefficient multiplicateur de 0,10 contre 0,06 . L'impact le plus significatif est celui sur le secteur des équipements de transport $(0,19)$. De tels liens peuvent être facilement expliqués par le fait que la région Rhône-Alpes inclut la ville de Lyon, la seconde puissance économique métropolitaine du pays, et avoisine la région PACA et de l'arrière-pays naturel du port de Marseille-Fos. Plus surprenant sont les liens importants entre le port de Marseille-Fos et l'économie de la région métropolitaine d'île de France, dont Paris : environ un tiers de l'offre additionnelle générée par la nouvelle demande dans le port de Marseille-Fos est localisée en Île de France (Tableau 11).

\section{Les services maritimes à forte valeur ajoutée}

Les grandes villes portuaires sont des lieux privilégiés de localisation des donneurs d'ordres et de convergence des informations sur les opérations monétaires, les bourses de marchandises, le prix d'affrètement des navires et les règles d'organisation de l'industrie maritime. Les grands centres d'impulsion des échanges maritimes se distinguent en fonction de leur poids au sein de l'offre de services maritimes, mesurée par: la présence d'activités bancaires, financières et boursières; le regroupement de compagnies d'assurances; le siège social de transporteurs et opérateurs de terminaux globaux; et l'autorité d'organismes qui imposent des standards à l'industrie maritime, parmi d'autres secteurs.

Les études existantes ne considèrent pas Marseille comme un centre de services maritimes leader au niveau international. L'une de ces études s'intéresse aux villes leader dans le domaine des services 
maritimes avancés, définis comme des entreprises assurant à la fois des services d'assurance maritime, de droit et de consulting (Jacobs et al, 2010). Or dans cette étude Marseille-Fos ne figure pas dans le top 20 des villes européennes ayant le plus grand nombre d'établissements considérés comme producteurs de services maritimes avancés. Cependant, Paris y figure à la $9^{\text {ème }}$ place, avec 55 établissements et 6 sièges d'entreprises. Anvers, rival de Marseille-Fos, dispose également d'une forte concentration, se positionnant à la $5^{\text {ème }}$ place. D'autres villes portuaires méditerranéennes figurant dans le classement sont Le Pirée $\left(2^{\text {nd }}\right)$, Limassol ( $\left.7^{\text {ème }}\right)$, Istanbul $\left(10^{\text {ème }}\right)$, Gênes $\left(11^{\text {ème }}\right)$ et La Valette $\left(13^{\text {ème }}\right)$. Les ports espagnols de Barcelone et Valence n'y figurent pas, ce qui explique une forte concentration dans la capitale, Madrid. Une autre étude identifie les principales villes où les compagnies de transport de conteneurs sont situées, en analysant les structures de bureaux de 35 des plus grands armateurs et opérateurs de terminaux (Verhetsel et Sel, 2009). En se basant sur la connectivité globale des ces villes en termes de bureaux, 6 niveaux de villes maritimes mondiales ont été identifiés. Malgré la présence du siège de CMA-CGM, Marseille ne figure que $38^{\text {ème }}$ sur un total de 50 villes maritimes mondiales, soit au niveau 6, à côté de villes comme Barcelone et Paris. Les deux villes mondiales figurant au $1^{\mathrm{er}}$ niveau sont Hong Kong et Hambourg. On observe également Anvers (classée $11^{\text {ème }}$ ) et Gênes (classée 14 ${ }^{\text {ème }}$ ) comme des centres maritimes mondiaux émergents, tout comme Le Havre $\left(30^{\text {ème }}\right)$. Enfin, une étude finale sur les villes maritimes leaders se limitant seulement à 12 villes n'inclut pas la ville de Marseille dans son classement (Menon, 2012).

Cette perception de Marseille est confirmée par les bases de données sur les services maritimes portuaires qui ont été collectées pour ce rapport. Dans plusieurs de ces bases de données, le port du Pirée se distingue comme le principal centre méditerranéen, suivi par d'autres ports, mais le rôle de Marseille reste lui limité. Au contraire d'Anvers et de Gênes, Marseille ne figure pas parmi les 30 villes les plus importantes en termes de sociétés de courtage de navires, se basant sur la localisation de plus de 2000 sociétés de courtage de navires enregistrés sur la base de données mondiale du secteur maritime. Les banques françaises ont un rôle relativement important dans le financement maritime, que l'on peut mesurer par des portfolios maritimes et des affaires maritimes à valeur montante, mais ces banques sont toutes basées à Paris. Marseille n'apparaît pas comme une localité majeure pour les entreprises de dragage, un domaine qui reste dominé par les entreprises hollandaises et belges, et où la France est représentée par Rouen. Pratiquement touts les activités de construction de navires ont disparu, et Marseille n'est pas une localité phare en ce qui concerne les services d'ingénierie rattachés au domaine maritime international, tout du moins pas d'après les comptes du guide de 2011 de la Lloyd's List Marine Equipment Buyers. Le rôle international de Marseille est de plus limité par la demande de brevet dans les secteurs reliés au domaine portuaire (maritime, pétrole, alimentaire etc.), d'après la base de données des brevets de L'OCDE, et d'après une recherche portant sur l'affiliation entre des villes et les auteurs et co-auteurs de 576 articles reliés au secteur portuaire et publiés dans des journaux académiques reconnus entre 1997 et 2011.

\subsection{Impact environnemental}

Le port de Marseille-Fos a des impacts négatifs sur la qualité de l'eau. Les dommages environnementaux constatés sur le secteur Est du GPMM sont les conséquences d'activités et aménagements passés du port. Le milieu naturel du bassin du port est médiocre, avec la contamination ancienne des sédiments par des polluants métalliques et organiques. La France avait été condamnée par la Commission Européenne pour la dégradation des écosystèmes de ce secteur et du Rhône (INEA 2009). Aussi sur le site de Fos-sur-Mer, les impacts environnementaux sont imputables aux infrastructures portuaires et à la zone industrialo-portuaire située dans la commune. Le positionnement du site de Fos dans les années 1960 a fait évoluer le paysage de la région. Cinq secteurs à proximité du site sont des zones protégées, or il existe des interactions entre les projets du port et ces zones protégées. Comme à Marseille, les sédiments du milieu marin ont été contaminés. Les sédiments de dragage sont désormais employés pour remblayer les quais ou immergés en mer, ce qui représente une perturbation pour l'écosystème. La qualité des eaux du Golfe de Fos est mise en jeu par l'activité maritime du port, avec des rejets d'effluents, et donc une pression anthropique. 
Les industries portuaires de Marseille-Fos ont un impact négatif sur la qualité de l'air. La quantification des émissions de dioxyde de carbone $\left(\mathrm{CO}_{2}\right)$ est de 8,2 teq $\mathrm{CO}_{2}$ (tonne équivalent $\mathrm{CO}_{2}$ ) par habitant sur Marseille Provence Métropole, et 109 teq $\mathrm{CO}_{2}$ par habitant pour le secteur incluant la zone industrialo-portuaire de Fos-sur-Mer. La moyenne par habitant pour la métropole Marseillaise est comparable aux taux des métropoles Lyonnaise et Lilloise. Or, si Marseille avait agrégé les émissions des bassins de Fos, cette moyenne aurait plus que doublé (BG Ingénieurs Conseils, 2011). Le transport maritime est source de pollution, avec $49 \%$ des émissions provenant du transport concentrées pour les navires et services aux navires. Malgré son efficacité énergétique, le transport maritime roulier ou passager, émet une grande quantité de polluants conduisant à une formation d'ozone troposphérique (ozone de basse altitude), car il emploie en majorité des produits pétroliers. Sur 1 million de tonnes de $\mathrm{CO}_{2}$ émis par le transport sur le territoire du SCoT (Schéma de Cohérence Territoriale) Ouest Étang de Berre, 920000 tonnes sont produites par le transport maritime (BG Ingénieurs Conseils 2012). Il s'agit pourtant du second poste d'émission après l'industrie (11.6 millions tonnes).

De tels impacts sont en partie dus à la répartition modale du trafic dans l'arrière-pays, avec une préférence relativement élevée pour le transport routier. Le transport des marchandises jusqu'au port compte pour $11 \%$ des émissions de $\mathrm{CO}_{2}$ de MPM, au deuxième rang après les émissions qui proviennent des procédés industriels sur la métropole (25\%). Le bilan en émission compte cependant les étapes pré et post acheminements des passagers et marchandises (respectivement 30 et $16 \%$ des émissions en $\mathrm{CO}_{2}$ ). Ces émissions viennent notamment du minimum de 200 poids lourds qui circulent de manière permanente sur la métropole en liaison avec le port (BG Ingénieurs Conseils 2011). La part du trafic routier dans la répartition modale du trafic entre le port et l'arrière-pays est relativement important à Marseille $(85 \%$ en 2010) ; la plupart des grands ports européens sont parvenus à réduire cette part en favorisant le transport soit par voies navigables intérieures (Rotterdam, Anvers, Amsterdam), soit par rail, comme notamment à Hambourg, Bremerhaven, Koper et Zeebruges (Figure 14).

Figure 14. Répartition modale pour le trafic de conteneur en Europe (2010)

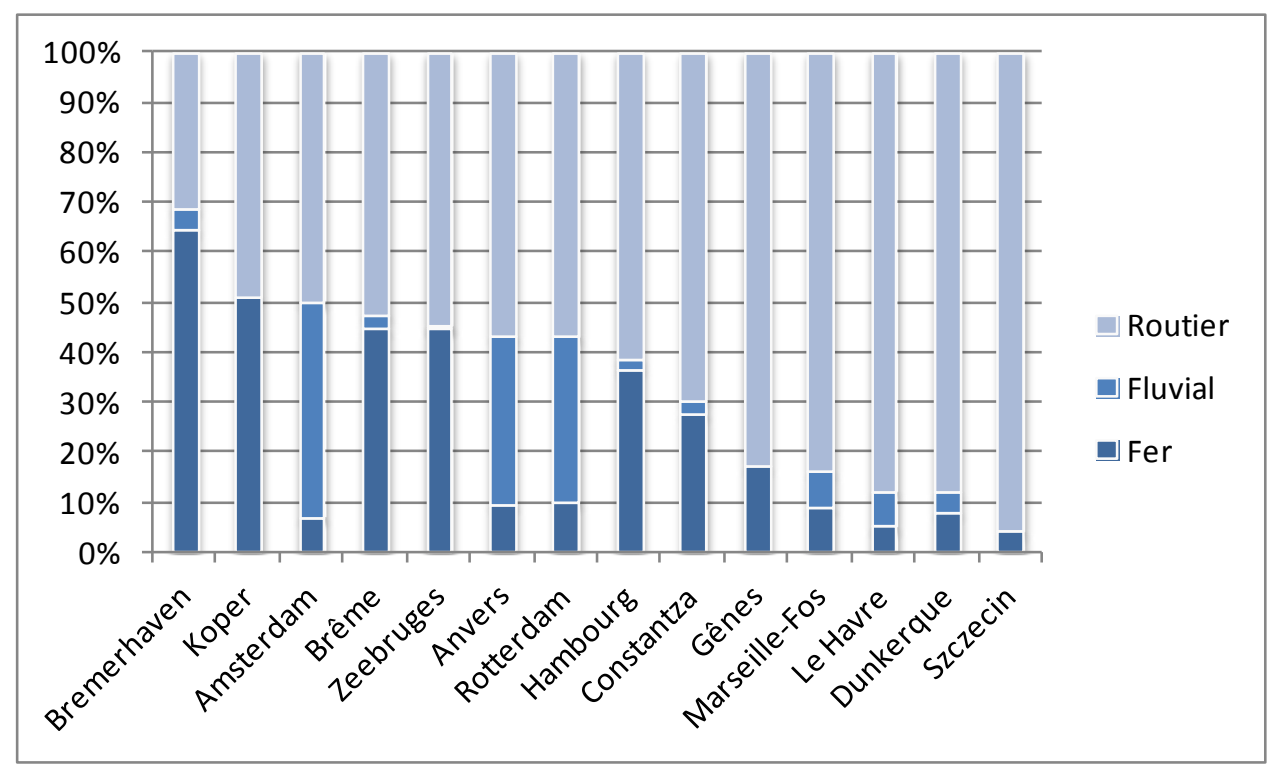

Source : graphique réalisé à partir des données de Schiffahrt Hafen Bahn et Technik, Merk et Hesse, 2012; et Beretta et al. 2012 


\section{POLITIQUES ET GOUVERNANCE}

Les chapitres précédents étaient axés sur les défis relatifs à la performance portuaire et aux impacts liés aux ports, mais quels sont les marges d'intervention et les moyens d'actions ? Telles sont les questions centrales de ce chapitre sur les politiques des villes portuaires et leur gouvernance. La première partie de ce chapitre s'attache à démontrer en quoi un développement stratégique et proactif peut améliorer la performance portuaire et accroître les impacts portuaires. La deuxième partie analyse les façons dont le port peut devenir un atout pour la métropole Marseillaise, en étudiant comment accroître les impacts positifs, tandis que la troisième partie se concentre sur les façons de réduire les impacts négatifs. Enfin la dernière partie étudie plus profondément les processus de mise en œuvre de telles politiques, et plus particulièrement ce qu'elles requièrent en terme de gouvernance.

\subsection{Vers un développement portuaire stratégique et proactif}

\section{La planification stratégique sur le long terme}

Plusieurs ports sont engagés dans des planifications stratégiques sur le long terme. De tels engagements sur le long terme s'expriment au travers des visions stratégiques rendues plus ou moins publiques. Elles permettent d'identifier de nouvelles directions pour le développement du port, les investissements à prioriser et les futurs goulots d'étranglement éventuels. S'il est bien conçu, le processus de planning stratégique peut permettre d'obtenir l'engagement des principaux intervenants, de renforcer les liens avec les clients et de former une réelle volonté locale. La planification sur le long terme est plus efficace quand ces visions de long terme sont traduites en plans opérationnels, et quand elles sont régulièrement mises à jour et révisées.

La vision stratégique du port de Marseille-Fos est détaillée dans le Projet Stratégique 2009-2013, qui a été actualisée en 2012. C'est un document rendu obligatoire par l'État pour tous les GPM. Ce document fournit une analyse détaillée des défis actuels auxquels le port est confronté, ainsi que les buts stratégiques du développement portuaire dans 5 secteurs différents, les projections pour l'année 2020 (et pour 2030 depuis l'actualisation de 2012) et les conditions pour atteindre ces projections. Les 5 grands secteurs (orientations) à prioriser ici sont les conteneurs, l'énergie, le vrac sec, le trafic roulier (RoRo) et le trafic de passagers. Les objectifs annoncés à la fois pour Marseille et pour Fos sont la répartition modale (modal split) et le trafic avec l'arrière-pays. Dans un contexte européen plus large, le port se considère comme un outil de développement durable: si une plus grande part du commerce extérieur français passait par Marseille-Fos plutôt que par Anvers, le nombre de camions circulant sur les routes européennes serait sensiblement réduit.

L'une des premières cibles de ce plan stratégique est l'exploitation de cinq fois plus de conteneurs en 2030 qu'en 2011. L'objectif de 5 millions EVP était à l'origine prévu pour 2020, mais a été repoussé à 2030 lors de l'actualisation du plan. Cet objectif reste ambitieux, sachant que cela nécessiterait un taux de croissance annuel de $22 \%$ sur les 19 prochaines années, soit environ 4 fois le taux de croissance du secteur des conteneurs des 19 dernières années à Marseille-Fos. Le plan suppose également que les marchés mondiaux génèrent un taux de croissance des marchés de conteneurs européens de 4 à $5 \%$, et donc une grande part de la croissance de chaque port dépendrait de leur propre capacité à récupérer les parts de 
marchés des ports rivaux, principalement en France, mais aussi sur les marchés suisse, allemand, italien et espagnol. Suivant le plan stratégique, la réalisation de cet objectif résulterait en la création de 22000 emplois supplémentaires. Le tonnage total prévu pour 2030 est de 156 millions de tonnes $(1,7$ fois le volume actuel), ce qui serait réalisable en doublant le trafic RoRo, tout en stabilisant et diversifiant le trafic actuel de vrac liquide.

Dans le cadre de cette stratégie, la part du transport ferroviaire et fluvial vers l'arrière-pays devrait accroître de $15 \%$ à $40 \%$. En $2010,85 \%$ du trafic de conteneurs avec l'arrière-pays était effectué par camionnage, $8,5 \%$ par train et $6,5 \%$ par canaux. Le plan stratégique cherche à modifier ces données dans une distribution de $60 \% / 30 \% / 10 \%$ pour 2030 . Cela signifierait 15 fois plus de conteneurs transportés par rail, et 7 fois plus par les voies navigables. Si l'on considère l'objectif d'accroissement du nombre de conteneurs, la réduction de la part du trafic par la route continuerait à représenter une hausse importante du nombre de camions, dont le nombre triplerait en volume entre 2010 et 2030. Sachant que la part des camions à Fos (86\%) est actuellement supérieure à celle de Marseille (81\%), les plus fortes augmentations devraient avoir lieu à Fos, qui concentrerait aussi les plus fortes augmentations de trafic.

En plus de ce plan stratégique, une vision sur le long terme a récemment été développée pour les Bassins Est du port, qui doit être confirmée et appliquée. Cette vision, élaborée par le Commission Cousquer à la demande du Conseil de Surveillance du Port de Marseille-Fos, proposait de diviser les berges du port en trois parties: une première partie, axée autour de la zone d'Euroméditerranée (établissement public d'aménagement) et du développement de l'interface ville-port, ainsi qu'autour du développement du secteur tertiaire et des passagers de Schengen; une seconde partie dédiée à l'exploitation des marchandises, au développement industriel et logistique ; et une troisième partie dédiée aux loisirs (plages, centre nautique, port de plaisance). Ces orientations stratégiques ont reçu un large soutien et devraient être rendues opérationnelles par la récente charte Ville-Port.

Une perspective largement partagée sur les développements futurs des Bassins Ouest sur le long terme s'avérerait nécessaire si le projet stratégique devait se réaliser. Or, en dépit du plan stratégique du port, les acteurs impliqués ne semblent pas partager de vision commune. Le soutien au développement du port est fragile, et la mesure et les types de développements industriels pour le futur restent indéfinis. Bien que le projet stratégique formule des ambitions claires et un horizon sur le long terme, il a été incapable de catalyser une vision stratégique commune aux différents acteurs pour deux raisons : il reste avant tout préoccupé par l'évolution du port sur le court terme, et ces acteurs n'ont pas été consultés lors de la formulation du plan. Pour mener à bien un tel projet, il serait essentiel de faire une évaluation axée sur les faits, une recherche d'intérêts communs et d'établir horizon sur le long terme. La consultation publique actuelle peut être remarquée comme une base encourageante pour le développement futur d'efforts coopératifs plus nombreux. Cette concertation continue sur la ZIP de Fos a été lancée par le GPMM sous le pilotage du Conseil de Développement en 2011. Elle a pour objectif de nouer un dialogue entre tous les acteurs concernés par le développement des bassins Ouest. Les travaux réalisés dans le cadre de la concertation continue seront pris en compte dans le prochain Projet Stratégique du GPMM (2014-2018).

L'implication forte des acteurs dans cette vision commune est essentielle, suivant l'exemple de la planification stratégique sur le long terme du port de Rotterdam. La Port Vision 2030 du Port de Rotterdam, qui a été adoptée en 2012, est beaucoup moins centrée sur des objectifs de trafic, et beaucoup plus imaginative sur l'aspect du port dans le futur, se basant sur plusieurs évolutions possibles pouvant mener à une transformation des fonctions portuaires. A l'égard du volume portuaire, le projet décrit un ensemble de scénarios, mettant l'accès sur la flexibilité comme atout majeur pour le futur. L'une des observations majeure est la transformation du paysage européen concernant la production d'énergie (rationalisations et raffineries), et l'ambition du port de devenir, en collaboration avec Anvers, le principal hub européen pour l'énergie et l'industrie pétrochimique. Cependant, l'accomplissement premier de Port Vision 2030 est sûrement le procédé de consultation des acteurs, et leur engagement à réaliser cette vision, 
qui en plus de renseigner l'autorité portuaire sur les challenges perçus par ses clients et partenaires, a également permis de rallier ses partenaires à la vision stratégique pour le port.

\section{Les connexions avec l'avant-pays}

À l'image de plusieurs ports du monde, Marseille-Fos a été affecté par la crise économique mondiale, ce qui montre que les trafics maritimes sont basés sur la demande de différents secteurs de production et de distribution. Or, ce sont les grands donneurs d'ordres dans les secteurs agricoles, industriels, de la distribution ou du secteur des services à l'échelle internationale qui décident des modalités de participation du port dans les processus d'acheminement du fret. Cargill, Bunge, Groupe Louis Dreyfus, multinationales du secteur agro-alimentaire, contrôlent le négoce du grain, les volumes de trafic et les choix de ports d'escales sur les réseaux portuaires d'Amérique, d'Europe et de Chine. L'adoption d'un plan de fermeture de plusieurs industries sidérurgiques européennes par Arcelor Mittal modifie profondément le trafic de minerais de fer tant sur le Rhin qu'en Méditerranée (CCNR, 2006). L'industrie pétrochimique mondiale est également en pleine mutation. Aucune raffinerie n'a été construite aux États-Unis et en Europe depuis 30 ans. Celles qui existent sont mal adaptées aux pétroles lourds. Certaines raffineries n'offrent plus de potentiel de croissance (Wingert, 2005). La fermeture de plusieurs sites pétrochimiques en Amérique et en Europe est déjà prévue depuis plus de 10 ans. Les stratégies induites par les processus économiques globaux ont des impacts imprévisibles sur les trafics portuaires. Les volumes de fret sont davantage déterminés que déterminants.

Le SCoT Ouest Étang de Berre reconnaît l'importance d'adopter une stratégie de diversification du tissu économique en accueillant des entreprises indépendantes des grands donneurs d'ordre (CAPM, 2010). Le GPMM effectue également un constat lucide de la situation des donneurs d'ordre dans le domaine de la pétrochimie et de la sidérurgie (GPMM, 2009). La massification des flux constitue la priorité majeure pour les chargeurs, les prestataires logistiques et les utilisateurs finaux. Conséquemment, le développement du port de Marseille-Fos doit être associé à une accentuation des processus d'intégration économique et à la mondialisation des marchés. Cette démarche représente une des conditions essentielles à l'accroissement des trafics maritimes en améliorant les logiques organisationnelles entre les acteurs qui participent à la chaîne de transport.

La Chambre de Commerce et Industrie Marseille Provence reconnaît l'excentricité géographique de Marseille par rapport à l'Europe du Nord (CCIMP, 2009). Cette perception du port à titre de «bout de ligne» doit être modifiée. La conquête de nouveau cargo au port de Marseille-Fos doit s'inscrire dans un nouveau périmètre géographique de missions en affirmant le rôle du port en tant qu'interface maritime des axes est-ouest et nord-sud Transméditerranéens. Le GPMM (2012), appuyé par le Conseil de développement de Marseille Provence Métropole (CDMPM, 2011), souligne l'importance de capitaliser sur les petits vracs et les lignes courtes intra-méditerranéennes. Cette orientation dans le projet stratégique 2009-2013 pourrait s'appuyer sur un programme de jumelage avec des villes portuaires de l'Afrique Méditerranéenne et ailleurs.

L'une des manières par laquelle Marseille-Fos pourrait récupérer des parts de marché serait d'être plus proactive dans la connectivité avec l'avant-pays maritime. Plusieurs ports mondiaux se sont lancés dans des acquisitions portuaires stratégiques afin d'attirer le trafic en provenance des marchés émergents. L'un des plus grands exploitants de terminal mondial, PSA, a commencé comme autorité portuaire, alors que les autorités portuaires de Shanghai et Ningbo ont créé un véhicule commun d'investissement, la Shanghai Port and Shipping Investment Co., pour investir dans les ports et d'autres activités. De tels exemples peuvent être trouvés en Europe. Le port de Rotterdam a fait l'acquisition de parts dans les ports d'Oman et au Brésil, et le port d'Anvers de parts dans des ports indiens. HHLA, lié au port d'Hambourg, exploite un terminal de conteneurs à Odessa. La plupart de ces ports disposent de divisions qui fournissent 
des services de consultation aux ports étrangers. De telles acquisitions et activités font partie d'une stratégie plus large visant à connecter les ports principaux avec les marchés émergents, afin de créer de nouveaux réseaux qui faciliteront le nouveau trafic portuaire. Des activités similaires ont lieu dans certains ports français. Ainsi le port de Rouen fournit une assistance technique à des ports situés au Vietnam, au Congo, en République Centrale Africaine et au Cameroun. Le Havre, lui, est fortement lié au programme d'études portuaires de l'École de Management de Normandie (IPER), qui propose une grande diversité de cours destinés à des administrateurs portuaires partout dans le monde. Les activités décrites ici ne sont que très peu pratiquées par le port de Marseille-Fos. Pourtant, les ambitions du port de reconquête de parts de marché et d'attraction de plus de trafic à Marseille-Fos pourraient en partie être réalisées grâce à une approche plus proactive envers son avant-pays maritime.

Le commerce de marchandises conteneurisées est largement dominé par les expéditeurs, transporteurs et opérateurs de terminaux internationaux (Slack et al, 2002). La présence à Marseille-Fos de CMA-CGM, troisième plus important transporteur mondial de conteneurs, et de Dubai Port World, troisième opérateur portuaire mondial de terminaux, constitue deux atouts privilégiés pour le port. À l'évidence, la décision de ces entreprises d'utiliser le port de Marseille-Fos est motivée par la position relative de ce port au sein de leurs réseaux globaux (Alix et al, 1999). Les stratégies commerciales de ces corporations exercent des impacts importants sur le volume de flux conteneurisés au port de Marseille-Fos. La présence de ces corporations suggère que la relance du port de Marseille-Fos nécessite un partage des responsabilités de démarchage entre les acteurs publics et les acteurs privés, comme appliqué à Hong Kong (Encadré 1) et Shanghai (Encadré 2). L'objectif consiste d'une part à permettre une meilleure compréhension des contraintes et obligations des parties prenantes, ainsi que le développement d'actions concertées, et d'autre part, à évaluer les besoins en infrastructures qui seront assumés par le secteur public, de même que les superstructures financées par le secteur privé.

\section{Encadré 1. L'expansion des parts de marché maritime de Hong Kong}

La recherche de nouveaux marchés à Hong Kong est affectée par l'accroissement des coûts unitaires du travail, capital, risque et information aux points de rupture de charge. II existe également des différences entre les transporteurs océaniques et les opérateurs de terminaux qui sont intensifs en capitaux alors que les gestionnaires des réseaux de transport terrestre et les expéditeurs sont intensifs en main-d'oeuvre. Depuis 2000, l'Administration portuaire de Hong Kong, dans ses plans stratégiques, collabore à la gestion unique d'un système de transport intermodal qui incorpore les activités des transporteurs océaniques, des opérateurs des terminaux, des gestionnaires des réseaux de transport terrestre et des expéditeurs. La recherche de nouveau cargo s'effectue par l'extension des marges spatiales liées au maillage de centres de distribution de fret correspondant à l'armature d'une grande étendue métropolitaine dans le delta de la Rivière des Perles. Les stratégies d'investissement de l'Administration portuaire de Hong Kong ont facilité le développement d'une alliance entre le conglomérat Hutchison Whampoa, propriétaire à $60 \%$ du terminal de Kwai Chung, et le transporteur chinois COSCO. Cette alliance permet d'insérer les opérations des terminaux portuaires dans la même trajectoire que celle de la compagnie chinoise. Cette situation a renforcé l'organisation régionale et créé de nouveaux sites d'investissements et des marchés attrayants. Les gestionnaires privés du terminal de Kwai Chung ont encouragé le développement de terminaux secondaires dans le delta de la Rivière des Perles (Comtois and Rimmer, 1996). En outre, l'introduction de l'échange de données électroniques qui relient toute la chaîne logistique a permis la mise en place d'un système de distribution performant, fondé sur de nouveaux corridors de services secondaires. Alors que les routes principales continuent de dominer le développement du transport, le rôle des réseaux secondaires devient complémentaire aux routes principales. Ces dernières revêtent une multitude de fonctions: 1) pénétrer de nouvelles niches de marché; 2) supporter les besoins de transport des routes principales; 3 ) rééquilibrer le trafic régional (Comtois et Slack, 2000). 


\section{Encadré 2. L'expansion des parts de marché maritime de Shanghai}

Au cours de la dernière décennie, Shanghai a connu les plus forts taux de croissance de trafic conteneurisé. Le port de Shanghai est le plus important port à conteneurs du globe avec un trafic de plus de 31 millions EVP en 2011. L'importance de Shanghai est partiellement le résultat d'une redéfinition des fonctions de production et de transport (Comtois and Dong, 2007). L'administration portuaire œuvre en collaboration avec le transporteur COSCO à faciliter le développement de fonctions commerciales et de valeur ajoutée. Cette démarche constitue un incitatif puissant pour la progression du trafic conteneurisé. Cette croissance doit également être interprétée dans le contexte d'investissements massifs dans des équipements maritimes le long du Yangtze pour le chargement et le déchargement de conteneurs. II y a un accroissement du volume de marchandises conteneurisées entre Chongqing et Shanghai. COSCO a réorganisé son service portuaire dans le cadre de sociétés conjointes avec des compagnies locales pour offrir des services de navettes pour le cabotage le long du Yangtze. COSCO a établi des bureaux, construit des entrepôts, développé le trafic de cabotage, unifié les contrôles du trafic de conteneurs, renforcé ses services de documentation et tissé des liens entre les ports du Yangtze et le port de Shanghai.

\section{Les connexions avec l'arrière-pays}

La gouvernance des villes portuaires est de plus en plus influencée par les processus de développement des corridors de commerce. L'objectif consiste à intégrer le système portuaire au sein d'un réseau de transport multimodal dans le but d'améliorer l'accès au marché, la fluidité des échanges commerciaux et le maillage industriel. Dans ce contexte, un port doit disposer d'interfaces majeures entre le commerce maritime océanique et les activités économiques des ports et des terminaux intérieurs qui fournissent les structures intermodales et les connexions entre les avant et arrière-pays du monde (Klink and Geerke, 1998; Notteboom and Rodrigue, 2005). De toute évidence, les transactions commerciales exigent un effort d'adaptation des moyens d'acheminement. Inversement, l'amplification des capacités des modes de transport peut permettre l'expansion du commerce. Ces liaisons de causalité mutuelle sont désormais présentes dans les trafics des villes portuaires. La qualité et la capacité des modalités d'acheminement, des routes et des relais sont indispensables à toute expansion du commerce.

Le corridor Rhodanien apparaît comme une extension linéaire d'un réseau de villes s'étendant des eaux de l'estuaire vers le cœur du continent européen. Délimité par quelques-unes des plus grandes concentrations urbaines et un réseau de routes, de voies ferrées et de ports, le système présente en effet plusieurs caractéristiques d'un corridor, soit une structure d'échanges qui se produit le long d'un réseau linéaire d'artères de transport entre un chapelet de villes. Un examen plus approfondi révèle toutefois que l'unité du corridor doit être nuancée. Le corridor urbain du Golfe du Lion n'est pas vraiment intégré avec les villes du range nord-européen. Par ailleurs, il existe d'autres corridors nord-sud qui concurrencent l'axe Rhodanien, notamment le corridor Gênes-Rotterdam et l'axe Barcelone-Lyon-Allemagne méridionale qui contournent la ville portuaire de Marseille.

Des efforts considérables ont été faits afin d'améliorer la connexion avec l'arrière-pays via le rail et les voies navigables. Les ports de Marseille-Fos et de Lyon ont depuis 1999 adopté une stratégie commune pour améliorer leur connectivité, sous la forme d'une plateforme multimodale (rail, route et fleuve). En plus de ça, ils se sont accordés sur un accord douanier permettant de réduire le temps d'acheminement fluvial des biens entre Marseille-Fos et Lyon à 24 heures, et sur un projet d'amélioration de l'offre fluviale pour les conteneurs. Afin de rendre l'offre fluviale et ferroviaire cohérentes, le Port de Lyon accueille et redistribue les conteneurs acheminés par rail. Le port de Fos a organisé un traitement dédié pour le déchargement des barges de céréales. Une infrastructure innovante permet de transférer directement les produits céréaliers de la péniche au cargo. 
Sur le plan fluvial, le port de Marseille-Fos a su profiter des stratégies européennes. L'Union européenne est engagée dans un vaste effort de promotion des modes de transport alternatifs à la route. Le programme Marco Polo visait à promouvoir toutes les initiatives allant dans ce sens. La première phase du programme Marco Polo (2001-2006) disposait d'un budget de EUR 75 millions. L'objectif consistait à réduire la congestion routière en Europe et à revenir au partage modal des niveaux de 1998. Le projet impliquait le détournement de 12 milliards de tonnes-kilomètres du transport routier vers les autres modes de transport. Dans le domaine précis du transport fluvial, les ministres européens des transports ont adopté en 2001 la Déclaration de Rotterdam dont le budget de EUR 820 millions visait aussi à la promotion de ce secteur. La seconde phase du programme Marco Polo (2007-2013) a pour but de détourner 144 milliards tonnes-kilomètres du réseau routier. Durant la période 2003-2006, le programme Marco Polo a financé 56 projets dont 20 comportaient un volet maritime (Guy et Urli, 2009). La majorité de ces projets concernaient le développement de services rouliers. La Commission Européenne a également lancé le programme Naïades dans le but de dynamiser le transport fluvial. Le programme agit en tant qu'outil promotionel de la navigation fluviale au sein des politiques publiques.

Le contrat de projets État-région - Provence Alpes Côte d'Azur 2007-2013 annonce une volonté politique de développer le transport fluvial. Plusieurs ententes de financement ont été réalisées entre l'État, la Compagnie Nationale du Rhône et les Conseils régionaux. Le GPMM a déjà affirmé sa volonté de développer le transport fluvial dans le cadre du Plan Rhône. Concrètement, le GPMM a pris part au capital de la plateforme tri-modale de Pagny, en Bourgogne, et reconnaît l'importance du partenariat commercial proposé par Medlinks Ports qui réunit huit plateformes fluviales de l'axe Rhône-Saône autour du port de Marseille-Fos. Cette vision, partagée entre les parties prenantes, permet une croissance du trafic sur le bassin Rhône-Saône.

En dépit de ces efforts, plusieurs défis liés à l'arrière-pays restent non résolus. Sur le plan ferroviaire, le port de Marseille-Fos est propriétaire et gestionnaire des voies ferrées sur son territoire, mais les voies d'accès ferroviaire au port sont pénalisées par l'inadéquation des infrastructures. La Cour des comptes (2011) reconnaît que le GPMM n'est pas suffisamment intégré avec son arrière-pays. Le Conseil de développement de Marseille Provence Métropole souligne la nécessité de développer une liaison ferroviaire avec l'Italie par le Val De Durance et le Montgenèvre. Mais les avancées sont liées au plan de réforme présentement en cours à la SNCF. Nonobstant les initiatives de l'Axe Rhône, Marseille-Fos est loin d'avoir achevé un système de port sec comparable à celui de Göteborg (Encadré 3), Savannah (Encadré 4) ou Virginia (Encadré 5). Au contraire de la majorité des ports hanséatiques, les camions restent dominants dans la répartition modale de l'arrière-pays, et bien que les voies navigables intérieures soient en augmentation, la part du rail a au final diminué entre 2005 et 2011. Les grands couloirs ferroviaires, tels que ceux reliant Rotterdam-Gênes et Barcelone-Lyon-Turin-Trieste-Budapest, compliquent les tentatives de Marseille-Fos de conquérir ces nouvelles zones d'arrière-pays. Parallèlement, Marseille-Fos est parvenu à intégrer le TEN-T pour les couloirs 3 et 9.

\section{Encadré 3. Le système de fret ferroviaire à Göteborg}

Göteborg a mis en place un large système de fret ferroviaire : chaque jour, 25 navettes permettent d'acheminer des conteneurs dans 24 destinations en Suède et en Norvège. Ce système permet de transporter directement par rail les conteneurs arrivés par cargo vers des centres de distribution situés dans un périmètre de $300 \mathrm{~km}$ autour de la ville. La Ville de Göteborg a décidé de mettre en place en 2000 afin d'améliorer les performances environnementales et économiques du port. En effet, le système de fret ferroviaire, tel qu'il est conçu à Göteborg, permet d'acheminer plus rapidement les biens vers leur destination finale en limitant les émissions de gaz à effet de serre. En 2002, grâce aux financements conjoints du ministère des transports suédois, de l'autorité portuaire de Göteborg et de la région Västra Götaland, la ville a mis en place une infrastructure multimodale permettant un transport ferroviaire direct des marchandises grâce à la délocalisation des services douaniers dans les centres de distribution de l'Hinterland. Ce système permet de limiter les ruptures de charges, notamment dans la mesure où les services douaniers opèrent, non plus dans l'enceinte du port à l'arrivée des cargos, mais dans les centres de distribution de l'Hinterland. Une fois arrivés dans le centre de distribution, des camions se chargent d'acheminer les conteneurs vers leur destination finale. 
Ce système permet le transport de conteneurs de 20 et de 40 pieds. Afin de permettre à davantage de clients de profiter de ce système, l'autorité portuaire a également mis en place des formats de conteneurs innovants, permettant par exemple de transporter par train des rouleaux de papier.

Le système de fret ferroviaire de Göteborg est reconnu pour ses avantages en termes de coûts. La vitesse du transport des conteneurs a augmenté sous l'effet de plusieurs mécanismes. Dans un premier temps, l'arrivée du système de fret ferroviaire a permis de réduire les embouteillages causés par les camions partant du port dans l'enceinte de la ville. Ce système permet de décharger la ville d'environ 360 camions par jour. Dans un second temps, les services douaniers ont décidé d'opérer directement dans l'hinterland permettant de décaler les ruptures de charges à l'extérieur de l'enceinte portuaire et aux marchandises d'être acheminées plus rapidement vers leur destination finale. De la même manière, les services douaniers décentralisés permettent à davantage de marchandises de transiter par le Port de Göteborg. Cela permet peut-être d'expliquer la croissance importante du trafic de conteneurs du Port entre 2001 (ce qui correspond plus ou moins à la date de mise en place du système de fret ferroviaire) et 2011: $+61,2 \%$

Par ailleurs, ce nouveau système douanier permet à davantage de marchandises de transiter par le port en déplaçant les ruptures de charge du port vers les centres de distribution de l'Hinterland. En effet, chaque année 200 000 conteneurs sont envoyés dans un hinterland de $300 \mathrm{~km}$ autour de Göteborg. Ce périmètre correspond à peu près à la plus grande zone industrielle de Scandinavie, dans la mesure où $70 \%$ des industries scandinaves se situent dans un rayon de $500 \mathrm{~km}$ autour de Göteborg. Les besoins des entreprises de la région en termes d'import et d'export permettent d'expliquer l'engouement des décideurs politiques pour le système de fret ferroviaire. En 2011, 887000 conteneurs ont transité par le port de Göteborg et 374000 d'entre eux ont été transportés dans l'hinterland par fret ferroviaire, ce qui correspond environ à $40 \%$ du trafic. L'objectif du port est d'augmentation le nombre de conteneurs transportés par rail à $50 \%$ en 2020 en augmentant l'efficacité du système. Pour ce faire, l'autorité portuaire a mis en place un système d'évaluation participatif du fret ferroviaire permettant à plusieurs catégories d'utilisateur de mettre en avant les points à améliorer. Enfin, l'efficacité du système de fret ferroviaire du Port de Göteborg est renforcée par la capacité de la ville de l'intégrer dans des plans de développement urbains plus larges renforçant sa cohérence.

Le succès du système de fret ferroviaire du port de Göteborg peut être expliqué par trois facteurs principaux: le système de gouvernance collaboratif piloté par une autorité portuaire efficace, l'importance des investissements publics ainsi que sa capacité à répondre aux attentes des utilisateurs. Ce système de gouvernance a été rendu possible par la modification du statut juridique du port en 2010, passant d'un service municipal à une entreprise d'intérêt public. Depuis 2010, l'autorité portuaire est responsable des décisions stratégiques et coopère avec un grand nombre d'acteurs, c'est-à-dire la municipalité de Göteborg, le ministère des transports, la Région Västra Götaland, les services douaniers et les nombreux acteurs privés opérants au sein même du système, à la fois pour les trains et les terminaux. L'autorité portuaire est en charge de la coordination des différents acteurs et sa capacité à arbitrer les intérêts de chacun. Cela permet une meilleure coopération des acteurs entre eux sous la tutelle de l'autorité portuaire. De la même manière, le nombre d'acteurs participant au processus décisionnel explique la pertinence des plans d'urbanisme associés au port (comme le projet Marieholm et le Plan Compréhensif de 2009). L'efficacité de la mise en place du système permet également d'expliquer son succès fulgurant. En effet, le projet a été approuvé au conseil municipal en 2000. Entre 2000 et 2002, 6 navettes ferroviaires étaient construites et 25 d'entre elles fonctionnent en 2011. La rapidité de la mise en place du fret ferroviaire a été facilitée par l'importance des investissements publics pour la construction des infrastructures.

Enfin, le succès du système peut être expliqué par la capacité des acteurs publics à orienter leur stratégie en fonction des besoins des acteurs privés, par exemple la mise en place de contenants spécifiques pour les transporteurs n'ayant pas de conteneurs à proprement parler. Parallèlement, l'utilisation du système de fret ferroviaire permet une réduction des coûts pour les usagers: la vitesse de chargement et de déchargement des cargos est réduite, ce qui permet de réduire leurs frais de stationnement à quai. De la même manière, le stockage des marchandises à l'extérieur du port permet une réduction des frais (dans la mesure où la demande pour un même entrepôt est réduite) et enfin, le port offre des tarifs différenciés aux clients faisant le choix de réduire leurs émissions de particules polluantes. L'augmentation du nombre de conteneurs transportés par rail depuis la création sus système prouve l'efficacité de ce système et l'engouement des utilisateurs. 


\section{Encadré 4. Savannah Logistics Centre}

Le port de Savannah est la composante principale du pôle logistique de Savannah en raison de l'importance du marché axé vers le commerce transcontinental et de la quantité de fret transitant au port. La croissance des activités commerciales mondiales et la quantité de fret entrant et sortant au port de Savannah ont mis en évidence le besoin d'entrepôts et de centre de distribution dans la région (Atlanta Business Chronicle, 2009). Le pôle logistique de Savannah s'est surtout développé dans l'optique de subvenir à cette demande. Le Georgia Port Authority possède et opère le port de Savannah tandis que A\&B Properties et Colliers Neely Dales sont les principaux promoteurs et développeurs du pôle logistique (A\&B Properties, 2009).

Le port de Savannah a manutentionné près de 3 millions EVP en 2011 et prévoit d'augmenter sa capacité jusqu'à 4 millions d'EVP d'ici 2015. Ces prévisions de croissance ont entraîné la construction intensive de centres d'entrepôts. II existe une forte demande pour des entrepôts d'environ $50,000 \mathrm{~m}^{2}$. Les promoteurs prévoient d'accroître le site d'exploitation en accaparant des terrains situés dans le comté de Jasper en Caroline du Sud. L'acquisition de nouveaux terrains permettra au pôle logistique de doubler la taille des terrains actuels (Bruns, 2009).

Le pôle logistique de Savannah fait partie du réseau ferroviaire étendu de Northfolk Southern Railway, ce qui lui permet d'offrir des avantages comparatifs de transport. Savannah facilite le transfert des conteneurs du rail aux navires en offrant une connexion directe au port. Le réseau essentiellement bimodal permet de desservir la côte est américaine, notamment les ports de New York/New Jersey, de Philadelphie et de Baltimore (Lower Savannah Council of Governments, 2002). Savannah offre surtout des services reliés à la demande d'entreposage et de distribution dans la région (Southeast Real Estate Business, 2006).

\section{Encadré 5. Le port sec de Virginie}

Le centre logistique de Virginia Inland Port permet de transférer les conteneurs du camion au rail. Le centre logistique sert de système intérieur assurant la gestion des conteneurs destinés au port de Virginie ainsi qu'aux villes régionales. Plus spécifiquement, les conteneurs arrivant par camion de la Vallée de l'Ohio et de Pittsburgh sont transférés par rail (Norfolk \& Southern Railway) à Front Royal vers le port intérieur (Norfolk Southern Corporation, 2009). Le but du Virginia Inland Port est de capturer une plus grande part du marché dans la région de la Vallée de I'Ohio (Ohio, Pennsylvanie, l'ouest du Maryland et l'ouest de la Virgnie). Avant l'implantation du Virginia Inland Port, le cargo devait transiter par les ports de Baltimore ou de Philadelphie. Afin de capturer le marché international et de développer l'économie locale, les développeurs ont misé sur des prévisions de trafic afin d'attirer des expéditeurs (Heerwawgen, 1996; Online Ressource Center, 2009).

Virginia Inland Port est planifié de façon à mettre en place des installations pour des conteneurs dans un endroit non congestionné où les rails et routes sont facilement accessibles et où les conflits liés à l'utilisation de l'espace sont moindres. L'implantation du Virginia Inland Port a généré des retombées économiques positives en raison du lien ferroviaire entre le Virginia Inland Port et le terminal maritime à Hampton Roads permettant l'accès direct à plus de 75 compagnies d'expéditeurs internationales (Online Ressource Center, 2009). Un des avantages de Virginia Inland Port concerne la présence de services douaniers, car le pôle logistique fait partie du US Custom-Designates Port of Entry

Une implication active du gouvernement national serait nécessaire pour faciliter l'accès à de nouvelles zones d'arrière-pays. Du progrès doit être fait pour résoudre les problèmes d'engorgements actuels, par exemple le contournement de Lyon par le rail, une connexion à un canal à grand gabarit entre la Saône et le Rhône. En plus de ces projets, il en existe d'autres dans lesquels le port à lui-même un rôle à jouer, par exemple un canal direct allant des terminaux de conteneurs de Fos jusqu'au Rhône (Caban Nord). 


\subsection{Le port comme atout métropolitain}

Les changements structurants que provoque la logistique globale annonce une redéfinition de l'interface entre le port et sa région. Les systèmes de transport sont fondamentaux à la formation des espaces économiques régionaux. Tous les scénarios de développement économique s'appuient sur une croissance du trafic de fret, de passagers et d'information. Mais cette croissance met en lumière la valeur du niveau d'accumulation de connexions entre infrastructures, production industrielle et le parc immobilier de l'environnement construit. L'établissement de synergies entre tous les modes de transport s'avère critique pour le succès des villes portuaires. L'organisation des systèmes de transport, liée à l'intermodalité et aux progrès technologiques, repose de plus en plus sur la qualité des services logistiques. Tant les autorités urbaines que les autorités portuaires doivent être conscientes que les plateformes logistiques sont désormais un élément critique qui permet de dépasser le contrôle des espaces métropolitains traditionnels pour des espaces logistiques et des systèmes de transport globaux.

Marseille a développé un plan d'utilisation du sol qui comprend une offre foncière pour le développement d'un parc logistique répondant aux besoins du port. Un des éléments clés de la réussite du projet est de lier les grandes compagnies maritimes aux manutentionnaires locaux de fret. L'Administration portuaire de Marseille-Fos reconnait sa multifonctionnalité avec la participation de 5 filières présentes sur les bassins Est. Dès 2008, l'administration portuaire, dans son schéma de pilotage des bassins Est, a entrepris des actions pour autoriser l'accueil des navires porte-conteneurs de plus grande taille et de plus grand tirant d'eau à Mourepiane. L'administration portuaire reconnaît d'ailleurs la pérennité du transport roulier indissociable de la logistique. Le SCoT de la Communauté Agglomération Ouest Étang de Berre opte pour le renforcement de la densification industrielle à Fos en favorisant le passage d'une logique strictement foncière à une logique de bassins d'activités (CAOEB, 2010). Ces plans peuvent être utilisés pour une nouvelle orientation dans la planification du port qui reconnaît la nécessité d'introduire des innovations dans les pratiques logistiques et environnementales.

Le développement des activités logistiques doit stimuler une culture d'entreprenariat et d'affaires fondée sur l'économie du savoir. La masse de travailleurs générée par les activités logistiques nécessite que ces derniers disposent d'une formation dans les opérations logistiques. La multiplicité des tâches est fréquemment exigée dans l'industrie. La fourchette des tâches varie de manuelles à techniques de très haut niveau. Les institutions d'enseignement de la grande région de Marseille doivent établir des programmes et des cours de formation sur mesure pour éduquer une jeune relève au sein de l'industrie, et pour offrir une formation d'appoint aux travailleurs expérimentés qui désirent se réorienter vers le milieu des activités logistiques. L'administration portuaire doit se maintenir à la fine pointe de la technologie et être à l'affut des nouvelles technologies et de nouveaux équipements. Des maillages doivent être établis avec les institutions universitaires et de recherche à Marseille. Les échanges avec les centres de recherche universitaire deviennent fondamentaux. L'objectif consiste à faire de la région de Marseille un centre d'excellence en recherche et formation logistique. Cette réputation pourrait devenir un puissant outil promotionnel pour attirer des entreprises logistiques cherchant à établir une plateforme européenne là où il existe une réserve de main-d'œuvre expérimentée et formée de façon adéquate.

\section{Attirer des services maritimes internationaux}

Les documents stratégiques de la ville et de l'agglomération de Marseille soutiennent non seulement le développement portuaire, mais expriment également l'ambition du port de devenir un centre leader dans les services et le commerce. La stratégie de développement économique de 2008-2014 de Marseille Provence Métropole (MPM) considère le port et l'économie logistique comme l'un des cinq porteurs de l'économie métropolitaine. Cette ambition est détaillée dans le titre même du document: «Métropole 
euroméditerranéenne des échanges et de la connaissance ». Dans cette ambition, le port et les industries portuaires constituent des éléments majeurs pour faire de Marseille la métropole commerciale du Sud de l'Europe, et lui garantir une place première dans l'économie touristique. Des mots-clés similaires apparaissent dans le document stratégique de la ville de Marseille. « Marseille Attractive 2012-2020 ». Les trois principaux axes de cette stratégie sont: devenir la plateforme commerciale première du Sud de l'Europe ; d'être une ville de la connaissance et de la créativité, et d'être une ville de destination. Cette stratégie définit aussi le rôle attribué au port et aux secteurs qui y sont reliés ; premièrement d'être l'un des moteurs des ambitions commerciales, et deuxièmement de faciliter la position de Marseille en tant que destination attractive.

Ces orientations stratégiques peuvent être utilisées pour développer un plan d'action concret en vue d'attirer des sièges sociaux et des services maritimes internationaux. La stratégie de développement de MPM a le mérite de proposer des actions concrètes et mesurables, et plusieurs de ces actions, par exemple l'éducation maritime, participeront sûrement à créer un climat plus favorable pour attirer les services maritimes internationaux. Cependant, son but n'est pas tellement d'attirer des sièges d'entreprises maritimes et des services tels que le consulting maritime, l'ingénierie, le droit et la finance, ce qui n'est pas non plus le but explicite du GPMM ni de la Charte Ville-Port, bien que ces activités à forte valeur ajoutée pourraient être intéressantes, et constituent une cible atteignable grâce à l'héritage maritime de Marseille et à la communauté portuaire et maritime déjà existante.

\section{Projeter une image positive}

Le développement spatial du port de Marseille-Fos est un exemple classique de développement dynamique de l'interface ville-port. Dans un article novateur sur les relations entre les ports et les villes auxquelles ils sont rattachés, Hoyle introduisit le concept d' «interface port-ville », indiquant la relation spatiale entre les ports et les villes (Hoyle, 1989). Cette interface est un concept dynamique, définissant plusieurs phases de développement des villes portuaires dans le temps, déterminées par des tendances de croissance démographique, croissance portuaire, développement industriel et des contraintes spatiales, pouvant mener à terme à la relocation du port, à la transformation d'anciennes zones portuaires et à la désintégration ou réintégration partielle des fonctions du port et de la ville. Dans cet article, le cas de Marseille est utilisé pour illustrer les différentes phases de cette interface port-ville. Ces processus ont eu lieu dans plusieurs grandes villes portuaires mondiales, posant toujours les mêmes problèmes : comment continuer à supporter les fonctions portuaires situés proches du centre-ville ; comment maintenir les liens existant entre les populations locales et les activités portuaires de plus en plus délocalisées, et généralement non accessibles au public?

Les développements de ces dernières années n'ont pas amélioré l'image du port de Marseille-Fos. Au niveau international aussi bien que national, le port est célèbre pour ses relations sociales compliquées et conflictuelles, pouvant mener à une fiabilité limitée et une baisse des rendements du port. L'interface entre la ville de Marseille et les Bassins Est du port a été pendant plusieurs années la source de plusieurs conflits, jusqu'à devenir imperméable, fermant l'accès et la visibilité des fonctions portuaires à la population. Les Bassins Ouest sont eux très éloignés et invisibles pour la majorité des Marseillais, mais bien visible pour la population environnante sujette à des impacts environnementaux importants, sans avoir aucun pouvoir d'influence sur le développement portuaire. En résumé, le port de Marseille-Fos est perçu localement avec méfiance et ignorance. Le sentiment local de fierté dans le port, que l'on observe pourtant dans d'autres grandes villes portuaires européennes telles qu'Hambourg, Anvers et Rotterdam, n'existe pas dans la région, qui contient cependant le $5^{\text {ème }}$ plus grand port européen.

Plusieurs ports mondiaux sont engagés dans des stratégies de communication externes, afin de supporter localement les fonctions exercées par le port. Un élément nécessaire dans ce but est l'accès et la transparence des informations sur le port. De nombreux ports fournissent des rapports publics annuels sur 
leurs activités, incluant leurs rapports financiers, la responsabilité sociale de leur entreprise, le capital humain et les indicateurs clé de gestion des finances publiques. Plusieurs ports fournissent également des informations plus pertinentes pour la population, nommément des informations claires et objectives sur les impacts environnementaux. Par exemple le port de Los Angeles rend public tous les ans un Air Quality Inventory Report (Encadré 6); le port d'Anvers publie annuellement un Sustainability Report; dans plusieurs ports américains les réunions de la commission portuaire sont accessibles à un large public, et l'agenda et les procédures sont disponibles sur le site internet du port. Les nouveaux projets portuaires sont discutés avec la population, lors de réunions d'information et de consultation; dans certains cas les projets sont même ouverts aux visites du public et expliqués dans des centres de visite, tel que par exemple celui destiné au Projet d'expansion portuaire Maasvlakte 2 à Rotterdam. Certains ports européens, comme Anvers et Gênes, disposent de centres d'information portuaire où la population peut se renseigner sur le port et ses fonctions. Dans leurs stratégies de communication, plusieurs ports utilisent les médias sociaux, et sont massivement suivis sur Facebook et Twitter.

\section{Encadré 6. Inventaire des Émissions Atmosphériques des Ports de Los Angeles et Long Beach}

Les ports de Los Angeles et de Long Beach ont depuis 2005 mis en place un Inventaire des Émissions Atmosphériques afin de mesurer la pollution atmosphérique liée à l'activité portuaire et informer le public à ce sujet. Cet inventaire s'inscrit dans le cadre du Plan de Préservation de l'Air de San Pedro qui a été conçu pour réduire les émissions de $\mathrm{CO} 2$ et les risques de santé liés à la pollution atmosphérique (voir l'encadré $\mathrm{x}$ ). L'Inventaire des Émissions Atmosphériques de 2005 sert de base pour mesure les progrès réalisés concernant ce plan d'action. La mise en place d'inventaires des émissions atmosphériques a été coordonnée par l'Agence de Protection de l'Environnement des États-Unis (EPA), le Bureau Californien en charge des ressources atmosphériques (CARB), et le Département de Gestion de la Qualité de l'Air de la Côte Sud (SCAQMD). Les locataires du port ainsi que les armateurs jouent également un rôle clé en proposant des activités adéquates et des informations quant à leurs opérations. Les données d'activité opérationnelles collectées sont alors utilisées pour estimer les émissions pour chacune des diverses catégories de sources en adéquation avec les dernières méthodologies d'estimation sur lesquelles se sont mis d'accord le Port et les agences de régulation concernées. Tous les inventaires annuels détaillés sont ouverts au public et consultables sur les sites web des ports.

Les inventaires évaluent les émissions émanant de cinq catégories de sources mobiles en lien avec l'activité portuaire: navires de haute mer, port de bateaux, les équipements hors route de manutention portuaire, les locomotives de chemin de fer, les véhicules lourds sur la route. Pour chaque catégorie, les gaz d'échappement sont estimés pour les polluants suivants: Particules en en suspension dans l'air (PM) (10-micron, 2.5-micron), particules de diesel en suspension (DPM), oxydes d'azote $\left(\mathrm{NO}_{\mathrm{x}}\right)$, oxydes de soufre $\left(\mathrm{SO}_{\mathrm{x}}\right)$, hydrocarbures $(\mathrm{HC})$ et monoxyde de carbone $(\mathrm{CO})$. Les ports ont commencé à mettre en place des estimations d'émissions de gaz à effet de serre (GHG) en lien avec la maintenance portuaire depuis l'Inventaire de 2006 qui prend en compte l'équivalent dioxyde de carbone $\left(\mathrm{NO}_{\mathrm{x}}\right)$, le dioxyde de carbone $\left(\mathrm{CO}_{2}\right)$, le méthane $\left(\mathrm{CH}_{4}\right)$ et l'oxyde nitreux / de diazote $\left(\mathrm{N}_{20}\right)$. En utilisant les niveaux d'activité de 2005 comme année de référence, les inventaires nous permettent également de comparer l'évolution des principaux polluants atmosphériques entre l'année de référence et l'année d'évaluation. Dans le dernier rapport datant de 2011, le port de Los Angeles avait vu ses émissions polluantes cumulatives réduites de $76 \%$, ceci incluant une chute de $71 \%$ des émissions de particules de diesel depuis 2005, des émissions d'oxyde d'azote en baisse de $51 \%$ et des émissions d'oxyde de soufre réduites de $76 \%$.

Les événements liés au port sont une autre composante de ces stratégies de communication externe. Ces événements annuels vont de l'anniversaire du port, aux «journées portuaires », journées de croisières, etc. Le thème commun à ces évènements est la présentation au public de l'héritage maritime, d'un grande nombre de navires divers, et l'ouverture au public des parties du port, toujours dans le but d'intéresser et passionner la population pour le secteur portuaire et maritime. Dans certains cas, des ports décident également d'ouvrir certaines zones privées aux visites du public. Par exemple le port d'Hambourg a construit des pistes cyclables au sein même du port, et fournit des guides informant sur des tours organisés à vélo. L'expansion portuaire Maasvlakte 2 de Rotterdam prévoit elle d'inclure une nouvelle plage publique. De plus, plusieurs ports sont engagés dans des programmes d'enseignement sur le port et ses 
fonctions dans les écoles; dans certains ports américains les travailleurs portuaires sont également impliqués dans le volontariat, à travers le sponsor de projets communautaires, dans le but de prouver leur bonne volonté aux populations locales.

En comparaison, le port de Marseille-Fos a une communication externe bien plus modeste. Il ne diffuse pas de rapports publics annuels, et n'a sorti qu'un seul rapport sur le développement durable (en 2009). Bien que les impacts environnementaux soient suivis et contrôlés, ils ne sont ni publiés annuellement ni accessibles de façon transparente. Si une consultation des différents acteurs intéressés a bien lieu, c'est d'une façon limitée, et la population n'est impliquée que dans le cas où la loi oblige le port à une telle décision. Les événements et autres activités ayant pour but de projeter une image positive du port pour les citoyens restent très rares.

La transformation actuelle de l'interface port-ville, ainsi que le statut de Marseille Provence comme future Capitale Européenne de la Culture en 2013, laissent entrevoir de nouvelles possibilités pour améliorer l'image positive et la visibilité du port. Dans le cadre du projet de redéveloppement urbain Euroméditerranée, la connexion entre la ville de Marseille et le port est réaménagée, par exemple le centre commercial les Terrasses du Port, établit sur un toit terrasse situé en haut d'un des terminaux de ferry, avec vue sur les terminaux des Bassins Est. De plus, des anciens bâtiments portuaires sont en train d'être partiellement transformés en espaces publics, trouvant une nouvelle utilité urbaine comme espaces de reconnexion entre la ville et son héritage maritime. Les événements découlant du statut Marseille Provence comme Capitale Européenne de la Culture en 2013 fournissent aussi de nouvelles opportunités de projeter l'image d'une ville fière de son héritage maritime. Ces événements devraient véhiculer avec force une nouvelle stratégie externe de communication sur la ville et son port.

\subsection{Réduire des impacts négatifs}

Les corrélations étroites entre performance environnementale et capacité concurrentielle des ports suggèrent que des percées technologiques permettent de surmonter certaines contraintes environnementales tout en réduisant au minimum les effets externes négatifs. Sur le plan économique, les améliorations apportées aux pratiques portuaires dépendent du leadership régional motivé par la libéralisation dans l'organisation des systèmes de transport. Les cadres dirigeants qui soutiennent le développement du port et $\mathrm{du}$ transport fluvio-maritime obtiennent souvent le soutien des gouvernements et la participation de partenaires pour concevoir des politiques et faciliter l'élaboration de stratégies. Sur le plan de l'environnement construit, l'introduction d'innovations est associée à l'ajout d'infrastructures nouvelles et plus denses pour moderniser les réseaux portuaires existants et renforcer les capacités de transport des activités commerciales.

Le GPMM exerce un leadership reconnu dans la gestion écologique de la région par différentes stratégies de développement durable concernant la qualité de l'eau, la gestion des déchets et le traitement des sédiments de dragage. L'état initial de l'environnement du schéma de cohérence territorial Ouest Étang de Berre 2009, le rapport annuel de développement durable 2009 du GPMM établissent des diagnostics rigoureux et des réponses environnementales aux activités portuaires et à la navigation commerciale. Le rapport méthodologique, d'analyses et de recommandations pour les ports (2012) fournit un excellent cahier des charges pour l'évaluation de la performance environnementale. L'initiative de la Communauté urbaine Marseille Provence Métropole, eu égard à une analyse du bilan carbone et de la vulnérabilité du territoire, doit être saluée. Malgré la complexité de la gouvernance du système, force est de constater que les gouvernements ont établi des politiques et des réglementations qui améliorent la santé environnementale des Bouches du Rhône. 
Ce cadre légal ne permet toutefois pas à l'Administration portuaire de Marseille-Fos de remplir adéquatement sa vocation d'aménageur du territoire portuaire. La région Provence-Alpes-Côte d'Azur participe à la protection de l'environnement et à la conservation de la biodiversité. La Chambre de Commerce et Industrie Marseille Provence souligne toutefois la nécessité de repenser la sanctuarisation du territoire. Les pratiques et politiques durables au sein de l'industrie du transport semblent témoigner des besoins de flexibilité et d'adaptabilité des systèmes de transport aux défis de la protection des écosystèmes, soit par l'adoption de technologie, de produits et substances appropriées (même rythme que l'écosystème) ou par l'ingénierie génétique (transformation du rythme de l'écosystème).

La compatibilité des pratiques d'aménagement des systèmes portuaires avec le maintien de l'équilibre des écosystèmes repose de plus en plus sur des techniques compensatoires. Certaines mesures de compensation environnementale permettent de réhabiliter des sites contaminés, de créer de nouveaux écosystèmes et de lutter contre les changements climatiques, notamment en ciblant sur la création de puits de carbone par la plantation d'arbres à croissance rapide et sur le développement de tourbières. Dans le Bassin Ouest, plusieurs de ces mesures compensatrices ont été prises afin de prouver la volonté du GPMM de restaurer la biodiversité dans la zone. Ces mesures ont entrainé un cloisonnement spatial de la zone portuaire, alors qu'elles sont de plus en plus considérées comme permanentes par les ONG environnementales, ce qui résulte en la situation paradoxale d'un site portuaire en grande partie non utilisé pour des activités portuaires, avec des possibilités limitées d'expansion future. Dans une telle situation, une solution doit être trouvée, par exemple en permettant des compensations environnementales en dehors de la zone portuaires, afin de pouvoir libérer, en cas de besoin, les zones naturelles actuelles à l'intérieure de la zone portuaire pour des usages industriel et portuaire.

En dépit de nombreux outils mis en place, il existe un potentiel non exploité qui permettrait de continuer à rendre le port de Marseille-Fos plus 'vert', ceci en mettant notamment en place un plan détaillé visant à améliorer la qualité de l'air. La pollution atmosphérique est en effet l'une des conséquences néfastes les plus importantes des sites portuaires comme celui de Fos, mais également des ports urbains avec de nombreux navires de croisière, comme celui de Marseille. D'autres ports à travers le monde se sont servis de plusieurs outils pour atténuer ces impacts en mettant en place des plans d'incitation, des régulations, des récompenses ou en utilisant des données diverses. Le Plan de Préservation de l'Air des ports de San Pedro (Encadré 7) est l'un des plans de qualité de l'air les plus développés concernant les espaces portuaires. Un plan similaire pourrait être mis en place pour le port de Marseille-Fos. Dans le cadre d'un plan de qualité de l'air détaillé et en faisant suite à l'organisation de la conférence Greenport 2012, le port pourrait se connecter aux meilleurs pratiques internationales partagées par des organisations comme Eco Ports tout en rejoignant des plans d'incitation positifs comme l'Index Maritime Environnemental (Encadré 8). Le processus de rationalisation des industries pétrochimiques et des raffineries actuellement en cours en Europe pourrait être l'occasion d'entamer une discussion constructive et tournée vers l'avenir sur comment les infrastructures portuaires et sites existants pourraient être transformés en hub industriels écologiques, conformément à la production de biomasse ou aux économies cycliques mises en place dans les ports japonais comme celui de Kitakyushu.

\section{Encadré 7. Plan d'Action pour la préservation de l'air des ports de la Baie de San Pedro}

Le Plan D'action pour la préservation de l'air des ports de la baie de San Pedro (San Pedro Bay Ports Clean Air Action Plan, CAAP) est une stratégie globale de réduction des émissions de CO2 générées par les mouvements de marchandises dans les zones portuaires. En tant que complexe maritime le plus important d'Amérique du Nord, les deux ports de la baie de San Pedro constituent également la plus importante source de pollution de Californie du Sud, d'après le South Coast Air Quality Management District (SCAQMD). En 2005, les deux méga ports jumelés de Los Angeles et Long Beach généraient environ $25 \%$ de la pollution au diesel dans la région (O'Brien, 2004). Le CAAP a été instauré en réponse au problème issu de l'expansion continue du port et des impacts environnementaux sur les régions voisines de la ville, qui y sont associés. Le but du CAAP était de réduire fortement les émissions et les risques pour la santé associés en Californie du Sud, et ce sans entraver le développement continu du port. Le plan a été 
premièrement approuvé en 2006, puis mis à jour en 2010, instaurant des objectifs à moyen terme jusqu'en 2014 et des objectifs sur le long terme, comme par exemple la réduction des émissions portuaires de $59 \%$ pour $\mathrm{NO}, 93 \%$ pour SO, et $77 \%$ pour DMP prévue pour 2023 , et un rabaissement des standards liés aux risques de cancer du à la pollution au diesel dans la région. Comme stipulé dans le plan, les deux ports ont développé des Inventaires Annuels d'Émissions, rendus publics, afin de pouvoir suivre leur progression vers les standards du CAAP. Le CAAP emploie une combinaison de régulations, de frais, de subventions et d'incitations afin de forcer l'industrie du transport des marchandises à utiliser des technologies moins polluantes et des systèmes opérationnels spécifiques, tels que le Clean Truck Program, le Vessel Speed Reduction Program et l'Alternative Maritime Power program. En support au développement et à la démonstration de technologies d'épuration de l'air, les deux ports ont crée conjointement un programme de technologie avancé qui, depuis 2007, a fourni plus de 9 millions $\$$ de financement à l'industrie portuaire.

Les analyses de 2011 les plus récentes indiquent que deux ports ont substantiellement réduit les polluants clés de leurs activités portuaires depuis 2005, dont une réduction respective de $71 \%$ et $75 \%$ des particules diesel en suspension dans l'air. La mise en place de programmes phares en Californie du Sud a largement contribuée à ces performances. Ces programmes incluent le Clean Truck Program (CTP) et le Vessel Speed Reduction Program (VSR). Le CTP vise l'une des sources de pollution portuaire majeure : le transport de marchandises dans le port par camions fonctionnant au diesel. II établit un bannissement progressif des anciens camions polluants dans les terminaux d'expédition. Depuis le $1^{\text {er }}$ janvier 2012, seuls les camions conformes aux Federal Clean Truck Standard établi en 2007 ont accès à ces terminaux. Actuellement, plus de 11000 camions «propres » sont en activité dans les ports, dont plus de 800 camions fonctionnant au gaz naturel. En tout, les deux ports ont fourni plus de 110 millions \$ de subventions afin d'inciter au remplacement des anciens camions. Ajouté à l'interdiction des camions sur les terminaux et aux frais qui y sont associés, ces incitations ont générées environ 1 milliard \$ d'investissement privé dans le renouvellement du parc de camions. Grâce aux efforts associés des autorités portuaires, des opérateurs de terminaux et de l'industrie du camionnage, le CTP a jusqu'alors entrainé une réduction d'environ $80 \%$ et $90 \%$ du taux d'émission des camions par rapport à 2007, dans les ports respectifs de Los Angeles et Long Beach. L'objectif du VSR est lui de réduire $\mathrm{NO}$, les émissions des navires de haute mer, en ralentissant leur vitesse quand ils approchent ou partent du port, soit généralement a 20 miles nautiques $(\mathrm{nm})$ de Point Fermin. Le VSR a d'abord été adopté en 2001, avec la participation volontaire du secteur des revêtements de conteneurs, après que les deux ports aient signés un Memorandum of Understanding (MOU) coopératif avec les U.S. EPA, CARB, SCAQMD, Steamship Association of Southern California et la Pacific Merchant Shipping Association (PMSA). La Marine Exchange of Southern California fournit aux navires les données relatives à la vitesse autorisée pour les deux ports. Depuis que le CAAP de 2006 a identifié le programme VSR comme l'une des principales mesures de contrôle de pollution de l'air, les deux ports ont commencé à offrir des incitations sous formes de déduction de taux d'impureté aux opérateurs participants - $15 \%$ de déduction pour ceux se conformant à $20 \mathrm{~nm}, 30 \%$ de déduction (POLA) et $25 \%$ de déduction (POLB) pour 40nm. De plus, les navires de haute mer respectant les consignes à $90 \%$ sur une année perçoivent ces bénéfices pour l'ensemble de leurs escales durant cette même année. En mars 2012, le respect de ces règles à POLA était de $94 \%$ à $20 \mathrm{~nm}$ et $74 \%$ à $40 \mathrm{~nm}$, et à POLB il était de $97 \%$ à $20 \mathrm{~nm}$ et $84 \%$ à $40 \mathrm{~nm}$. En 2007, les deux ports estimaient que le programme VSR avait permis une réduction de 1,345 tonnes de NO, 832 tonnes de SO, 112 tonnes de PM et 52502 tonnes de $\mathrm{CO}_{2}$.

Le CAAP marque une étape importante pour l'industrie portuaire dans le processus de réduction des impacts environnementaux causés par l'activité maritime. Le CAAP était un projet de coopération entre les deux ports à l'origine du concept et qui en ont été des acteurs clés, parmi d'autres intervenants du secteur et dirigeants d'organismes (Giuliano et Linder, 2011). Le facteur clé d'un tel succès a été la coopération des utilisateurs du port, dont les terminaux opérateurs, les camionneurs, les transporteurs, et le support des corps régulateurs aux niveaux local, fédéral et national, ainsi que des communautés voisines (Mongelluzzo, 2012). De plus, les ports étaient soumis à une forte pression sociale alors que les risques pour la santé de la communauté, issus des particules de diesel dans l'air, s'étaient accrus suite à une série d'études sur la qualité de l'air et la corrélation entre les taux de cancers et maladies respiratoires et la proximité avec des corridors de transports de fret. Alors que le volume des marchandises atteignait son maximum en 2004 et entrainait la nécessité d'étendre encore plus les deux ports, une contestation croissante de la population, ainsi qu'une série de procès, rendait toute expansion pratiquement impossible. De plus, une pression politique pesait sur le législatif pour inciter à une surveillance réglementaire accrue, ce qui incita encore plus les ports à répondre à l'insatisfaction de la population quant à la qualité de l'air, et à conduit finalement à l'adoption d'un plan global. Le CAAP a été dépeint comme une solution pour les ports afin d'avoir plus de crédibilité dans l'obtention de projets futurs, alors qu'ils engageaient tous les acteurs clés identifiables. Une étude considérait que «Le CAAP a été une réponse à la perte de légitimité sociale, et aux pressions sociales et réglementaires qui restreignaient la capacité des ports à s'étendre »(Giuliano et Linder, 2011). Un dernier point est que les parts de marché détenues par deux ports de Californie du Sud ont également joué un rôle important dans les efforts d'atténuation du conflit. Leurs statuts de passerelles les rendent capables d'imposer des frais aux industries et donc de générer les revenus supplémentaires nécessaires à la mise en place de telles politiques environnementales. 


\section{Encadré 8. L'Index Maritime Environnementale}

L'Index Maritime Environnemental (Environmental Ship Index) est un outil permettant de déterminer la performance environnementale maritime au niveau des polluants atmosphériques et du dioxyde de carbone. L'idée derrière cet index réside dans le fait que les ports peuvent désormais récompenser les navires obtenant de bons scores sur cet index maritime environnemental en leur proposant notamment des redevances portuaires moins élevées. L'Index Maritime Environnemental mesure les émissions des navires en se basant sur la quantité d'oxyde d'azote (NOx), d'oxyde de soufre (SOx), les particules en suspension dans l'air (PM) et de gaz à effets de serre qu'ils rejettent. II s'agit d'un système d'adhésion volontaire, ouvert aux sociétés de transport maritime, aux armateurs et aux autorités portuaires. L'Index utilise une formule afin d'accorder des points aux navires en fonction de leur performance environnementale, prenant en compte la législation internationale en vigueur, principalement celle de l'Organisation Maritime Internationale (IMO). II y a actuellement 1439 navires possédant un score à l'Index valide et 18 ports qui y participent, dont Rotterdam, Hambourg, Anvers, Le Havre, Los Angeles et New York/New Jersey. L'Index a été conçu dans le cadre de l'Initiative pour le Climat des Port Mondiaux (World Port Climate Initiative, WPCl), qui s'emploie à réduire les émissions de gaz à effet de serre (GHG) liées à l'activité portuaire. La base de données regroupant les navires de l'Index est remplie et administrée par le Bureau de l'Association Internationale des Ports (IAPH) en charge de l'Index.

Dans le cadre de ce plan global sur la qualité de l'air, l'introduction d'un système d'alimentation électrique à quai doit être considérée, en se basant sur un projet actuel entre GPMM et la compagnie maritime CMN (Compagnie Méridionale de Navigation). Un nombre croissant de ports utilisent des systèmes d'alimentation à quai pour recharger les navires qui rentrent dans le port. Ainsi, au lieu d'utiliser des moteurs diesel, ces navires peuvent utiliser l'énergie générée par le réseau local, réduisant la pollution de l'air. L'alimentation à quai nécessite non seulement des fils électriques connectés aux quais, mais aussi des bateaux capables de se connecter à ces sources d'énergie. C'est pourquoi l'alimentation à quai est plus pertinente, et a été crée plus spécialement pour les liaisons régulières "point to point", comme c'est le cas pour les ferries et les navires rouliers, comme à Göteborg, l'un des premiers ports à avoir introduits ce système (Encadré 9). De plus en plus, d'autres types de navires se connectent à l'alimentation à quai des ports. La majorité des ports américains de la côte Ouest appliquent le système d'alimentation à quai aux porte-conteneurs et aux bateaux de croisières, et certains ports (Long Beach et Salalah, Oman) ont également installé l'alimentation à quai pour les navires pétroliers.

\section{Encadré 9. Alimentation à quai à Göteborg}

Depuis la fin des années 1990 et le début des années 2000, le port suédois de Göteborg a mis en place une politique innovante de branchement des navires au réseau électrique terrestre. Les navires stationnés à quai ont en effet besoin d'énergie pour remplir certaines fonctions indispensables (éclairage, chauffage, ventilation etc.) et utilisent habituellement pour cela leurs moteurs diesel. Cette activité est la source d'une importante pollution de l'air au niveau local et de l'émission de gaz à effets de serre. Le port de Göteborg a été, en 2000, un des premiers ports au monde à proposer aux navires de se connecter au réseau électrique local, leur permettant ainsi d'éteindre leurs moteurs le temps de l'escale dans le port.

Depuis 1989, le port de Göteborg fournissait déjà de l'électricité aux navires faisant escale dans le port, mais par le biais de plusieurs câbles à basse tension par navire, ce qui ne permettait pas de couvrir les besoins en énergie. Suite à l'initiative d'une grande entreprise de production de papier, Stora Enso, qui cherchait à améliorer le bilan carbone du transport de ses produits, le port a entrepris la conception d'un système plus performant, en partenariat avec plusieurs compagnies de navigation et avec une entreprise spécialisée dans les produits électriques appelée ABB. Le système est opérationnel depuis 2000 : un seul câble à haute tension, pouvant fournir $6,6 \mathrm{et} 10 \mathrm{KW}$ à $50 \mathrm{~Hz}$, permet d'alimenter tout un navire en énergie, à partir de plate-formes présentes sur les quais. Les navires ont donc la possibilité d'arrêter leurs moteurs, ce qui se traduit par une baisse significative à la fois du bruit et des émissions de carbone; le port de Göteborg estime en effet qu'un navire roulier ne se connectant pas au réseau électrique terrestre 
émet au cours de son escale environ 25 tonnes de dioxyde de carbone, $520 \mathrm{~kg}$ de Nox et $22 \mathrm{~kg}$ de particules. Cette innovation bénéficie ainsi à la fois à l'environnement en termes de changement climatique et à la qualité de vie ou de travail des populations se trouvant sur ou à proximité du port (habitants, dockers, équipage des navires). Afin de s'assurer que l'électricité terrestre fournie aux navires est produite en contribuant le moins possible à la pollution atmosphérique, le port a pris la décision d'utiliser deux éoliennes pour produire l'énergie destinée aux navires. Aujourd'hui un navire sur trois faisant escale dans le port de Göteborg a recours au branchement au réseau électrique terrestre, mais cette proportion a vocation à augmenter. Les navires rouliers et les ferries sont ceux qui utilisent le plus le nouveau système, car les liaisons qu'ils assurent sont très régulières, mais toutes les catégories de navire peuvent bénéficier de cette nouvelle technologie. Afin de se connecter au réseau électrique une adaptation des navires est requise, ce qui a un coût mais peut-être compensé par de probables économies de carburant.

Grâce à ce programme, le port de Göteborg a acquis une position de précurseur technologique dans le domaine du branchement des navires au réseau électrique terrestre. Ce système est également présent dans d'autres ports cependant, comme à Anvers, Zeebruges ou Lübeck dans le Nord-Ouest de l'Europe. A l'échelle mondiale, de nombreux ports mettent en place des systèmes similaires ; un obstacle important à leur diffusion réside toutefois dans la non-harmonisation des normes internationales, certaines régions du monde utilisant des systèmes à $50 \mathrm{~Hz}$ et d'autres des systèmes à $60 \mathrm{~Hz}$. Ce problème freine l'adaptation des navires aux nouveaux réseaux, bien que des tentatives d'harmonisation soient en cours. Du fait de son rôle pionnier sur cette technologie, le port de Göteborg a été choisi comme leader du groupe de travail sur le branchement aux réseaux électriques terrestres mis en place par l'instance de coopération internationale World Port Climate Initiative. Aux côtés des ports d'Anvers, de Hambourg et d'Amsterdam, il cherche ainsi à contribuer à l'élaboration, au partage et à la diffusion d'informations au sujet de cette technologie, en particulier auprès des autorités portuaires, des opérateurs de terminaux et des compagnies maritimes.

\subsection{Gouvernance portuaire métropolitaine}

\section{La régionalisation de la gouvernance portuaire}

En France, la gouvernance portuaire est traditionnellement contrôlée par l'État. Cela s'est formalisé avec la création des Ports Autonomes, entre 1923 et 1965, dans le but de réduire l'influence de l'économie locale, en particulier celle des chambres de commerce. Le rôle fort de l'État a persisté sous un nouveau statut, Grands Ports Maritimes (GPM), crée par la réforme portuaire de 2008, mise en place en 2011. Concernant la planification des nouveaux ports, là aussi l'État a un rôle dominant. Le port à Fos a été à la fois développé, planifié et dirigé par l'État.

Les responsabilités des ports français de petite taille ont été décentralisées dès 2004-2008, mais pas celles des sept plus grands ports, dont Marseille-Fos. La décentralisation de ces ports délègue la gouvernance des ports aux gouvernements locaux, estimant qu'ils ne relèvent pas de l'intérêt national. Cela a généré une riche diversité dans les modèles de gouvernance portuaire au niveau local, avec soit le conseil régional, soit le conseil général, soit la CCI, soit les syndicats mixtes, parfois supportées par la communauté d'agglomération et la ville (Debrie et Lavaud-Letilleul, 2010). Les sept ports maritimes restants sont restés sous le contrôle de l'État, suivant la logique selon laquelle ces ports sont d'intérêt national. Bien qu'en effet les ports de Marseille-Fos et Le Havre aient un rôle majeur en France, ce n'est pas le cas des autres GPM, comme par exemple les ports de Bordeaux et La Rochelle qui n'ont qu'une importance régionale. Or dans ces GPM l'État reste l'acteur dominant, comme c'était le cas des ports autonomes.

Les instances locales de gouvernance sont impliquées dans certains des organes institutionnels du port de Marseille-Fos, mais leur influence reste limitée. Ils sont représentés par le Conseil de Surveillance et le Conseil de Développement du port. 4 des 17 membres du Conseil de Surveillance sont des représentants de ces collectivités territoriales; les autres membres sont soit des représentants étatiques, soit des représentants des employés des entreprises du port et des «personnalités qualifiées ». Bien que l'État ne dispose que de 5 représentants sur les 17 membres totaux, il nomme également les 5 «personnalités qualifiées». Les représentants du gouvernement local au Conseil de Surveillance sont le Conseil Régional, le Conseil 
Général, le SAN Ouest Provence et la Ville de Marseille. A l'inverse d'autres GPM, ce n'est pas l'agglomération urbaine de Marseille (MPM) qui est représentée au Conseil de Surveillance, mais la Ville de Marseille. Les collectivités territoriales sont aussi représentées au sein du Conseil de Développement, mais cet organe n'a qu'une fonction consultative, et non de prise de décision, et ici encore ces représentants sont en proportion inférieurs aux autres membres. En plus d'une représentation faible des instances locales de gouvernance dans les organes de gouvernance portuaire, l'État est l'unique actionnaire des GPM, nomme les directeurs de ces GPM, donne son approbation sur les plans stratégiques de ses ports, et est une source importante de financement des investissements portuaires.

La sous-performance relative du port de Marseille-Fos, comme celle d'autres villes portuaires françaises, est probablement liée au pilotage de la gouvernance portuaire par l'État. Cette question soulève un double problème. Premièrement, le fait que des ports soient contrôlés par l'État pourrait rendre ces ports moins sensibles aux questions locales (comme la création de valeur économique et d'emplois au niveau local, la réduction des impacts environnementaux) en comparaison avec les ports contrôlés par la ville ou les gouvernements régionaux. Deuxièmement, les villes portuaires qui n'ont pas la responsabilité de leur port peuvent s'avérer moins désireuses de créer des conditions favorables au maintien du développement portuaire, sous la forme par exemple d'investissements, de permissions, de planification de zones logistiques ou par la création de corridors de fret. On observe dans ce rapport une stagnation de la croissance portuaire, une valeur ajoutée en provenance du port limitée au niveau local, d'impacts environnementaux importants et très localisés mais peu pris en compte, en plus une interface ville-port conflictuelle où l'on commence juste à observer des effets de synergie. Parmi l'ensemble des facteurs pouvant mener à une telle situation, la gouvernance portuaire est sans aucun doute l'une des explications.

\section{La gouvernance métropolitaine à Marseille}

Le développement de la ville portuaire de Marseille a lieu dans un contexte de relations métropolitaines très fragmentées et polarisées. Si la France est un pays caractérisé par des institutions complexes et fragmentées, le cas de Marseille l'est d'autant plus. Alors que dans la plupart des villes françaises, comme à Lille ou à Lyon, la création de la communauté urbaine a permis depuis 1966 d'achever une certaine forme de coordination métropolitaine, ce nouvel instrument n'existe à Marseille que depuis 2001 et reste très limité, considérant que la communauté urbaine de Marseille (Marseille Provence Méditerranée) n'est qu'un des nombreux acteurs de la zone métropolitaine Marseillaise. Si l'on considère la zone métropolitaine fonctionnelle, mesurée en termes de relations économiques entre villes, cette zone comprend alors également six structures intercommunales supplémentaires: la communauté d'agglomération du Pays d'Aubagne, Pays d'Aix, Pays de Martigues, Salon-Étang de Berre-Durance et SAN Ouest-Provence-Istres, Arles Crau Camargue Montagnette. Les relations entre ces intercommunalités et MPM sont polarisées, hantées par des controverses passées, par exemple la décision d'imposer un incinérateur à Fos-sur-Mer.

Une telle fragmentation institutionnelle a des conséquences sévères pour le développement de la métropole portuaire. La planification de l'activité économique est fragmentée et souvent mal coordonnée, comme on peut le voir dans l'établissement de plusieurs schémas de cohérence territoriale (SCoT). Ces SCoTs donnent naissance à une liste de projets, souvent cloisonnés, préservant au mieux les intérêts des «parties prenantes». Le découpage de la décision en multiples lieux, secteurs, projets et sujets rend très difficile l'élaboration d'une ligne politique d'ensemble pour accroitre la capacité de transformer le port de Marseille-Fos en axe prioritaire de transport. La Chambre de commerce et d'industrie Marseille Provence souligne l'importance pour le San Ouest Provence et la Communauté d'Agglomération du pays de Martigues de réfléchir au-delà du périmètre administratif du Schéma de Cohérence Territoriale en renforçant le dialogue et la coopération avec les territoires voisins, notamment Marseille Provence Métropole. Force est de reconnaître que les initiatives pour rédiger des inter-SCOT à l'échelle métropolitaine dans le but d'accroître la compétitivité de la ville-port à l'échelle européenne présentent des 
succès mitigés. Cela entrave la création de synergies entre les différents secteurs économiques. De plus, divers challenges métropolitains restent non résolus, tels que le transport urbain, l'habitat, l'emploi, la pauvreté et le crime en milieu urbain, ce qui limite l'attractivité de la zone, déjà en déficit d'entreprises à forte valeur ajoutée et de sièges de direction dans le secteur maritime et le commerce international.

Les mécanismes de coordination métropolitaine basés sur la coopération peuvent difficilement venir à bout d'une telle fragmentation. La culture du ressentiment, la courte expérience de collaboration et le manque de positions stratégiques communes rendent la structure gouvernementale actuelle propice à la stagnation. Des mécanismes similaires ont pourtant fonctionné dans une métropole portuaire française relativement comparable à Marseille : Nantes St. Nazaire. Cependant ce succès s'explique à Nantes par des facteurs qui n'existent pas à Marseille : une longue tradition de coopération, des acteurs faisant tous partie de la même famille politique, un engagement commun envers l'idée métropolitaine et un besoin partagé de développer des solutions intermodales afin de résister à la compétition du port Le Havre (Encadré 10).

\section{Encadré 10. Les mécanismes de concertation entre le port de Nantes Saint-Nazaire et les collectivités territoriales}

Nantes Saint-Nazaire est devenu depuis la réforme de 2008 un Grand Port Maritime, dont l'unité de gestion remonte à 1965. II possède donc le même statut juridique que celui de Marseille-Fos, celui d'Établissement public à caractère industriel et commercial, placé sous la tutelle du Ministère de l'Écologie, du Développement Durable et de l'Énergie. Si le port de Nantes Saint-Nazaire est placé sous l'autorité de l'État, il n'en demeure pas moins que ses relations avec les collectivités locales sont de plus en plus placées sous le signe de l'interdépendance, notamment en raison du processus de décentralisation, au cours duquel ces dernières ont acquis de nouvelles compétences. Or, tout comme à Marseille, les infrastructures portuaires s'étendent sur plusieurs communes, distantes d'une soixantaine de kilomètres l'une de l'autre pour les plus éloignées. En effet, les plateformes portuaires principales sont réparties entre Saint-Nazaire, Montoir-de-Bretagne, Donges et Cordemais, complétées par des terminaux plus petits, tel que celui de Nantes-Cheviré. Bien que $90 \%$ du trafic ait lieu dans la zone aval, en particulier pour l'énergie, qui représente $70 \%$ du trafic total, et qui est majoritairement traitée à Donges, la question de la concertation avec les collectivités locales se pose vivement. Ainsi, comment assurer une concertation et une coopération efficaces lorsque l'aire métropolitaine de Nantes Saint-Nazaire regroupe plus de 100 communes, et qu'elle est divisée entre la communauté urbaine de Nantes - devenue Nantes Métropole en 2004- et la communauté d'agglomération de la région nazairienne et de l'estuaire (CARENE), toutes deux créées en 2001 ?

Face à la multiplicité des échelons locaux en interaction avec le port, ceux-ci ont mis en place des mécanismes facilitant le dialogue avec l'autorité portuaire. La coopération politique entre les différentes entités a commencé en 1962 avec la création de la «métropole d'équilibre » de Nantes Saint-Nazaire par l'État. Celle-ci a été renforcée en 1970 par la mise en place du Schéma directeur de l'Aire Métropolitaine (SDAAM). Jusqu'à cette période, les relations entre Nantes et Saint-Nazaire ont été caractérisées par une relative rivalité plutôt que par une coopération, et les tentatives de rapprochement ont été le fruit de l'État plutôt que des acteurs locaux. A partir de 1985, avec la création de l'ACEL (Association Communautaire de l'Estuaire de la Loire), les collectivités locales, ont profité du processus de décentralisation pour renforcer leur rôle dans la coopération. L'ACEL est un outil de débat et de concertation, qui regroupe aujourd'hui les collectivités territoriales telles que la Région Pays de la Loire, le Département de LoireAtlantique, Nantes Métropole, la CARENE, ainsi que les Chambres d'industrie de Nantes et Saint-Nazaire, le port autonome et l'union maritime Nantes Port (union des entreprises présentes sur le port), afin de dégager des positions communes sur les enjeux d'aménagement du territoire.

La création de l'ACEL souligne la mise en évidence de problèmes communs et la volonté politique de dessiner une vision commune du territoire s'illustre également dans la mise en place en 2007 du Scot (Schéma de Cohérence Territorial), élaboré par un syndicat mixte composé de 107 élus. Ce document d'urbanisme donne des orientations générales, qui sont ensuite appliquées au niveau des intercommunalités et des plans locaux d'urbanisme. Ces deux instances montrent donc la volonté politique de concertation et de cohérence territoriale, non seulement au sein des collectivités publiques, mais également avec d'autres acteurs.

Cependant, cette volonté politique de concertation, si elle est clairement affichée dans le discours dominant, est à relativiser. En effet, le périmètre du Scot est beaucoup moins étendu que celui du SDAAM ; ainsi, une partie de la zone sud-Loire n'est pas incluse, témoignant de crainte identitaires de certaines collectivités territoriales, d'une appréhension face aux villes conquérantes et de divergences politiques. En outre, il faut prendre en considération la couleur politique des principales collectivités territoriales de la région. En effet, depuis 2004, le département de Loire- 
Atlantique, la Région des Pays de a Loire, tout comme Nantes Métropole et la CARENE sont dirigées par le PS.

Toutefois, à la différence de Marseille, la métropolisation de Nantes Saint-Nazaire demeure un projet politique très ancré dans les discours. Si la métropole de Nantes Saint-Nazaire n'est pas une réalité officielle, les élus ont cependant accepté la création d'un pôle métropolitain. . Ainsi le syndicat mixte du Scot s'est transformé en pôle métropolitain en juillet 2012. Si le pôle métropolitain, en tant qu'outil de coopération, est plus souple et plus limité en compétences que la métropole, qui est un outil d'intégration, il témoigne d'une volonté de continuer sur la voie de la concertation afin d'offrir un discours politique cohérent face à l'autorité portuaire.

Les acteurs politiques locaux soulignent l'importance de partager une vision commune des défis que représentent la concurrence du Havre, la connexion à l'arrière-pays ainsi que le développement de l'intermodalité. Pour ce faire, des mécanismes existent : tout d'abord les collectivités territoriales, en partenariat avec le port, devenu en mai 2011 l'exploitant de son réseau ferré, tentent de développer une infrastructure coordonnée au trafic en privilégiant les relations interrégionales. Ainsi, elles promeuvent une liaison ferroviaire de Lorient à la Rochelle, ce qui améliorerait les relations entre le Port de Nantes Saint-Nazaire et son arrière-pays et permettrait la croissance du fret ferroviaire, car aujourd'hui seul 1,5 Mt de trafic transite par le fer. Le deuxième mécanisme de coopération est centré sur la réflexion autour de l'intermodalité. Ainsi, l'ACEL a créé la signature Nantes Atlantic Logistics, une zone foncière de 120 hectares en zone portuaire, à l'embouchure de l'estuaire, à proximité de Montoir-de-Bretagne. Cette zone, désignée par l'autorité portuaire comme un exemple unique d'intermodalité, englobe la plateforme logistique $2 \mathrm{LE}$ (logistique Loire Estuaire), qui regroupe à la fois du maritime (bord à quai), du fluvial (pour remonter les barges à Nantes sur les $68 \mathrm{~km}$ de l'estuaire), du ferroviaire, du terrestre et de l'aéroportuaire (avec l'aéroport de Gron dédié au fret).

\section{Encadré 11. Métropolitanisation et le rééquilibrage de multiples sites portuaires ; le cas de Auckland}

Située sur un isthme étroit très urbanisé, Auckland est une ville aux sites portuaires multiples. Ses nombreux ports constituent un des piliers centraux de l'économie de la Nouvelle Zélande, pays insulaire au milieu de l'océan pacifique : en 2011, on estime que l'activité économique générée par les ports d'Auckland (import, export, et son activité propre) représentait quelques 21 milliards de dollars néo-zélandais en valeur ajoutée, soit $16 \%$ du PIB (ME 2011). Ainsi, la bonne coordination de ces multiples sites portuaires constitue un enjeu majeur pour la ville comme pour le pays. Or, les premiers travaux de réclamation, à l'origine des formes embryonnaires de sa structure portuaire contemporaine, ont été réalisés pendant l'entre deux guerres, bien avant que la ville ne devienne une véritable métropole, avec une population de 1,3 million d'habitants en 2007, et avant l'arrivée des nouvelles technologies de conteneurisation, qui ont totalement changé les besoins et la trame logistiques de la ville. Pendant la deuxième moitié du 20 ème siècle, la croissance urbaine (et surtout l'étalement résidentiel), couplée aux changements technologiques dans l'industrie maritime, ont accentués le déséquilibre existant entre les différents ports d'Auckland, de moins en moins adaptés au contexte spatial et économique moderne. L'enchevêtrement des acteurs portuaires et urbains, tous compétents sur un aspect différent des ports et agissant à des échelles variées, a contribué à un déficit de planification stratégique et coordonnée, rendant la situation plus dysfonctionnelle encore. Cependant au cours des années 2000, suite aux évolutions dans la gouvernance urbaine et portuaire, la ville va reprendre le contrôle de l'interface ville-port, dynamisant et rééquilibrant l'activité de ses multiples sites portuaires.

Au cours des années 1980, l'inadaptation de la morphologie portuaire d'Auckland est de plus en plus manifeste. Divisée entre une petite gare maritime liée au centre-ville au centre, un port commercial (conteneurs et marchandises diverses) à l'est, et un mélange d'activités pétrochimiques, de port de plaisance, d'industrie de la pêche, et de petites opérations de fret sous performantes à l'ouest, la ville se trouve alors face à un déséquilibre dans son espace portuaire fonctionnel. Ce déséquilibre consistait notamment en une asymétrie contreproductive entre un site est, relativement protégé de la croissance urbaine par la limite fixée par une autoroute et par la possibilité d'extensions futures vers l'est, et un site ouest, dont les activités commerciales et industrielles étaient davantage coupées du port commercial à l'est, et étaient en conflit constant avec l'expansion du tissu urbain. La gare maritime centrale, quant à elle, servait de simple point de passage pour les navetteurs travaillant dans le centre-ville, mais ne contribuait nullement au marché local du quartier sud du centre-ville (le 'downtown'), un secteur riverain sous-exploité depuis la relocalisation du commerce de détail vers le quartier nord du centre-ville. Jusqu'en 1988, le mode de gouvernance qui régie les ports de la ville est celui du Auckland Harbour Board, constitué d'un conseil dont les membres sont élus pour un mandat de trois ans. Voulant dynamiser leur productivité, le parlement néo-zélandais a décidé en 1988 de corporatiser les ports d'Auckland, en créant la corporation Ports of Auckland Limited (POAL), afin d'acheter les terrains et les actifs du Harbour Board. Les actions ont alors été mises sur le marché : le conseil régional d'Auckland devient détenteur de $80 \%$ de ces actions et le conseil régional de Waikato de $20 \%$. En 1993, le conseil régional de Waikato 
décide de vendre ses actions, permettant ainsi à la région d'Auckland de les racheter, et, en 2005, de les retirer du cours de la bourse néo-zélandaise.

Cette concentration de la gouvernance du port au niveau régional a permis la mise en place des premiers éléments de réponse à l'asymétrie est-ouest dans les ports d'Auckland. Durant les années 1990, la corporation POAL entreprend une démarche qui altère la morphologie portuaire de manière fondamentale : elle cède aux collectivités d'Auckland la moitié de ses actifs et de ses terrains (soit 70ha) situés à l'ouest de l'espace portuaire. La stratégie des acteurs portuaires et des collectivités d'Auckland pendant cette période consiste en trois éléments : 1) la consolidation des activités de fret dans la zone est, à travers de grands projets de dragage et de réclamation, et par un usage plus intensif des quais du port commercial ; 2) l'ouverture des terrains industriels et commerciaux de la zone ouest aux usages urbains, en reconvertissant certaines zones en espaces publics, et en en vendant d'autres à des développeurs privés ; et 3) la transformation du petit port central en une gare maritime de calibre mondial, avec un port de croisière agrémenté d'un hôtel Hilton, dans le but de stimuler directement le commerce de détail dans le quartier sud du centreville lié au port.

Parallèlement à la régionalisation du contrôle des ports et à la mise en œuvre de cette stratégie de rééquilibrage, la ville d'Auckland a progressivement consolidé sa propre structure de gouvernance métropolitaine, renforçant ainsi la tendance vers une meilleure coordination des sites portuaires. Jusqu'en 2010, le système de gouvernance d'Auckland était composé d'un conseil régional, de trois conseils provinciaux, de quatre conseils municipaux et d'une trentaine de conseils communautaires [community boards]. En termes de planification urbaine, ce millefeuille néo-zélandais se traduisait par quinze plans provinciaux et municipaux, dont deux visant à gouverner l'espace frontalier entre le port et la ville. C'est alors que le "Conseil d'Auckland" a été crée en 2010. Constitué par une fusion de la région, des conseils provinciaux, et des conseils municipaux d'Auckland, le nouveau conseil remplace tous les acteurs précédemment cités par un seul acteur métropolitain. II est doté de forts pouvoirs de planification, d'un unique Masterplan pour la ville, de $100 \%$ des actions de la POAL, et d'une agence de développement chargée de la reconversion du waterfront, (sites portuaires à l'ouest et au centre). Ce nouvel acteur métropolitain fort de compétences et d'une vision claire et intégrée du développement d'Auckland a permis d'éviter une situation de concurrence entre les différents sites portuaires et les différentes municipalités auparavant compétentes de sa planification. Non seulement cette métropolitanisation a-t-elle contrecarré la tendance vers une fragmentation inefficace de l'espace urbano-portuaire, mais, en outre, elle a rendu plus simple les interactions entre les pouvoirs publics d'Auckland et les acteurs privés, en permettant une planification stratégique fiable sur le long-terme.

Revenant aux trois axes stratégiques du rééquilibrage des ports d'Auckland, le bilan s'avère encourageant. Tout d'abord, le port commercial à l'est va très probablement accroître sa capacité de plus de $250 \%$ d'ici 2015 , et sa stratégie de consolidation des activités commerciales est une réussite. Désormais, toute extension (dragage ou réclamation) se fera sur une trajectoire allant vers l'est. Ensuite, la reconversion des sites à l'ouest semble elle aussi réussie. Tout en conservant sa fonction de port de plaisance et les activités économiques liées à la pêche, les sites portuaires situés à l'ouest d'Auckland se sont largement ouverts au public. L'accès public est désormais assuré par un bon maillage de voies publiques, l'héritage maritime a été mis en valeur, et les habitants utilisent ces espaces reconvertis pour sociabiliser, travailler et habiter. Enfin, le port central a été intégré à un projet d'aménagement du quartier "downtown ", qui connaît un renouvellement de son tissu de commerces de détail. La rue principale du centre-ville a été reliée à l'axe majeur de la gare maritime, qui est équipée d'un nouveau port de croisière, contribuant de manière significative au marché touristique du quartier.

Ainsi, grâce à la synergie entre la planification urbaine, d'une part, et celle des ports centraux et occidentaux, d'autre part, la croissance urbaine ne constitue plus un facteur aggravant du clivage est-ouest de l'espace portuaire d'Auckland. La concentration au niveau métropolitain des compétences en planification et en aménagement de la ville et de ses ports a permis d'éviter la fragmentation interportuaire induite par une gouvernance trop complexe et enchevêtrée. En liant les intérêts du port aux intérêts de la ville en tant que métropole, les reformes de la gouvernance de la ville portuaire d'Auckland ont permis une concentration des opérations commerciales dans la zone est, au profit d'une redynamisation du centre et d'une reconversion de l'ouest.

Afin d'améliorer cette situation, l'État a proposé une forme de gouvernement métropolitain pour Marseille. La forme exacte n'est pas encore définie, mais l'idée de fond est de créer une seule agglomération, constituée de plusieurs pôles à l'égard de la diversité et de la complexité du territoire et des identités locales. Les responsabilités éventuelles qui ont été identifiées sont le transport urbain, l'environnement, le développement économique, l'éducation supérieure et la transformation urbaine (Premier Ministre, 2012). Les éléments mentionnés pour une stratégie métropolitaine incluent l'accélération des transformations du port, le désengorgement du transport urbain, et visent des projets liés 
à l'éducation, l'éducation supérieure et la recherche, la transformation urbaine et le soutien aux entreprises. L'État, comme les collectivités, tient à supporter certains projets portuaires, tels que la réouverture du chantier de réparation navale «Forme 10 », le terminal intermodal de Marseille-Mourepiane et l'amélioration des connexions de Fos aux routes de l'arrière-pays. Le renforcement du gouvernement métropolitain de Marseille pourrait certainement être bénéfique pour la ville portuaire, mais également améliorer l'articulation des intérêts portuaires vis-à-vis des collectivités territoriales, ce qu'illustre le cas d'Auckland (Encadré 11).

Une structure de gouvernement métropolitain doit aller de pair avec une réflexion sur une gouvernance portuaire davantage régionalisée. Il est évident qu'un organe du gouvernement métropolitain ferait un candidat logique pour faire partie de différents organes portuaires, comme le Conseil de Surveillance et le Conseil de Développement. Mais l'implication des autorités métropolitaines de Marseille pourrait aller plus loin. En tenant compte du rôle stratégique que le port de Marseille-Fos joue dans l'économie nationale, et en tenant également compte du rôle clé que l'État français joue afin de faciliter tout en limitant le développement du port et de l'arrière pays, il serait difficile d'imaginer un modèle de gouvernance portuaire sans une implication de l'État. Même dans les villes portuaires hanséatiques avec une longue tradition d'implication des autorités locales dans les activités portuaires, les gouvernements nationaux jouent un rôle clé dans le développement d'une infrastructure et d'une planification en lien avec le port. Cependant, pour résoudre en profondeur certaines difficultés auxquelles la ville portuaire de Marseille fait face concernant la création locale à valeur ajoutée ainsi que l'atténuation des impacts négatifs, une réflexion sur une gouvernance portuaire plus régionalisée doit être envisagée. Cela pourrait prendre la forme d'un système de responsabilités partagées entre un gouvernement métropolitain et l'État. 


\section{ANNEXE 1 : ACTEURS INTERROGÉS}

\begin{tabular}{|c|c|}
\hline M. ARDITI & Syndicat des transitaires \\
\hline M. BABRE & Sous-préfet d'Istres \\
\hline M. BALLADUR & Président de l'Union maritime (UMF) \\
\hline Mme BARDIN & Cluster PACA Logistique \\
\hline M. BEAULIEU & LTM \\
\hline Mme BENOIST & Cabinet CAPM \\
\hline M. BERIDOT & Conseil Général 13 chef du service aménagement et urbanisme \\
\hline Mme BONNARD & CMA-CGM \\
\hline M. CAMBESSEDES & Premier adjoint au Maire de Martigues \\
\hline M. CHARRIER & Maire de Port-Saint-Louis-du-Rhône et conseiller général \\
\hline M. CHARROUX & Président de la Communauté d'Agglomération du Pays de Martigues \\
\hline M. CLAUDE & SNCF Fret \\
\hline M. COUSQUER & Rapporteur du Conseil de Surveillance du GPMM sur les Bassins Est \\
\hline Mme DOUADY & Ville de Marseille, directrice de l'attractivité économique \\
\hline M. FERRARI & SAN, élu à l'économie \\
\hline Mme FOSSATI & Directrice du développement économique CAPM \\
\hline M. FRISON & Groupement des Industriels \\
\hline M. GARNIER & CMA-CGM \\
\hline M. GARNIER & Professeur d'Économie \\
\hline M. GROLLEAU & Transcargo \\
\hline M. GROSJEAN & Ville de Marseille, direction de l'attractivité économique \\
\hline M. HAUTERAT & Carfos \\
\hline M. HEDELIN & Eurofos \\
\hline M. HENRY & MedEurope Terminal \\
\hline
\end{tabular}




\begin{tabular}{|c|c|}
\hline M. JALINOT & Directeur Euroméditerranée \\
\hline M. LATIL D'ALBERTAS & MPM, Directeur de pôle Économie et attractivité du territoire \\
\hline M. LIAUTARD & Greenmodal \\
\hline M. LODOVICCI & Élu à l'économie la Communauté d'Agglomération du Pays de Martigues \\
\hline M. MADELENAT & Wilhelmsen \\
\hline M. MAHE DES PORTES & Président de MGI \\
\hline M. MALIVERNEY & Logirhône \\
\hline M. MARCHAND & Marseille Provence Métropole DGA \\
\hline M. MARCHETTI & Transmavin \\
\hline J. MASSONI & Directeur du MPCT \\
\hline M. MAURY & Provence promotion \\
\hline M. MATAR & TLF Méditerranée \\
\hline M. MAZZETTI & Transitaires \\
\hline M. MOIROUX & L'agence d'urbanisme de Marseille direction des études \\
\hline M. MOREL & Conseiller régional PACA \\
\hline M. NOYES & Conseil Général 13 conseiller général \\
\hline M. PAYAN & Union Française des Industries Pétrolières (UFIP) \\
\hline M. PFISTER & Président de la CCI de Marseille-Provence \\
\hline M. PONCHON & Port d'Arles \\
\hline M. QUENIAT & Lyon Terminal \\
\hline M. RAIMONDI & Maire de Fos \\
\hline M. REVERCHON & Président du Conseil de Développement du GPMM \\
\hline M. RIZOULIERES & Institut d'Études Politiques d'Aix-en-Provence \\
\hline M. SEMERDJIAN & Provence promotion \\
\hline M. SPAZZI & Directeur de l'aménagement du GPMM \\
\hline M. TAILLANDIER & DGA CG13 \\
\hline
\end{tabular}


M. TERRIER

M. THOMAS

M. TOUZE

M. TRUAU

M. VALETTE

M. VAN DEN HOOGEN

M. VIDIL

Marfret
Président du directoire GPMM

SAN, directeur du développement économique

Marseille Provence Métropole pôle Économie et attractivité du territoire

Président du Club de la Croisière

Conseiller municipal délégué à l'urbanisme et président de l'agAM

AACN 


\section{ANNEXE 2: EFFICACITÉ PORTUAIRE}

L'efficacité portuaire en terme de temps est définie dans ce rapport comme le temps moyen passé par un navire dans le port avant de repartir vers un autre port. Le temps passé dans le port est connu grâce aux données détaillées de mouvements de bateaux. Il est considéré comme un équivalent à l'efficacité temps, sachant que la majorité des escales impliquent des actions de chargement ou de déchargement de marchandises. Des délais très courts de temps passé dans le port sont souvent associés au ravitaillement des navires, tandis que des escales très longues peuvent être attribuées à des travaux de réparation, entre autres. C'est pourquoi les séjours très courts (de moins d'une heure) et très longs (plus de 10 jours) ont été exclus de la base de données, afin d'accroître la probabilité que ces données reflètent l'efficacité temps et non d'autres variables et cas isolés.

Les données utilisées sont les mouvements des bateaux, collectées par le Lloyd's Maritime Intelligence Unit (LMIU) en 2011. Les données se limitent au mois de mai ; ce mois est considéré comme un mois de référence par la Lloyd's Maritime Intelligence Unit. La base de données contient, pour la majorité des navires, des données sur les horaires précis de départ et d'arrivée (en heures et en minutes). En observant les escales des porte-conteneurs intégraux (plus grands que $100 \mathrm{gt}$ ), on a exclu de l'étude les cas où soit les données d'arrivée, de départ, soit les deux ensembles étaient manquantes, ainsi que les valeurs extrêmes pouvant affecter les résultats ; c'est-à-dire les escales de durées inférieure à une heure ou supérieure à 10 jours. Cette étude exclut également les canaux et voies stratégiques, ainsi que les localités non portuaires (par exemple, les pays, continents, mers, détroits etc.) Enfin, certains ports/terminaux associés ont été agrégés (par exemple, le Port Botany et Sidney).

Afin de définir le temps total passé par un navire dans un port spécifique, des mesures moins précises (en jours, et non en heures et minutes) ont été ajoutées pour palier aux valeurs manquantes dans la base de données. Cela a été nécessaire, sachant que pour certains ports, très peu de données temporelles précises étaient disponibles, remettant en cause la précision de leur analyse. Concernant ces valeurs manquantes, il est admis que le temps d'escale pour les navires arrivant et repartant le même jour est de 12 heures, de 36 heures pour ceux repartant le lendemain, de 50 heures pour ceux restant 2 jours dans le port, etc.

L'indicateur de production principal utilisé est la différence moyenne entre la « date d'arrivée » et la « date de départ » reportée par le port et par les navires (en nombre de jours). Cette moyenne est calculée en divisant le temps total passé dans un port par un navire (multiplié par un coefficient de 89/31 afin d'estimer le temps du deuxième trimestre, et non juste pour le mois de mai) par le volume des rendements du port en TEU au deuxième trimestre de 2011, d'après Eurostat. Les données du second trimestre 2011 ont été utilisées afin de correspondre le plus possible avec les données du LMIU pour mai 2011. 


\section{ANNEXE 3: EFFICACITE DES PORTS PETROLIERS}

Dans ce rapport l'efficacité des ports pétroliers est analysée à l'aide de la technique d'Analyse d'Enveloppement des Données (AED). Cette méthode empirique dérive les scores de productivité de chaque unité de décision impliquée dans le processus homogène de production, tels que les entreprises et les ports maritimes. Un port performant est défini comme un port ayant un débit maximal, considérant un niveau d'input égal à tous les ports (décisionnaires efficaces en termes de sortie), ou un port avec une quantité d'input minimale pour un débit donné (décisionnaires efficaces en termes d'entrées). La limite d'une production efficace est déterminée par un ensemble de décisionnaires qui constituent le point de référence de la majorité des ports maritimes performants. Les gains potentiels pour les ports les moins efficaces (par exemple qui se situent en dessous de la limite de production efficace) sont mesurés en fonction de leur distance, à la fois en termes d'entrées et sorties, vis à vis de la limite de productivité. Cette méthode est largement utilisée dans la littérature récente ${ }^{67}$

L'approche AED comporte des avantages mais a aussi des limites. Concernant les avantages, AED n'impose aucun forme fonctionnelle à la fonction de production, ni à la forme des rendements d'échelle (i.e. non paramétrique), notamment lors de l'utilisation d'une fonction de production Cobb Douglas. Pour les ports maritimes en particulier, il est très difficile de deviner ou d'imposer des rendements d'échelles croissants ou décroissants. Une autre propriété utile de l'AED est qu'il permet de traiter plusieurs processus de sortie à la fois, tout particulièrement concernant les ports aux activités variés, et dans les cas où on observe un certain degré d'homogénéité dans les processus de production de plusieurs ports. Cependant l'AED a aussi des inconvénients, dont sa nature déterministe, qui ne permet pas de séparer les erreurs aléatoires, liées aux bruits ou aux calculs, des mesures de pure inefficacité. ${ }^{8}$ Cependant, l'intégration de la technique de bootstrap ${ }^{9}$ de Bonilla (2000) et Barros (2007) peut limiter cet effet.

Cette technique d'échantillonnage permet de produire une distribution stochastique et des intervalles de confiance autour des estimations (Simar et Wildon, 2000). Les estimations d'efficacité qui dérivent de cette technique sont souvent plus faibles qu'avec la technique AED qui utilise un échantillon standard. De plus, les ports efficaces atypiques (caractérisés par une faible densité des observations situés à la frontière) sont caractérisés par de plus hauts degrés d'incertitude. Cependant l'efficacité reste une mesure relative, qui dépend des ports maritimes et des inputs choisis, et donc la moindre omission peut affecter les résultats finaux. Un échantillon excluant des ports maritimes potentiellement efficaces, ou incluant des cas isolés, entrainerait respectivement un transfert vers le bas/ vers le haut de la limite de productivité, et impacterait (vers le haut/ vers le bas) les scores relatifs de productivité. De même, l'omission de facteurs de production, ou leur inclusion dans les valeurs non documentées (zéro ou non disponible), pourrait générer de plus haut scores de productivité pour les ports qui utilisent une grande quantité de ces facteurs de production, ou pour ceux produisant «sans » facteur de production.

Il existe trois types d'efficacité qui peuvent être distingués : i) l'efficacité globale, ii) l'efficacité technique, et iii) l'efficacité d'échelle.

i) L'efficacité globale. Cet indicateur général, qui dérive d'un model supposant es rendements d'échelle constants, fournit une mesure de l'efficacité globale du port. Cet indicateur AEDCCR, développé par Charnes, Coopers et Rhodes (1978), suppose que toutes les combinaisons de facteurs production peuvent être ajustées, à la hausse comme à la baisse. 
On considère que la variation de la taille de la production ou de l'échelle n'a pas d'impact sur le score d'efficacité, ce qui signifie que les petits ports comme les ports plus larges ont les mêmes capacités d'efficacité. Des ports efficaces le sont à la fois au niveau de l'efficacité technique et de l'efficacité d'échelle. Inversement, l'inefficacité (le différentiel d'efficacité mesuré en pourcentage, avec comme base les scores des ports les plus performants) reflète à la fois l'inefficacité technique et l'inefficacité d'échelle.

ii) L'efficacité technique. L'efficacité technique pure est estimée en assouplissant les contraintes d'efficacité d'échelle, permettant aux rendements de varier de façon disproportionnée avec l'accroissement marginal des facteurs de production. Cet indicateur AED-BCC, développé par Banker, Charnes et Cooper (1984), dérive d'un model supposant des rendements d'échelle variables, et reconnaît que les ports de plus petite taille peuvent être désavantagés à cause des effets d'échelle de production (Cheon, 2008). En prenant en compte et en neutralisant ces inefficacités d'échelle, les différentiel d'efficacité entre ports témoignerait donc uniquement des différences d'inefficacité opérationnelles, aussi appelées inefficacité technique.

iii) Les inefficacités d'échelle. Les déséconomies d'échelles surviennent quand l'échelle de production n'est pas appropriée, ou inférieure au niveau optimal, générant ainsi des pertes de production. Formellement, on les observe quand il y a une différence entre l'efficacité au niveau technique et celle au niveau global, mesurée selon le ratio suivant ${ }^{10}$

\section{$\mathrm{SE}=\mathrm{CRS} / \mathrm{VRS}$ et où $\mathrm{SE}<1$}

Dans cette équation, CRS et VRS désignent les estimations d'efficacité dérivées respectivement de rendements d'échelle constants et variables. Quand $\mathrm{SE}<1$, les ports font face à une déséconomie d'échelle, ayant une inefficacité globale en comparaison avec l'efficacité technique pure. En revanche, quand $\mathrm{SE}=1$, les ports fonctionnent à une échelle efficace, produisant au niveau optimal. Cependant, la direction appropriée des ajustements d'échelle peut être déterminée seulement suivant la nature des rendements, qui peuvent être croissants (REC) ou décroissants (RED). Pour les ports fonctionnants à REC (le rendement croit plus vite proportionnellement aux facteurs de production utilisés), le niveau de production devrait augmenter. C'est habituellement le cas des ports qui fonctionnent en dessous du niveau optimal tant que leur trafic commercial reste inférieur à la capacité optimale des infrastructures portuaire. En revanche, quand les ports fonctionnent à RED (le rendement croît proportionnellement moins vite que les facteurs de production utilisés), ils doivent réajuster leur production vers des niveaux plus bas pour limiter l'inefficacité liée, entre autres, à l'engorgement. Dans une perspective sur le long terme, cependant, il faudrait également considérer la solution alternative d'une hausse du niveau optimal de production par des investissements dans des infrastructures portuaires ayant plus de capacité.

Il est crucial d'identifier et de définir les variables d'entrée et de sortie appropriées. Ces variables doivent rendre compte des principaux objectifs du port, ici la maximisation du volume de fret et de la productivité tout en utilisant efficacement les infrastructures et les équipements. D'après la théorie économique, le rendement mesuré par l'exploitation de volumes de fret (chargé/déchargé) dépend également des facteurs de production travail et capital. Dans la littérature sur le port, le facteur travail est perçu comme le plus problématique, à cause d'un manque de comparabilité et de fiabilité des données. L'une des raisons principales est que l'organisation du travail portuaire est complexe, avec différents types de contrats à temps-plein et temps-partiels, et de contrats gérés partiellement par le privé, le public et les autorités portuaires, ce qui rend difficile de collecter des données complètes. Les intermédiaires sont souvent pris comme argument pour débattre que le facteur travail est habituellement corrélé négativement avec le matériel : le matériel est ainsi considéré comme un substitut pour le facteur travail. Ainsi, dans cette étude, le volume de matériel de chargement/déchargement, de bateau à quai et de quai à bateau, a été 
collecté dans les terminaux de pétrole brut de chaque port. Le facteur de production capital, d'autre part, sont plus facilement disponible tant qu'ils concernant les terrains et les infrastructures. Il inclut principalement la surface du terminal, la longueur du quai ou encore la capacité de stockage.

Cette étude utilise une nouvelle base de données de sortie, basé sur une mesure du volume de rendement : le nombre de navires agrégés en tonnes métriques accostant à un port donné. Ces données peuvent être obtenues à partir de bases de données compréhensives existantes sur les mouvements des navires, qui incluent des informations détaillées sur les types de navire (dont le volume), ainsi que sur les horaires d'arrivée et de départ aux différents ports. Cette approche suppose que le volume d'un navire accostant à un port est corrélé avec le nombre de tonnes métriques chargé où déchargées de ce navire. Cette supposition est particulièrement importante pour les catégories de chargements délivrés en lots, tel que le pétrole brut. La disponibilité des informations de la base de données sur les différents types de navire, dont les transporteurs de pétrole brut, rend possible de calculer le volume de navires agrégés par port, pour le pétrole brut. Bien que «total de tonnes métriques accostant au port» (la mesure de rendement) ne soit pas parfaitement corrélée avec le débit effectif, cette mesure n'est pas plus imparfaite que ce débit reporté directement en tonnes métriques.

Pour les besoins de cette étude, une base de données a été constituée pour analyser l'efficacité portuaire de ports mondiaux à des niveaux d'activité agrégés et désagrégés, rassemblant les données disponibles les plus récentes possible (2011). La majorité des données sur les facteurs de production proviennent du Port of the World 2011 Yearbook de Lloyds, tandis que les données sur les rendements et outputs proviennent de la base de données compréhensive sur les mouvements des navires de la Lloyd's Marine Intelligence Unit (mai 2011). Étant donné les limites fixées par les données et la méthode AED, plusieurs agrégations/approximations ont été faites afin d'évaluer la fiabilité des résultats.

Cet échantillon inclut 71 ports mondiaux majeurs. La configuration régionale révèle un déséquilibre dans la distribution des terminaux dans le monde. Environ deux tiers des ports pétroliers de l'échantillon sont concentrés en Asie (dont 34\% dans l'Asie du Sud-est, et 24\% en Asie du Sud et de l'Ouest), tandis que le reste des ports sont situés en Europe et en Amérique du Nord (représentant respectivement 24\% et $10 \%$ de l'échantillon total). Tableau 12 montre les variables d'entrée spécifiques à l'échantillon de ports pétroliers. Les variables liées au capital sont substituées par la capacité des terminaux à accueillir les navires pétroliers, incluant la longueur du quai/ de la jetée, la capacité maximum des navires, le tirant et la profondeur des canaux, et la capacité de stockage des pétroliers. La variable travail est ici substituée par la capacité de chargement des équipements, mesurée par le taux de déchargement (tonne/heure), et la capacité des organes de conduite et de chargement.

Table 12. Statistiques descriptive des variables d'entrée/sortie de l'échantillon de ports pétroliers (brut)

\begin{tabular}{|c|c|c|c|c|c|c|c|}
\hline Oil terminal sample & $\begin{array}{r}\text { Output May } \\
2011\end{array}$ & Quay length & $\begin{array}{r}\text { Max vessel } \\
\text { capacity } \\
(\mathrm{dwt}) \\
\end{array}$ & $\begin{array}{r}\text { Max } \\
\text { draught/dept } \\
\mathrm{h}\end{array}$ & $\begin{array}{r}\text { Tank } \\
\text { storage } \\
\text { capacity } \\
\end{array}$ & $\begin{array}{r}\text { Discharge } \\
\text { rate }(\mathrm{t} / \mathrm{h})\end{array}$ & $\begin{array}{r}\text { Pipeline/loa } \\
\text { ding arm } \\
\text { capacity } \\
\end{array}$ \\
\hline Average & $2,665,512$ & 1,833 & 250,346 & 19 & $2,300,030$ & 32,016 & 9,623 \\
\hline Max & $33,557,799$ & 16,222 & 750,000 & 50 & $7,092,000$ & 112,000 & 25,245 \\
\hline Min & 2,247 & 100 & 2,000 & 5 & 123,211 & 382 & 2,040 \\
\hline Normalised standard deviation & 1.98 & 1.40 & 0.66 & 0.44 & 1.04 & 1.13 & 0.85 \\
\hline $\mathrm{N}$ (non missing) & 71 & 52 & 47 & 66 & 9 & 11 & 12 \\
\hline
\end{tabular}

Source: OECD base de données. 


\section{ANNEXE 4 : LISTE DES COMMUNES PORTUAIRES}

\begin{tabular}{|c|c|c|}
\hline code & nom & Port \\
\hline 33003 & AMBARES-ET-LAGRAVE & Bordeaux GPM \\
\hline 33004 & AMBES & Bordeaux GPM \\
\hline 33032 & BASSENS & Bordeaux GPM \\
\hline 33035 & BAYON-SUR-GIRONDE & Bordeaux GPM \\
\hline 33056 & BLANQUEFORT & Bordeaux GPM \\
\hline 33058 & BLAYE & Bordeaux GPM \\
\hline 33063 & BORDEAUX & Bordeaux GPM \\
\hline 33249 & LORMONT & Bordeaux GPM \\
\hline 33256 & LUDON-MEDOC & Bordeaux GPM \\
\hline 33312 & PAREMPUYRE & Bordeaux GPM \\
\hline 33314 & PAUILLAC & Bordeaux GPM \\
\hline 33434 & SAINT-LOUIS-DE-MONTFERRAND & Bordeaux GPM \\
\hline 33544 & VERDON-SUR-MER & Bordeaux GPM \\
\hline 59094 & BOURBOURG & Dunkerque GPM \\
\hline 59159 & CRAYWICK & Dunkerque GPM \\
\hline 59183 & DUNKERQUE & Dunkerque GPM \\
\hline 59248 & FORT-MARDYCK & Dunkerque GPM \\
\hline 59271 & GRANDE-SYNTHE & Dunkerque GPM \\
\hline 59273 & GRAVELINES & Dunkerque GPM \\
\hline 59359 & LOON-PLAGE & Dunkerque GPM \\
\hline 59532 & SAINT-GEORGES-SUR-L'AA & Dunkerque GPM \\
\hline 59540 & SAINT-POL-SUR-MER & Dunkerque GPM \\
\hline 17300 & ROCHELLE & La Rochelle \\
\hline 76169 & CERLANGUE & Le Havre GPM \\
\hline 76305 & GONFREVILLE-L'ORCHER & Le Havre GPM \\
\hline 76351 & HAVRE & Le Havre GPM \\
\hline 76489 & OUDALLE & Le Havre GPM \\
\hline 76533 & ROGERVILLE & Le Havre GPM \\
\hline
\end{tabular}




\begin{tabular}{|c|c|c|}
\hline 76595 & SAINT-JOUIN-BRUNEVAL & Le Havre GPM \\
\hline 76657 & SAINT-VIGOR-D'YMONVILLE & Le Havre GPM \\
\hline 76660 & SANDOUVILLE & Le Havre GPM \\
\hline 13026 & CHATEAUNEUF-LES-MARTIGUES & Marseille-Fos GPM \\
\hline 13039 & FOS-SUR-MER & Marseille-Fos GPM \\
\hline 13054 & MARIGNANE & Marseille-Fos GPM \\
\hline 13055 & MARSEILLE & Marseille-Fos GPM \\
\hline 13056 & MARTIGUES & Marseille-Fos GPM \\
\hline 13077 & PORT-DE-BOUC & Marseille-Fos GPM \\
\hline 13078 & PORT-SAINT-LOUIS-DU-RHONE & Marseille-Fos GPM \\
\hline 44020 & BOUGUENAIS & Nantes-St-Nazaire GPM \\
\hline 44045 & CORDEMAIS & Nantes-St-Nazaire GPM \\
\hline 44052 & DONGES & Nantes-St-Nazaire GPM \\
\hline 44074 & INDRE & Nantes-St-Nazaire GPM \\
\hline 44103 & MONTOIR-DE-BRETAGNE & Nantes-St-Nazaire GPM \\
\hline 44109 & NANTES & Nantes-St-Nazaire GPM \\
\hline 44162 & SAINT-HERBLAIN & Nantes-St-Nazaire GPM \\
\hline 44184 & SAINT-NAZAIRE & Nantes-St-Nazaire GPM \\
\hline 14001 & ABLON & Rouen \\
\hline 76157 & CANTELEU & Rouen \\
\hline 76164 & CAUDEBEC-EN-CAUX & Rouen \\
\hline 76319 & GRAND-COURONNE & Rouen \\
\hline 76322 & GRAND-QUEVILLY & Rouen \\
\hline 14333 & HONFLEUR & Rouen \\
\hline 76384 & LILLEBONNE & Rouen \\
\hline 76457 & MOULINEAUX & Rouen \\
\hline 76476 & NOTRE-DAME-DE-GRAVENCHON & Rouen \\
\hline 76497 & PETIT-COURONNE & Rouen \\
\hline 76498 & PETIT-QUEVILLY & Rouen \\
\hline 76499 & PETIVILLE & Rouen \\
\hline 14536 & RIVIERE-SAINT-SAUVEUR & Rouen \\
\hline 76540 & ROUEN & Rouen \\
\hline 76592 & SAINT-JEAN-DE-FOLLEVILLE & Rouen \\
\hline 76659 & SAINT-WANDRILLE-RANCON & Rouen \\
\hline 76684 & TANCARVILLE & Rouen \\
\hline 76709 & TRAIT & Rouen \\
\hline
\end{tabular}




\begin{tabular}{|lll|}
\hline $\mathbf{7 6 7 1 7}$ & VAL-DE-LA-HAYE & Rouen \\
\hline $\mathbf{7 6 7 2 7}$ & VATTEVILLE-LA-RUE & Rouen \\
\hline $\mathbf{7 6 7 5 0}$ & YAINVILLE & Rouen \\
\hline
\end{tabular}




\section{ANNEXE 5 : MÉTHODOLOGIE POUR L'ANALYSE INPUT/OUTPUT MULTIRÉGIONALE}

L'analyse input-output (analyse «entrées/sorties») est une technique quantitative, développée initialement par Leontieff, qui est utilisée pour décrire, analyser et expliquer les structures, les dépendances et les changements économiques. Un tableau input-output (tableau d'entrées/sorties) décrit les livraisons d'un secteur industriel à un autre secteur industriel, à des clients, à un gouvernement ou en direction de l'étranger (exportations). L'idée subséquente est que si une industrie se développe rapidement, les industries qui délivrent des produits à cette industrie en croissance connaîtront une demande plus forte et croîtront également. L'impact qui en résulte peut être exprimé par un multiplicateur. Dans le cadre de cette étude de cas sur Marseille-Fos, un tableau input-output multirégional a été construit.

La base de ce tableau input-output (IO) multirégional pour Marseille-Fos est formée à partir d'un tableau input-output national pour la France portant sur 15 secteurs, datant de 2005, et disponible sur le site Internet de l'INSEE. Des données régionales et sectorielles à l'échelle NUTS 2 (disponibles dans la base de données de l'OCDE), portant sur l'emploi (la production), la valeur ajoutée, les salaires et la population, ont été utilisées pour redistribuer le tableau input-output pour la France dans un tableau multirégional pour quatre régions, dans lequel les inputs et les outputs pour les régions de PACA, Rhône-Alpes, Bourgogne, Languedoc-Roussillon, d'Île-de-France et du reste de la France sont distingués. Des données très localisées sur l'emploi par activité (en lien avec le port du Marseile-Fos et portant sur l'emploi lié à l'activité portuaire) ont été utilisées afin de diviser la région de PACA entre le cluster portuaire du Marseille-Fos et le reste de la région PACA. Le résultat est un tableau input-output avec sept régions différentes : le cluster portuaire du Marseille-Fos, les régions PACA, Rhône-Alpes, Bourgogne, Languedoc-Roussillon, d'Île-deFrance et la reste de la France. 


\section{REFERENCES}

BG Ingénieurs Conseils (2011), Profil climat de Marseille Provence Métropole: Bilan carbone et vulnérabilité du territoire, Plan Climat Marseille Provence Métropole.

BG Ingénieurs Conseils (2012), Réalisation du profil climat sur le territoire du SCoT Ouest étang de Berre.

Blum, R., (2010), La Desserte ferroviaire et fluviale des grands ports maritimes, Rapport parlementaire

Cheon, S., (2008), Productive Efficiency of World Container Ports ; a global perspective, Transportation Research Record, pp. 10-18

Cheon, S., (2009a), Impact of global terminal operators on port efficiency : a tiered data envelopment analysis approach, International Journal of Logistics Research and Applications, Vol. 12, pp. 85101

Cheon, S., (2009b), Evaluating impacts of institutional reforms on port efficiency changes: Ownership, corporate structure, and total factor productivity changes of world container ports, Transportation Research Part E, Vol. 46, No4, pp.546-561

Cheon, S., Dowall, D., Song, D., (2009), Typology of Long-Term Port Efficiency Improvement Paths: Malquist Total Factor Productivity for World Container Ports, Journal of Infrastructure Systems, pp. 340-350

Coppens, F., (2007), Economic impact of port activity: a disaggregate analysis; the case of Antwerp, Working paper document no. 110, National Bank of Belgium

Cour des Comptes, (2006), Les ports français face aux mutations du transport maritime: l'urgence de l'action, Paris

Cour des Comptes (2011), Le Grand port maritime de Marseille : blocage social et déclin, Paris

Crozet, Y., (2010), La contribution du fret ferroviaire à la mobilité des marchandises en France et en Europe, Club parlementaire HERMES Mobilité et Transport durables, février 2010

Cullinane, K., Song, D., (2006), Estimating the relative efficiency of European container ports: a stochastic frontier analysis, Research in Transport Economics, Vol. 16, pp. 85-115

Cullinane, K.P.B., Wang, T.F., (2006), The efficiency of European container ports: A cross-sectional data envelopment analysis, International Journal of Logistics Research and Applications 9(1), pp. 19-31, http://pdfserve.informaworld.com/126484 743777491.pdf

Debrie, J., Lavaud-Letilleul, V., (2010), La Décentralisation portuaire : réformes, acteurs, territoires, L'Harmattan, Paris 
Ducruet, C., Lee, S., Song, J. (2011), "Network Position and Throughput Performance of Seaports”, in : Notteboom (ed) : Current Issues in Shipping, Ports and Logistics, Brussels

Egis Eau (2012), Etude de l'impact énergétique et des émissions des ports et aéroports de la région Provence-Alpes-Côte d'Azur, Rapport Méthodologique, d'analyses et de recommandations pour les ports.

Ferrari, C., Parola, Gattorna, E. (2011), Measuring the quality of port hinterland accessibility: The Ligurian case, Transport Policy, Vol. 18, pp. 382-391

Ferrari, C., Merk. O., Bottaso, A., Tei, A. (2012), Ports and Regional Development: A European Perspective, OECD Regional Development Working Paper, Paris

Frémont, A., Franc, P., Slack, B., (2009), Inland barge services and container transport: the case of the ports of Le Havre and Marseille in the European context, Cybergeo: European Journal of Geography; www.cybergeo.eu/index21743.html

Giuliano, G. and A. Linder, July 2011. "Motivations for voluntary regulation: The Clean Air Action Plan," submitted for presentation at the 2012 TRB Annual Meeting. Available at http://docs.trb.org/prp/122628.pdf

Gouvernal, E., Slack, B., Franc, P., (2010), Short sea and deep sea shipping markets in France, Journal of Transport Geography, Vol. 18, pp. 97-103

GPMM (2009a), Projet Strategique 2009-2013

GPMM (2009b), Rapport Annuel de développement durable 2009.

GPMM (2011), L'Évolution des Bassins Est du Grand Port Maritime de Marseille à l'horizon 2025 : un projet ville-port, Commission spécialisée Évolution des Bassins Est, présidée par Yves Cousquer, Conseil de Surveillance, GPMM

GPMM (2012), Actualisation janvier 2012 Projet Strategique 2009-2013

Guerrero, D. (2010), «Les aires d'influence des ports de la France : entre réseau et gravitation, doctoral thesis », Université Paris Diderot - Paris 7

Haezendonck, E., (2001), Essays on strategy analysis for seaports, Garant: Leuven

Herrera, S., Pang, G., (2008), Efficiency of infrastructure: the case of container ports, Revista Economia 9(1), pp. 165-194, http://www.anpec.org.br/revista/vol9/vol9n1p165_194.pdf

INEA (Ingénieurs-Conseil, Nature Environnement Aménagements) (2009), SCoT Ouest Etang de Berre, Etat Initial de l'Environnement

Jacobs, W., Ducruet, C., De Langen, P.W., (2010), Integrating world cities into production networks: the case of port cities, Global Networks 10 (1), pp. 92-113

Market Economics (2011) 'Economic Role of the Ports of Auckland Limited 2010, 2021 and 2031'. Report prepared for Ports of Auckland Ltd. October 2011. Accessed on 27/10/2012. URL: http://www.poal.co.nz/news_media/publications/POAL_economic_role_2011.pdf 
Marseille Provence Métropole (2007), Métropole euroméditerranéenne des échanges et de la connaissance ; une stratégie de développement pour 2008-2014

Merk, O, Hesse, M. (2012), The Competitiveness of Global Port-Cities: The case of Hamburg, OECD Regional Development Working Paper, Paris

Mongelluzzo, B., 2012. "How California's Ports Cleared the Air", The Journal of Commerce, January 23, 2012. Accessed on Oct 1st, 2012 at http://www.joc.com/portsterminals/how-californias-portscleared-air?page $=2$

O’Brien, T., 2004. "Quality of Life and Port Operations: Challenges, Successes and the Future", White Paper prepared for the sixth Annual CITT State of the Trade and Transportation Industry Town Hall Meeting. CITT: Long Beach.

Premier Ministre (2012), Réunion de ministres sur l'agglomération marseillaise ; Relevé de conclusions, Hotel de Matignon, 6 septembre 2012

Rodrigue, J. et al., (2010), Functions and actors of inland ports: European and North American dynamics, Journal of Transport Geography, Vol. 18, pp. 519-529

Verhetsel, A. and Sel, S. (2009) "World Maritime Cities: from Which Cities Do Container Shipping Companies Make Decisions", Transport Policy, Vol. 16, No 5, pp. 240-250.

Ville de Marseille (2012), Marseille Attractive; un projet pour une strategie partenariale, 2012-2020, Marseille

Wu, Y.C.J., Goh, M., (2010) Container port efficiency in emerging and more advanced markets, Transportation Research Part E, 46, pp. 1030-1042. 


\section{NOTES}

Le degré de centralité correspond au nombre d'éléments voisins adjacents à un nœud; il s'agit de l'outil de mesure de la centralité le plus simple et communément accepté. Il est souvent en corrélation avec le trafic total (plus de connections sous entend plus de trafic). La centralité de sunexité correspond au nombre de chemins les plus courts traversant chaque nœud. Le coefficient d'agglomération permet d'évaluer si les éléments voisins adjacents à un nœud sont connectés les uns aux autres (ex. «mes amis sont aussi amis entre eux »), formant par conséquent des triangles (triplettes) ; le coefficient correspond au ratio entre le nombre de triplettes observées et le nombre maximum possible de triplettes connectées à un nœud donné. Le ratio va de 0 (pas de triplettes observées) à 1 (tous les éléments voisins sont connectés). Concernant les fonctions de hub dans un système de transport, en théorie le «hub pur» aura un coefficient d'agglomération proche de 0 car il sert de plateforme centrale redistribuant les flux vers/en provenance des plateformes satellites (terminaisons) qui sont uniquement connectées à ce hub ou point de connexion central (réseau en étoile). A l'inverse, les valeurs proches de 1 désignent une configuration plus dense avec davantage de liens transversaux (et par conséquent moins hiérarchique). Dans un réseau maritime, les hubs de transbordement ont en principe des coefficients d'agglomération peu élevés contrairement à d'autres configurations où les liens sont encore plus distribués entre les ports (ex. l'absence de hubs comme c'est le cas en Mer Baltique ou aux États-Unis). Les différents outils de mesure de connectivité des ports sont liés entre eux mais sont également complémentaires. Des nœuds très centraux (centralité de sunexité élevée) jouent souvent le rôle de hubs ou points de connexion centraux (coefficient d'agglomération peu élevé) et il est commun d'observer une forte corrélation entre le degré de centralité et la centralité de sunexité du fait de la contrainte physique que représente le littoral pour la circulation. Dans certains cas comme celui des hubs isolés ou servant de relais, certains nœuds n'ont que quelques liens locaux. Cela s'explique par le fait qu'ils jouent le rôle de «ponts » entre les sous-composants de ce réseau, tout comme dans le réseau mondial du fret aérien la ville d'Anchorage fait office de pont entre l'Asie et l'Amérique du Nord.

Marseille et Fos disposent de 8 connexions portuaires en commun, constituant à eux deux 29 connexions

Les ports des côtes atlantiques Sud de l'Espagne sont inclus dans ce chiffre

Nous utilisons ici une définition de l'emploi lié au port prenant en compte l'emploi en fait lié aux principales villes portuaires en France. Cette approche s'appuie sur une proposition faite dans Musso et al. 2000 de définir l'emploi lié au port afin qu'il soit sur représenté dans les régions avec des ports importants, plutôt que de se baser sur des suppositions permettant de définir si les industries sont liées au port ou non. La méthode suit différentes étapes logiques. Tout d'abord, deux groupes de régions différents sont définis : les régions portuaires et les régions non portuaires; les différentes industries dans lesquelles ces deux groupes sont spécialisés sont identifiées. Pour les industries dans lesquelles l'ensemble des régions portuaires est spécialisé, l'indice de spécialisation de chaque région portuaire individuelle est identifié afin de définir combien de régions portuaires sont spécialisées dans ces industries. Cette information est ensuite comparée à la distribution de la probabilité standard afin d'estimer dans quelle mesure l'emploi dans ces industries peut réellement être attribué à la présence d'un port. Moins on trouvera de spécialisations similaires dans un ensemble aléatoire de régions, plus élevé sera le pourcentage d'emplois dans ce secteur qui seront considérés comme « liés au port ». Cette méthode a été employée en France, utilisant une base de données comprenant toutes les municipalités en France et leurs emplois dans environ 700 secteurs en 2010. Pour cette analyse les municipalités connectées à sept grands ports maritimes étaient considérées comme des villes portuaires (voir l'Annexe 3 pour la liste des municipalités concernées) ; toutes les autres municipalités étaient considérées comme des localités non portuaires. L'emploi total lié au port estimé se situe dans la même fourchette que celle trouvée dans des études précédentes, entre 40,000 et 45,000 
emplois. Le nombre exact d'emplois lié au port est difficile à établir en s'appuyant sur la base de données à proximité. La difficulté réside dans le fait que le secteur public général, le secteur hospitalier et le secteur de la sécurité sociale général ne sont pas divisés en des sous-secteurs plus petits, ce qui signifie qu'une partie importante de l'emploi dans ces secteurs a été attribué aux métropoles portuaires, alors que l'on peut supposer que ces secteurs ne sont pas à ce point lié au port. Pour cette raison, nous avons introduit un élément discrétionnaire dans notre définition et attribué seulement un tiers des valeurs liés au port à ces secteurs. Cependant, les résultats diffèrent quant à la distribution de l'emploi par secteurs. Les secteurs liés au port les plus importants sont le transport, le stockage et la communication, représentant presque 15,000 emplois. Mais une grande partie des emplois liés au port se situent dans le domaine des services non commerciaux ainsi que dans certains services industriels majeurs, comme l'extraction minière et l'approvisionnement en énergie, l'immobilier, la location et l'activité commerciale.

Bien qu'Hambourg dispose d'un large cluster de services maritimes, dans la finance maritime, le conseil et les services d'ingénierie entre autres, ces services n'ont pas été pris en compte dans la définition des industries portuaires, car ils ne sont pas en lien direct avec le port.

Cependant, d'après un rapport de Trujillo et Gonzales (2008), il existe un nombre égal d'études portant sur l'efficacité s'appuyant sur une limite de production stochastique, et donc une forme fonctionnelle prédéfinie, suggérant ainsi une absence de consensus quant à la meilleure méthode à utiliser.

Cheon, et al, 2010; Wu et Goh, 2010; Martinez-Budria, et al, 1999; Wang et Cullinane, 2006; Al-Eraqui, et al, 2007; Tongzon, 2001.

Cela rend légitime l'usage des frontières stochastiques et de l'approche économétrique, bien qu'elles imposent une forme fonctionnelle à la production.

La technique du bootstrap est une méthode de deuxième échantillonnage, qui consiste à produire un certain nombre de nouveaux échantillons à partir de la base de données observée, de taille égale, où chacun de ces échantillons est obtenue aléatoirement par remplacement avec la base de données originelle. 